\title{
WestVirginiaUniversity
}

THE RESEARCH REPOSITORY @ WVU

Graduate Theses, Dissertations, and Problem Reports

2001

\section{Induction of fertile estrus during seasonal anestrus in ewes and fall born ewe lambs}

\author{
Marlon Knights \\ West Virginia University
}

Follow this and additional works at: https://researchrepository.wvu.edu/etd

\section{Recommended Citation}

Knights, Marlon, "Induction of fertile estrus during seasonal anestrus in ewes and fall born ewe lambs" (2001). Graduate Theses, Dissertations, and Problem Reports. 1347.

https://researchrepository.wvu.edu/etd/1347

This Dissertation is protected by copyright and/or related rights. It has been brought to you by the The Research Repository @ WVU with permission from the rights-holder(s). You are free to use this Dissertation in any way that is permitted by the copyright and related rights legislation that applies to your use. For other uses you must obtain permission from the rights-holder(s) directly, unless additional rights are indicated by a Creative Commons license in the record and/ or on the work itself. This Dissertation has been accepted for inclusion in WVU Graduate Theses, Dissertations, and Problem Reports collection by an authorized administrator of The Research Repository @ WVU.

For more information, please contact researchrepository@mail.wvu.edu. 
INDUCTION OF FERTILE ESTRUS DURING SEASONAL ANESTRUS IN

EWES AND FALL BORN EWE LAMBS

Marlon Knights Dip. Ag (Hons.) BSc. (Hons.) MSc.

Dissertation

Submitted to the College of Agriculture, Forestry and Consumer Sciences

at West Virginia University

in partial fulfillment of the requirements for the Degree of

Doctor of Philosophy

in Reproductive Physiology

Paul E. Lewis, Ph.D., Chair

E. Keith Inskeep, Ph.D.

Robert A. Dailey, Ph.D.

Robert L. Goodman, Ph.D.

William V. Thayne, Ph.D.

Division of Animal and Veterinary Sciences

Morgantown West Virginia

2001

Keywords: anestrus, season, fertility, ewe lambs 


\section{ABSTRACT \\ INDUCTION OF FERTILE ESTRUS DURING SEASONAL ANESTRUS IN EWES AND FALL BORN EWE LAMBS}

\section{Marlon Knights}

The quantity of progesterone $\left(\mathrm{P}_{4}\right)$ delivered by a new $\mathrm{P}_{4}$ releasing intravaginal insert (polycapralactone [PCL] insert), was inadequate to increase serum concentrations of $\mathrm{P}_{4}$ to that observed in cycling ewes during the luteal phase. Percentage of ewes in estrus was greater in $\mathrm{P}_{4}$ treated than in control ewes. Estrous response was greater after treatment with $\mathrm{P}_{4}$ for 5 than for $12 \mathrm{~d}$. Progesterone increased the percentage of ewes lambing to both service periods by 20 percentage points. Prolificacy to the first service period in ewes treated with FSH was greater than the prolificacy in control and all ewes lambing to the second service period. Treatment with $\mathrm{P}_{4}$ for $5 \mathrm{~d}$ was as effective as for $12 \mathrm{~d}$ to induce fertile estrus in FSH-treated anestrous ewes.

In the second experiment, a $5 \mathrm{~d}$ pre-treatment with $\mathrm{P}_{4}$ prior to ram introduction induced estrus in anestrous ewes. The estrous response varied quadratically with time after ram introduction, and the conception rate varied quadratically with the time of observation of onset of estrus. Progesterone treatment increased the percentage of ewes lambing and the number of lambs born per ewe exposed over that observed in ewes introduced to rams alone. Prolificacy to the first service tended to be greater in FSH treated ewes than in ewes receiving $\mathrm{P}_{4}$ alone and all ewes lambing to the second service period.

In the third experiment, ram introduction by itself but not $\mathrm{P}_{4}$ pre-treatment alone induced an increase in LH secretion, follicular development, an LH surge and ovulation in fall-born ewe lambs. Progesterone delayed the RI LH surge, an effect that was prevented by the administration of estrogen $24 \mathrm{~h}$ after $\mathrm{P}_{4}$ withdrawal. Progesterone pre-treatment for 5 days prior to ram introduction resulted in the expression of estrous behavior in a small percentage of fall-born ewe lambs. Estrogen increased the percentage of $\mathrm{P}_{4}$ pre-treated ewes displaying estrus. Poor reproductive performance of fall-born ewe lambs treated with $\mathrm{P}_{4}$ and exposed to rams during anestrus is not due to the inability of rams to induce ovulation but may be related to a reduced secretion of or sensitivity of behavioral centers to estrogen. 


\section{TABLE OF CONTENTS}

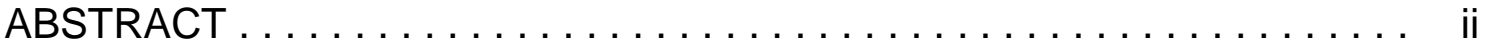

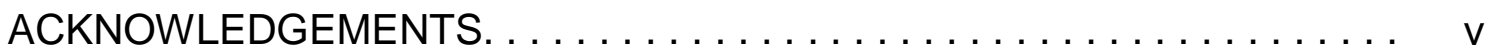

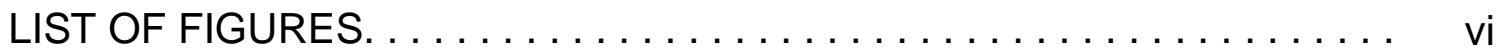

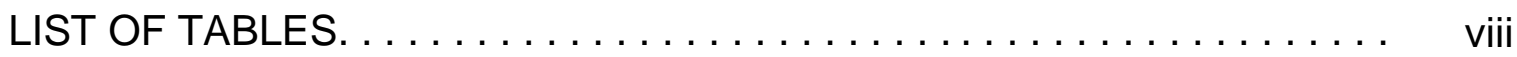

REVIEW OF LITERATURE. $\ldots \ldots \ldots \ldots \ldots \ldots \ldots \ldots \ldots \ldots \ldots$

Characterization and regulation of seasonal anestrus in the ewe.... 1

Factors influencing the occurrence of reproductive cycles in the ewe. . 3

Methods that alter the occurrence of reproductive cycles in the ewe . . 6

Ram effect....................... 6

Endocrine response

Follicular development and ovulation

Male cue

Factors affecting responsiveness of anestrous ewes to ram introduction

Progestogen pre-treatment ...................

Role in display of behavioral estrus.

Role in maintenance of the induced $\mathrm{CL}$ in anestrous.

Role in the induction of gonadotropin secretion

Types of progestogens

Methods of progestogen administration

Duration of progestogen treatment

Dosage of progestogen required

Progestogen pre-treatment with gonadotropins $\ldots \ldots \ldots \ldots$.

Progestogen pre-treatment and ram introduction without gonadotropins.

Ovulation rate and Prolificacy of ewes bred out- of-season.........

Factors involved in the reduced ovulation rate during

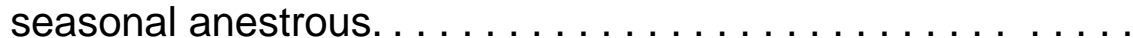

Approaches to increasing ovulation rate and prolificacy.....

Effect of season on the occurrence of reproductive cycles in the fallborn ewe lamb and approaches to induce fertile estrus during 
Age of puberty in fall born ewe lambs. . . . . . . . . 51

Photoperiodic requirements for attainment of puberty in fall born ewe lambs.

Induction of fertile estrus during seasonal anestrus in fall born ewe lambs

STATEMENT OF THE PROBLEM

EFFECTIVENESS OF INTRAVAGINAL PROGESTERONE INSERTS AND FSH FOR INDUCING SYNCHRONIZED ESTRUS AND INCREASING LAMBING RATE IN ANESTROUS EWES. . . . 60

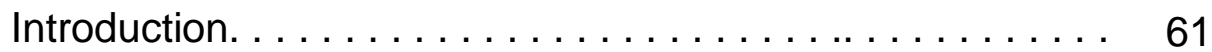
Materials and Methods .................... 62 Results and Discussion ................. 66

SHORT-TERM TREATMENT WITH A CONTROLLED INTERNAL DRUG RELEASING (CIDR) DEVICE AND FSH TO INDUCE FERTILE ESTRUS AND INCREASE PROLIFICACY IN

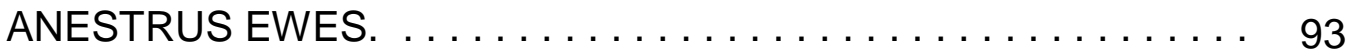

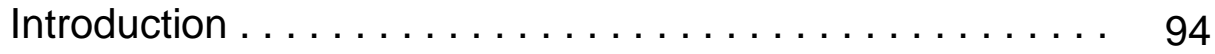

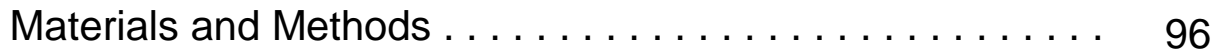

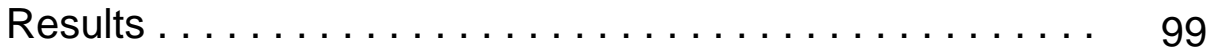

Discussion . . . . . . . . . . . . . . . . 106

ABILITY OF RAM INTRODUCTION TO INDUCE LH SECRETION ESTRUS AND OVULATION IN FALL-BORN EWE LAMBS

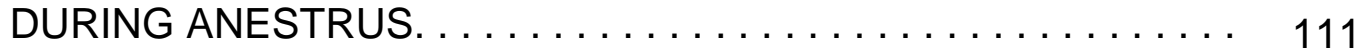

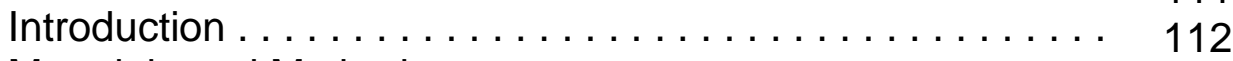

Materials and Methods . . . . . . . . . . . . . . . . . . 114

Results . . . . . . . . . . . . . . . . . . . . . . . . . 117

Discussion . . . . . . . . . . . . . . . . 123

GENERAL DISCUSSION. . . . . . . $\ldots \ldots \ldots \ldots \ldots \ldots \ldots \ldots \ldots, 128$

LITERATURE CITED . . . . . . . . . . . . . . . . . . . . 132

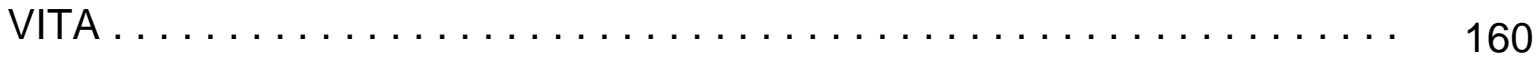




\section{ACKNOWLEDGEMENTS}

I would like to thank my mentor, Dr. Paul Lewis for his guidance, wisdom, support and faith in me that allowed me to grow both as a scientist and as an individual. I would also like to thank the other members of my committee Drs. Keith Inskeep, Robert Dailey, Robert Goodman and William Thayne for their assistance in improving my ability to think in the field of Reproductive Physiology. I would like to specially thank Dr. Keith Inskeep for his leadership, patience and his informal writing tutorials.

Sincere appreciation is also extended to my fellow graduate students, Dr. Hugo Fonseca-Hernandez, Dr. Phillip Bridges, Dr. Robert Taft, Dr. David Wright, Melissa McCormick, Timothy Maze, Quinn Baptiste, Beth Costine, Ida Holaskova, Allison Dixon and Todd Hoehn and our Postdoctoral Fellows Drs. Brian Sayre and Mathew Wilson who have helped to provide an atmosphere conducive to academic advancement and whose help made it possible to complete these and other experiments. I would like to specifically thank Hugo Hernandez and James Gekara - my original office mates through whom I learned the value of dedication and commitment to science and the benefits of long nights of work. A special acknowledgement is due to Dr. Miroslav Valent for his guidance in conducting LH radioimmunoassays and other laboratory techniques.

Finally I would like to thank my wife "Dee" who has stuck by my side and has always served as a source of motivation. Thanks to all members of my immediate and extended family and specifically my mother, Cecilia Knights, who made all the sacrifices worthwhile. 


\section{LIST OF FIGURES}

Figure 1. Mean concentrations of progesterone prior to ram introduction for control ewes (C ), ewes pre-treated with PCL inserts for $12 \mathrm{~d}$ without (P12) or with $\mathrm{FSH} 24 \mathrm{~h}$ before insert removal $(\mathrm{P} 12 \mathrm{~F})$ and ewes treated with $\mathrm{PCL}$ inserts for $5 \mathrm{~d}$ with FSH $24 \mathrm{~h}$ before insert removal (P5F). Treatment $\mathrm{X}$ time

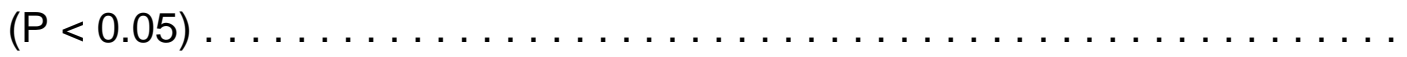

Figure 2. Distribution of estrus over the first $2.5 \mathrm{~d}$ after insert removal for control ewes $(C)$, ewes pre-treated with $P C L$ inserts for $12 \mathrm{~d}$ without (P12), or with $\mathrm{FSH} 24 \mathrm{~h}$ before insert removal $(\mathrm{P} 12 \mathrm{~F})$, and ewes treated with $\mathrm{PCL}$ inserts for $5 \mathrm{~d}$ with $\mathrm{FSH} 24 \mathrm{~h}$ before insert removal (P5F) . . . . . . .

Figure 3. Population of follicles $(>3 \mathrm{~mm})$ during the periestrous period for control ewes $(C)$, ewes pre-treated with $P C L$ inserts for $12 d$ without (P12), or with FSH $24 \mathrm{~h}$ before insert removal $(\mathrm{P} 12 \mathrm{~F})$ and ewes treated with $\mathrm{PCL}$ inserts for $5 \mathrm{~d}$ with FSH $24 \mathrm{~h}$ before insert removal (P5F). Number of follicles $>3 \mathrm{~mm}$ was greater in progesterone-treated than in control ewes $(\mathrm{P}<0.01)$ in $\mathrm{FSH}$-treated ewes than in ewes receiving progesterone only and in FSH-treated ewes receiving progesterone for 5 than for $12 \mathrm{~d}(\mathrm{P}<0.05) \ldots$

Figure 4. Pregnancy retention rate: Percentages of ewes lambing as a percentage of ewes diagnosed pregnant as a result of matings at the first, second or both service periods after ram introduction, for control ewes (C), ewes pre-treated with PCL inserts for $12 \mathrm{~d}$ without (P12), or with FSH $24 \mathrm{~h}$ before insert removal (P12F), and ewes treated with PCL inserts for $5 \mathrm{~d}$ with FSH $24 \mathrm{~h}$ before insert removal $(\mathrm{P} 5 \mathrm{~F}) \ldots \ldots \ldots \ldots \ldots \ldots \ldots \ldots \ldots .85$

Figure 5. Cumulative percentages of ewes lambing in control ewes (C), 
ewes pre-treated with PCL inserts for $12 \mathrm{~d}$ without ( $\mathrm{P} 12$ ), or with $\mathrm{FSH} 24 \mathrm{~h}$ before insert removal (P12F), and ewes treated with $P C L$ inserts for $5 \mathrm{~d}$ with $\mathrm{FSH} 24 \mathrm{~h}$ before insert removal $(\mathrm{P} 5 \mathrm{~F}) \ldots \ldots \ldots \ldots \ldots \ldots \ldots$ Figure 6. Pregnancy retention rate: Ewes lambing as a percentage of ewes diagnosed pregnant as a result of matings at the first, second, or both service periods after ram introduction, for control ewes (C), and ewes pre-treated with CIDR devices for $5 \mathrm{~d}$ without (P5), or with FSH $24 \mathrm{~h}$ before

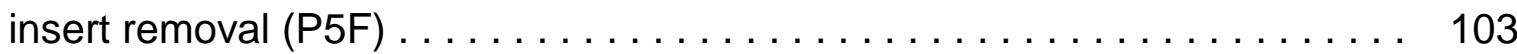




\section{LIST OF TABLES}

Table 1. Reproductive performance of anestrous ewes in response to ram introduction (C), or ram introduction $+12-\mathrm{d}$ progesterone pre-treatment (P12), 12-d progesterone pre-treatment + FSH (P12F) or 5-d progesterone pre-treatment $+\mathrm{FSH}(\mathrm{P} 5 \mathrm{~F}) \ldots \ldots \ldots \ldots \ldots \ldots \ldots \ldots \ldots \ldots \ldots \ldots$

Table 2. Characteristics of the ovarian follicular population during the periestrous period in control ewes $(C)$, ewes pre-treated with progesterone inserts for $12 \mathrm{~d}$ without (P12), or with FSH $24 \mathrm{~h}$ before insert removal (P12F) and ewes treated with progesterone inserts for $5 \mathrm{~d}$ with FSH $24 \mathrm{~h}$

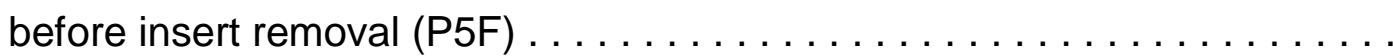

Table 3. Summary of reproductive performance of anestrous ewes in response to ram introduction $(C)$, or ram introduction $+5-d$ CIDR pre-treatment without (P5) or with FSH (P5F) $\ldots \ldots \ldots \ldots \ldots \ldots \ldots$

Table 4. The percentage of lambs with a detectable $\mathrm{LH}$ surge and characteristics of the LH surge profile for control $(C)$, ram-introduced $(R)$, progesterone pre-treated $(\mathrm{P})$, and ram introduced lambs without $(\mathrm{PR})$ or with estrogen (PER)

Table 5. Mean concentration of LH and LH pulse frequency and amplitude 12-20 $\mathrm{h}$ after ram introduction in control (C) and lambs introduced to rams

Table 6. Follicular development and ovulatory and estrous responses in control $(C)$, ram-introduced $(R)$, progesterone pre-treated $(P)$ and ram

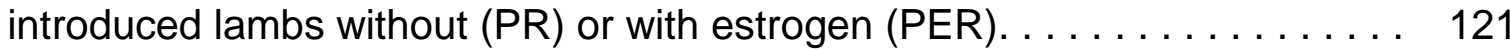




\section{REVIEW OF LITERATURE}

\section{Characterization and regulation of seasonal anestrus in the ewe.}

The ewe is a seasonally polyestrous animal. Seasonality of reproduction is geared towards the synchronization of reproductive functions with annual changes in the environment. Synchronization of these events is, therefore, important to the survival of the species. In the case of the sheep, the time of breeding activity and conception complement the gestation period such that parturition occurs in the spring - a time when environmental conditions are most favorable to the survival of the dam and the newborn.

Seasonality of reproduction in the ewe is characterized by both changes in the occurrence of estrous activity and in the ovulation rate. The percentage of ewes displaying estrus is higher during the late summer, fall and early winter months (McKenzie and Terrill, 1947; Hafez, 1952; Dermody et al., 1970; Mallampati et al., 1971). For example, nearly all Targhee ewes display estrus during September through February. The percentage of ewes displaying estrus then declines from March through June when only $10 \%$ of ewes display estrus followed by a gradual increase as the breeding season approaches (Mallampati et al., 1971). The ovulation rate follows a similar pattern, being highest during the breeding season (September and October) and lower during transition periods with the lowest values occurring during anestrus (Dermody et al., 1970; Mallampati et al., 1971; Hulet et al., 1974; Hall et al., 1986). 
At the hypothalamic-pituitary axis, seasonal changes in reproductive activity are paralleled by and are a consequence of changes in the secretion of GnRH (Barrel et al., 1992) and LH (Yuthasastrakosol et al., 1975; Scaramuzzi and Baird, 1977; Goodman et al., 1982). A slowing down in the secretion of LH during anestrus is thought to be primarily due to an increase in the sensitivity to the negative feedback effect of estradiol (Legan et al., 1977; Legan and Karsch, 1980), although a minor steroid independent mechanism may also exist (Goodman et al., 1982). The mechanism by which the increased sensitivity to estradiol is achieved and the sites of its actions have not been elucidated. However, the activation of inhibitory $\alpha$-adrenergic and dopaminergic neurons may be involved (Goodman and Meyer, 1984; Meyer and Goodman, 1985; Havern et al., 1994; Lehman et al., 1996).

Daylength sets both the timing and the duration of the breeding season (Karsch et al., 1984). Marshall (1937) observed that when ewes were transferred across the equator the annual reproductive cycle shifted in accordance with the seasonal swings in photoperiod and other environmental variables in the new location. Artificially reversing the photoperiod such that ewes are exposed to results in an accompanying reversal in the annual reproductive cycle (Yeates, 1949; Thwaites, 1965; Wodzicka-Tomaszewska et al., 1967). These findings also demonstrated that light is the cue that caused this response and that decreasing and increasing daylength is associated with reproductive induction and arrest, respectively. 
The mechanism by which daylength is perceived have been reviewed previously (Karsch et al., 1984; Goodman, 1994). A retinohypothalamic tract that projects from photoreceptors in the retina to the suprachiasmatic nuclei (SCN) has been identified (Legan and Winans, 1981). The pathway from the SCN includes the paraventricular nucleus (PVN) and superior cervical ganglion (SCG) which in turn innervates the pineal gland. The pineal gland does not send projections to other parts of the central nervous system but responds to darkness and light with increases and decreases in melatonin secretion (Goodman, 1994). The involvement of components of this system in the annual reproductive cycle in sheep has been demonstrated in experiments involving orbital enucleation and pinealectomy. In both cases the timing and synchrony of reproductive cycles were disrupted (Legan and Karsch, 1983; Bittman et al., 1983; reviewed in Karsch et al., 1984; Goodman, 1994). Administration of melatonin that mimics the seasonal changes in secretion could effectively time and synchronize the occurrence of reproductive cycles in pinealectomized ewes (Karsch et al., 1984). The exact mechanism through which melatonin acts to regulate the hypothalamic-pituitary axis is unknown.

\section{Factors that Influence the Occurrence of Reproductive Cycles in the Ewe}

Whisnant and Inskeep (1992) reviewed the factors influencing the duration of the breeding season and seasonal fluctuations in ovulation rate. This review will merely highlight some of these factors. 


\section{Breed/type and place of origin}

In general breeds originating from the tropics and Mediterranean region and those with a large percentage of Merino blood have longer breeding seasons than breeds from temperate latitudes (Whisnant and Inskeep, 1992). However notable exceptions to this generalization occur as in the case of the Dorset (Hafez, 1952) and Finn sheep (Wheeler and Land, 1977). Further, as noted by Whisnant and Inskeep (1992), large variations within breeds and among locations and years exist. These variations may be related to other factors that impact on the duration of the breeding season including latitude of the study, age, nutrition and lactation status, and presence of rams. Variations among breeds with respect to the duration of the breeding season have been exploited to improve the fertility of ewes bred out-of-season. Duration of seasonal anestrus was reduced from over 3 to less than 1 month with more than $83 \%$ of

ewes exhibiting estrus in May, June and July in a subset of ewes comprising $1 / 2$ Dorset, 1/4 Rambouillet and 1/4 Finn sheep (Al-Shorey and Notter, 1997; Vincent et al., 2000).

\section{Nutrition and lactational status}

Fertility is low when ewes are bred during lactation particularly if the lactation period is coincident with the anestrous period (Cognie et al., 1975). More than $70 \%$ of ewes lambing in the fall re-breed by 44 days postpartum. In comparison only $23 \%$ of spring lambing ewes re-breed, with a mean interval to 
first estrus of 66 days postpartum (Whiteman et al., 1972). The authors also observed that more non-lactating (50\%) than lactating ewes (23\%) conceive during the spring, however an effect of lactation status was not observed on postpartum re-breeding in the fall. Rhind et al. (1980) studied ewes lambing in the fall or late winter that were synchronized such that mating occurred during March or December. The authors observed that more than $88 \%$ of ewes from which lambs had been weaned before mating, lambed to the induced estrus regardless of month of mating. In contrast, lactating ewes had a lower lambing rate $(49 \%)$, which was exacerbated in March when only $33 \%$ of lactating ewes lambed to the induced estrus. In another study the authors observed that $55 \%$ of weaned ewes lambed to the induced estrus in July compared to only $34 \%$ of lactating ewes.

\section{Age}

Ewe lambs have a shorter breeding season than mature ewes (Cole and Miller, 1935; reviewed by Berardinelli, 1979). Dýrmundson (1973) suggested that the first breeding season of ewe lambs is centered within two weeks of the shortest day of the year. Regardless of date of introduction of rams, spring born ewe lambs were first mated late October to early November (Dýrmundson and Lees, 1972; Al-Mauly et al., 1991). Therefore, the first breeding season of ewe lambs is shorter because of a later start and an earlier conclusion. Further, while genetic selection may extend the breeding season of ewes, these improvements are not observed in ewe lambs or yearlings (Notter, 1992). 


\section{Methods that Alter the Occurrence of Reproductive Cycles in the Ewe}

The different approaches to out-of-season breeding have been extensively researched and documented and include the ram-effect (Signoret, 1990; Oldham and Fisher, 1992), melatonin treatments (Stellflug, 1992), progestogen pretreatments and ram introduction (Kiesler et al., 1992; Wheaton et al., 1992; 1993) and photoperiod manipulation (Kennaway et al., 1987; Ortavant et al., 1988). This review will focus primarily on the use of ram introduction - the 'ram-effect' with or without progestogen pre-treatments in breeding ewes out-of-season. The special case of fall born ewe lamb and maiden yearlings will be considered separately.

\section{The ram-effect}

Early reports by Underwood et al. (1944) indicated that the anestrous period in Merino ewes could be broken by introduction of rams. Schinckel (1954) later demonstrated that the abrupt introduction of rams to ewes could induce ovulation.

The endocrine response A pivotal step in the induction of ovulation is the sustained increase in tonic $\mathrm{LH}$ secretion that stimulates the final stages of follicular maturation, and increases secretion of estrogen needed to trigger the 
LH surge (McNeilly et al., 1982; Goodman, 1994). Release of LH from the anterior pituitary is in turn under the control of $\mathrm{GnRH}$, released from the hypothalamus. Thus, GnRH release from the hypothalamus is synchronous with and causes the release of LH (Clarke and Cummins, 1982; Levine et al., 1982). In the anestrous ewe $\mathrm{GnRH} / \mathrm{LH}$ pulses are released very infrequently (Scaramuzzi and Baird, 1977; Goodman et al., 1982; Barrel et al., 1992) due to the increased sensitivity of the hypothalamus to the negative feedback effects of estrogen (Legan et al., 1977; Legan and Karsch, 1980; reviewed by Karsch et al., 1980a).

Although it was originally suggested that ram introduction might directly trigger the preovulatory surge of LH (Knight et al., 1978; Oldham et al., 1978/79), it is now apparent that it results in increased tonic LH secretion, which probably induces events of a typical follicular phase (Martin et al., 1983). Introduction of novel rams results in a rapid increase in tonic LH secretion (Martin et al., 1980ab; 1983; Atkinson and Williamson, 1985), presumably as a result of increased $\mathrm{GnRH}$ secretion, which in turn may drive follicular development (Atkinson and Williamson, 1985). It is hypothesized that the increase in LH pulse frequency and increase follicular development induces a rise in the concentration of estradiol sufficient to trigger the LH surge (Goodman, 1994). This hypothesis is supported by the observation that the ram-induced increases in LH pulse frequency require the presence of the ovaries (Martin et al., 1983). The delay between the introduction of rams and the onset of the LH surge is generally $24-30 \mathrm{~h}$, but this timing has varied from 12-40 $\mathrm{h}$ among experiments (reviewed in Martin et al., 
1986). Although estradiol can induce an LH surge within $6-8 \mathrm{~h}$ in anestrous ewes (Goding et al., 1969), it is possible that the earliest surges induced by introduction of rams are not the result of the positive feedback system, as insufficient time is available for the increase in estrogen. Added to this, is the seemingly lower responsiveness of follicles to gonadotropin stimulation (Legan et al., 1985; Noël et al., 1999), which might limit the synthesis of estradiol to ram-induced increases in secretion of gonadotropins. Martin et al. (1986) also noted that the period of follicular growth following ram introduction (the period from ram introduction to the LH surge, $36 \mathrm{~h}$ ) is far shorter than the follicular phase of normally cycling animals (60 to $70 \mathrm{~h}$; Chamley et al., 1972). Martin et al. (1980b) advanced the possibility that these early surges are a result of excessive stimulation of tonic $\mathrm{LH}$ secretion by the rams. Speculation about whether the ram-induced LH surge in anestrous ewes is a result of the typical estrogen feedback system probably exist due to lack of a direct measurement of the estrogen profile (Martin et al., 1986). Further, the increase in basal concentration of LH and LH pulse frequency that drives follicular development may be short-lived, as values return to pre-ram introduction concentrations by 24-40 h (Atkinson and Williamson, 1985). Therefore, it is also possible that an increase in the sensitivity of LH surge system to estradiol rather than an increase in circulating estrogen may be responsible for triggering the $\mathrm{LH}$ surge (Oldham et al., 1978/79).

The exact mechanism by which ram introduction results in increased $\mathrm{LH}$ secretion in anestrous ewes is not known. Disruption of the estradiol negative feedback system seems likely (Martin et al., 1983; Goodman, 1994), as the ram- 
induced increase in LH pulse frequency is observed in estradiol-treated but not in untreated ovariectomized ewes (Martin et al., 1983). Inhibitory catecholaminergic neurons probably mediate the negative feedback effects of estrogen in anestrous ewes (Havern et al., 1994; reviewed by Lehman et al., 1997). Thus, the suppression of the inhibitory catecholaminergic neuronal systems is a possible mechanism by which the ram effect may induce increase LH secretion (Goodman, 1994). Therefore, the ram effect induces a follicular phase (Martin and scaramuzzi, 1983) by blunting the actions of inhibitory photoperiod, allowing ewes to temporarily revert to the breeding season condition.

Follicular development and ovulation. Little data exist on follicular development during the ram-induced follicular phase. Atkinson and Williamson (1985), reported an increase in the number of small, large and total follicles and a decrease in the number of medium sized follicles during the first $40 \mathrm{~h}$ after ram introduction. Increased follicular development was also observed during the first 20 days after ram introduction.

The interval from the onset of the $\mathrm{LH}$ surge to ovulation is $22-26 \mathrm{~h}$ (Cumming et al., 1973). This interval may be shortened by the presence of the ram (Martin et al., 1986). Most ewes ovulate within 50h of ram introduction (Oldham et al., 1978/79; Atkinson and Williamson, 1985; Martin et al., 1986), unless the LH surge is delayed, as occurs with progesterone pre-treatment (Martin et al., 1981; Pearce et al., 1985). The ovulation rate of seasonally anovulatory ewes responding to the ram effect is higher than that of flock mates 
spontaneously ovulating during the same time of the year (Pearce et al., 1984; Martin et al., 1986). The reported ovulation rate responses to ram introduction are inconsistent probably due to other factors such as nutritional status that also impact on ovulation rate (Martin et al., 1986). Further, comparisons are difficult to make because of several studies that used animals that were pre-selected, or where the ovulation rate was measured at ovulations subsequent to the first raminduced ovulation.

Corpora lutea from the ram-induced ovulation either persist for the length of a normal luteal phase or regress prematurely. Ewes with a normal luteal phase subsequently display estrus with ovulation about 18-19 days after initial ram introduction. Corpora lutea with a short-lifespan regress 5-6 days after ovulation. This is followed by another silent ovulation in most ewes. The interval between the first and the second LH surges in these animals is approximately 5.1 \pm .9 days (Pearce et al., 1985). The length of the resultant luteal phase is normal with ovulation and accompanying estrus occurring for the first time about 24 days after initial ram introduction (Oldham and Fisher, 1992).

The male cue. Watson and Radford (1960) suggested that scent from the male was the most important sensory cue. In support, Knight and Lynch (1980) demonstrated that fleece and ante-orbital wax from rams was sufficient to induce ovulation in anestrous ewes. Two olfactory systems, the main and accessory (vomeronasal) systems are capable of conducting sensory inputs to the central nervous system. Vomeronasal cauterization and vomeronasal nerve section 
operations that spared the main olfactory system failed to inhibit the increased $\mathrm{LH}$ response of ewes to the odor of the male (Cohen-Tannoudji et al., 1989). Therefore, in the ewe the main olfactory system is sufficient for conducting the smell/pheremonal stimuli to the central nervous system. Induction of $\mathrm{LH}$ secretion by the fleece (Knight and Lynch, 1980), ethanol or methylene extracts of the fleece of intact rams (Signoret, 1990) and the hair of male goats (Over et al., 1990) supports the concept that visual and physical components of perception of the ram are not essential. However, some data exist implicating the involvement of these senses in generating the response. For example, olfactory bulbectomy which destroys the main and accessory systems failed to prevent the increase in luteinizing hormone (LH) release in response to introduction of intact males but did inhibit LH secretion in response to ram's fleece stimulation in anestrous Ile-de-France ewes (Cohen-Tannoudji et al., 1986).

The neurons of the main olfactory bulbs project to the olfactory cortex. From the olfactory cortex, efferent fibers innervate the hypothalamus via the amygdalae and the fornix (Martin et al., 1986). Thus, a pathway exist through which pheromones detected by the olfactory mucosa can be transduced to the hypothalamus and stimulate the secretion of $\mathrm{GnRH}$.

Factors affecting the response of anestrous ewes to ram introduction. The factors affecting the response of anestrous ewes to ram introduction have been reviewed (Martin et al., 1990; Tilbrook and Cameron, 1990; Oldham and Fisher, 
1992). Isolation of ewes from the rams for at least one month prior to introduction is the generally accepted practice, although precise requirements of this isolation period have not been determined (Oldham and Fisher, 1992). Pearce and Oldham (1988) noted that separation of rams with a clear fence line was sufficient to prevented ovulation in ewes from which lambs were recently weaned but not in long-term ( $\geq 2$ months) open ewes. Oldham and Fisher (1992) suggested that a process of habituation occurs, where rams loose their ability to stimulate increased secretion of LH from ewes after joining. If habituation occurs after the first induced estrus, then ewes become anovular again before ever displaying estrus (Oldham and Cognié, 1980; Philips et al. 1984). Introduction of a novel ram induces ovulation in some previously un-stimulated and some habituated ewes (Pearce and Oldham, 1988).

The post-partum interval might be important. Only $4 \%$ of ewes $12 \pm 6$ weeks postpartum had ovulated 4 days after ram-introduction compared to 89$95 \%$ of ewes tested 65 days later (Pearce and Oldham, 1988). Further, Geytenbeek et al. (1984) observed a near linear increase in the percentage of ewes ovulating in response to ram-introduction between 0 and 50 days postpartum.

The stage of anestrous, as reflected by the percentage of spontaneously ovulating ewes in the flock, also influences the response of a flock to ram introduction (Lindsay and Signoret, 1980; Oldham and fisher, 1992). Lindsay and Signoret (1980) showed that the percentage of ewes ovulating in response to ram introduction was positively correlated with the proportion of the flock 
ovulating spontaneously. However, exceptions to this rule do occur. Pearce and Oldham (1988) observed an ovulatory response to ram introduction in $98 \%$ of ewes from flocks in which only $4 \%$ of the ewes were ovulating spontaneously.

Breed/strain differences of both the rams and ewes affect the ovulatory response. Ram introduction can induce ovulation throughout the anestrous period in Merino, but only near the end of the anestrous season in the lle de France (Oldham, 1980) and Romney ewes (Edgar and Bilkey, 1963). Dorset rams are more effective than Romney rams at stimulating Romney ewes to ovulate upon introduction (Tervit et al., 1977). Dorset rams have a lower concentration of testosterone than Romney rams, therefore the ram effect is not directly related to peripheral concentration of this steroid (Tervit et al., 1977; Oldham and Fisher, 1992), although testosterone is needed for the production of the pheromone that induces the ram-effect (Fulkerson et al., 1981; Signoret et al., 1982).

Cohen-Tannouji et al. (1986) reported that ewes with surgically ablated olfactory bulbs displayed similar LH responses to rams as intact controls. This suggests that behavioral stimuli may be important in the ovulatory response to ram introduction. Perkins and Fitzgerald (1994) identified rams with low and high sexual performance based on the number of mounts and ejaculations achieved over a 30-minute exposure to estrous synchronized ewes. The authors observed that a greater percentage of anestrous ewes ovulated when exposed to high performance (95\%) than low performance (78\%) rams. Rosa et al. (2000) reported that rams pre-treated with melatonin had higher concentrations of 
testosterone, showed greater sexual activity and induced more ewes to ovulate (56 \%) than untreated rams (24\%). Similarly, in goats, bucks exposed to a long day photoperiod during late winter and then treated with melatonin showed greater sexual activity than untreated bucks when introduced to does during the anestrous period. Treated bucks stimulated ovulation and estrous behavior in all females (40/40) within the first 11 days, while none of the females exposed to untreated bucks displayed estrous behavior and only 2 of 34 ovulated (Flores et al. 2000).

A complex interaction exists with respect to the effect of nutritional status of the ewe on the ovulatory response to ram introduction. The percentage of ewes responding to ram introduction with ovulation was greater in ewes on a high than low plane of nutrition during autumn and early winter. However, flushing with lupin grains significantly decreased the ovulatory response in ewes on a long-term low plane of nutrition (Oldham and Fisher, 1992). Fogarty et al. (1992) observed a decline in estrous response and an increase in the interval from lambing to first estrus in flushed ewes of $-0.2 \%$ and 1.3 days, respectively per kg gain in live weight.

The capacity for the male to induce ovulation might be affected by the age of the female. In general the response of ewe lambs and yearlings to introduction of rams is variable and typically worse than that observed in ewes (Oldham and Fisher, 1992). 


\section{Progestogen Pre-treatment.}

Dutt (1953) first used progesterone in combination with equine chorionic gonadotropin (eCG) to induce estrus and ovulation in seasonally anestrous ewes. Since then, several treatment combinations using different progestogens and gonadotropins at varying dosages have been evaluated (Gordon, 1958; 1963bcde; Lindsay et al., 1967; Robinson et al., 1967b; Robinson and Smith, 1967;). The results from these studies have been less than satisfactory and fertility of the ewe bred out-of-season continues to be lower than that observed during the normal breeding season. Progesterone plays a multitude of roles in reproduction. This review will focus on specific roles that progesterone plays in the stimulation of fertile estrus in anestrous ewes.

Role of progestogens in the display of behavioral estrus. In anestrous ewes the first ram-induced ovulation is not accompanied by estrus. However, if a second ovulation is induced 16 days later, estrus is exhibited (Cole and Miller, 1933). Early studies indicated that progesterone blocks the inductive effect of estrogen on estrus (Dutt and Casida, 1948). Since then, several authors have demonstrated stimulatory roles of progesterone pre-treatment on sexual behavior (Robinson, 1950; 1954abc; 1955; Scaramuzzi et al., 1971; Fabre-Nys and Martin, 1991 and others). The occurrence of estrus with ovulation in response to gonadotropin during anestrus is dependent on the presence and age of a CL in 
the ovary at the time of treatment (Hammond Jr., et al., 1942; Robinson, 1950). Robinson (1954b) observed a greater estrous response in ewes pre-treated with progesterone at all doses of estrogen used. Further, progesterone pre-treatment reduced the minimal dose capable of stimulating an estrous response and advanced the time to onset of estrous behavior. In another study using maiden Romney Marsh ewes during seasonal anestrus, Robinson (1955), observed estrous behavior in all progesterone pre-treated ewes receiving estrogen $(25 \mu \mathrm{g})$ or estrogen and eCG (1000 i.u.). Ewes receiving similar doses of estrogen or estrogen and eCG but without progesterone pre-treatment did not show estrous behavior. Fabre-Nys and Martin (1991) confirmed and extended the earlier findings of Robinson (1954abc; 1955). The authors observed that progesterone pre-treatment increased the proportion of ovariectomized ewes showing estrus, decreased the time from estradiol treatment to the onset of estrus, increased the duration of estrous behavior, and increased the intensity of the receptivity displayed by ewes.

Repeated injections of estrogen reduce the proportion of ewes showing estrous behavior (Robinson, 1954b; Scaramuzzi et al., 1972). The percentage of ewes displaying estrous behavior after the second of two estrogen injections administered 19 days apart was greater when ewes were treated with progesterone between days 5 and 11 (Fabre-Nys and Martin, 1991), indicating that progesterone treatment following estradiol administration and prior to a subsequent administration prevents the estrogen-induced desensitization. Apparently progesterone need not be present immediately prior to estradiol 
administration (Moore and Robinson, 1957), because ewes expressed estrus in response to estrogen treatment even though they were last treated with progesterone eight days before (Fabre-Nys and Martin, 1991).

\section{Role of progestogens in the maintenance of the first CL induced in} anestrous ewes. The CL from the ram-induced ovulation (Oldham and Martin, 1978/79; Pearce et al., 1985; Martin et al., 1986; Oldham and Fisher, 1992) or administration of $\mathrm{GnRH}$ (Crighton et al., 1975; Haresign et al., 1975; Mcleod et al., 1982ab) or LH (McNeilly et al., 1982) to anestrous ewes regresses prematurely in at least $50 \%$ of all ewes. Progesterone pre-treatment prior to induction of ovulation prevents the early demise of the $\mathrm{CL}$, irrespective of whether the length of progesterone is administered for 10-14 days (Oldham et al., 1980; Martin et al., 1981; McLeod et al. 1982a) or as a single i.m. injection (Cognie et al., 1982; Oldham et al., 1985). The minimal effective dose and duration of exposure to progesterone may be related (Martin et al., 1986). The minimal duration of progestogen exposure prior to ram introduction that will completely prevent short cycles is $24 \mathrm{~h}$ (Martin et al., 1986). A single injection of progesterone (20 mg i.m.) at (Cognie et al., 1982; Oldham et al., 1985) or up to 5 days prior to ram introduction (Cognie et al., 1982; Oldham et al., 1985; Martin et al., 1986) will prevent short cycles. This dosage of progesterone is capable of elevating serum concentrations of progesterone to greater than $1 \mathrm{ng} / \mathrm{ml}$ for at least 30 hours (Pearce et al., 1985), equivalent to the minimal duration of progesterone needed. 
Several hypotheses were forwarded to account for this effect of progesterone. Pearce et al. (1985) observed that progesterone treatment (20 $\mathrm{mg}$ ) at ram introduction or $24 \mathrm{~h}$ prior to $\mathrm{GnRH}$ administration reduced the occurrence of short-lived CL. Administration of progesterone was associated with a delay in the LH surge leading the authors to speculate that progesterone priming allowed the developing follicle longer exposure to gonadotropins, which in turn increased the functional capacity of the CL. The duration $(\sim 34 \mathrm{~h})$ from ram introduction to the onset of the LH surge was similar in ewes treated with a single injection of progesterone 3 or 5 days before ram introduction and in untreated ewes. However, treatment with progestogens totally prevented the occurrence of short-lived CL (Martin et al. 1986). Apparently, progesterone was preventing the premature regression of the $\mathrm{CL}$ by some other mechanism apart from delaying the LH surge.

In another study, Hunter et al. (1986) observed that follicles recovered around the time of the initiation of the $\mathrm{GnRH}$-induced $\mathrm{LH}$ surge from progesterone pre-treated ewes showed a greater estradiol secretion and hCG binding in vitro compared to follicles from ewes that were not pre-treated. The authors suggested that inadequate luteal function in anestrous ewes induced to ovulate might be due to a poor response to the LH surge probably due to problems in the final maturational stages of the follicle.

Southee et al. (1988b) provided evidence for the role of the uterus in short-lived CL from anestrous ewes. Progesterone pre-treatment increased the percentage of anestrous ewes having normal CL lifespan form 40 to $100 \%$, 
however all hysterectomized ewes irrespective of progesterone pre-treatment had a CL that was maintained for at least 21 days. The authors suggested that uterine derived $\mathrm{PGF}_{2 \alpha}$, was responsible for the premature regression of $\mathrm{CL}$ induced in anestrous ewes without progesterone pre-treatment. Hu et al. (1991) observed short luteal phases in unilaterally hysterectomized ewes in which ovulation occurred exclusively on the ovary ipsilateral to the remaining uterine horn, but not in ewes with at least one $\mathrm{CL}$ in the ovary contralateral to the remaining horn. The $\mathrm{CL}$ ipsilateral to the remaining horn weighed less and contained less progesterone than the contralateral $\mathrm{CL}$. These findings thus supported those of Southee et al. (1988) of a uterine involvement in the regression of the induced CL. However the serum concentration of PGFM did not differ among treatment groups.

Hunter et al. (1989) provided evidence for the direct involvement of $\mathrm{PGF}_{2 \alpha}$ in the premature demise of the induced CL in anestrous ewes. They observed that ewes in which the progesterone profile remained elevated following $\mathrm{GnRH}$ induced ovulation (i.e. all progesterone pretreated and some untreated ewes) had a lower concentration of PGFM between day 3 and 5 compared to ewes that had a premature decline in progesterone secretion. Ewes treated with flunixin meglumine, a $\mathrm{PGF}_{2 \alpha}$ synthetase inhibitor, every $12 \mathrm{~h}$ from 3 to 6 days after ram introduction showed decreased PGFM pulses, a reduced number of short cycles, and had a single peak in estrous activity 15-16 d after ram introduction (Lassoued et al., 1997). The authors concluded that premature release of $\mathrm{PGF}_{2 \alpha}$ was the cause of early luteal regression. 
While comparisons of concentration of $\mathrm{PGF}_{2 \alpha}$ between progesterone pretreated and untreated ewes following induced ovulation has not been done, studies in the cow suggest that progesterone prevents the occurrence of shortlived $\mathrm{CL}$ by preventing the increase in uterine $\mathrm{PGF}_{2 \alpha}$ associated with induced $\mathrm{CL}$. Cooper et al. (1991) observed that treatment of early post partum cows with the progestogen, norgestomet, for 9 days prior to induction of ovulation with hCG resulted in luteal life spans of normal length. Additionally, lower concentrations of $\mathrm{PGF}_{2 \alpha}$ in the posterior vena cava were observed between days 4 through 9 in cows pre-treated with the progestogen compared to controls. In another experiment, early postpartum cows that were treated with norgestomet the authors observed a rise in $\mathrm{PGF}_{2 \alpha}$ on $\mathrm{d} 3$ to 5 after the commencement of progestogen treatment but not in controls. They concluded that the post-partum uterus increases secretion of $\mathrm{PGF}_{2 \alpha}$ very early after first exposure to endogenous or exogenous progestogen. Similarly, in the anestrous ewe progesterone pretreatment may cause an early rise in $\mathrm{PGF}_{2 \alpha}$ prior to ovulation and/or before the $C L$ becomes susceptible to the luteolytic effects of $P G F_{2 \alpha}$.

\section{Effect of progestogen pre-treatment on the hypothalamic pituitary axis} during anestrous. Ovulation and estrus followed by at least one normal luteal phase is observed in anestrous ewes pre-treated with progestogens prior to ram introduction or administration of gonadotropins. The role(s), if any that progesterone pre-treatment plays in the resumption of ovulatory activity independent of the "ram-effect" has not been established. The critical step in the 
ovulatory process is the sustained increase in tonic $\mathrm{GnRH}$ secretion that drives increases in tonic LH secretion, which in turn stimulates final follicular maturation and the enhanced estradiol production that triggers the pre-ovulatory $\mathrm{LH}$ surge (Baird and Scaramuzzi, 1976; Haugher et al., 1977; Karsch et al., 1980b; Goodman, 1994). In the cyclic ewe this increase in $\mathrm{GnRH} / \mathrm{LH}$ secretion is initiated at progesterone withdrawal following luteolysis.

Progesterone is a potent negative feedback hormone on gonadotropin secretion in the cyclic ewe (Baird and Scaramuzzi, 1976; Karsch et al., 1979; 1980b), and suppresses GnRH/LH pulse frequency (Karsch et al., 1980b), estrus (Scaramuzzi et al., 1971) and ovulation (Dutt and Casida, 1948; Karsch et al., 1980b). This inhibitory effect of progesterone on the hypothalamic-pituitary axis is reflected in an increase in the interval from estrogen administration (FabreNys and Martin, 1991), or ram introduction (Pearce et al., 1985) to the LH surge. The delay to the initiation of the LH surge in progesterone pre-treated ewes resulted in a closer association of the LH surge with the display of estrous behavior than in ewes treated with estrogen alone (Fabre-Nys and Martin, 1991).

Progesterone priming might have a stimulatory effect on $\mathrm{GnRH} / \mathrm{LH}$ secretion via at least two mechanisms. As indicated before, the seasonal decline in reproductive activity in the ewe is believed to be due to an increase in the sensitivity to the negative feedback effects of estradiol (Legan et al., 1977). If progesterone pre-treatment decreases the negative feedback effect of estradiol on the hypothalamic-pituitary axis then an escape from the inhibitory effects of estradiol may occur leading to increase $\mathrm{GnRH} / \mathrm{LH}$ secretion. Barrel et al. (1992) 
provided evidence against this hypothesis. Administering progesterone implants for 9 days induced an artificial luteal phase, but the authors did not observe increases in $\mathrm{GnRH}$ or $\mathrm{LH}$ pulse frequencies following withdrawal of implants. A major limitation in this study was the time at which blood samples were collected (44-50 $\mathrm{h}$ after withdrawal). This period could theoretically be after any induced changes in the $\mathrm{GnRH} / \mathrm{LH}$ secretion patterns, thus precluding the detection of increases in gonadotropin secretion.

Progesterone pre-treatment might also affect the $\mathrm{GnRH} / \mathrm{LH}$ surge. Using an artificial model of the follicular phase in ovariectomized ewes during the anestrous season, Caraty and Skinner (1999), observed that progesterone pretreatment was necessary for the full expression of the estrogen-induced $\mathrm{GnRH}$ surge. However, although a delay in the initiation of the LH surge was observed, neither the amplitude nor the duration of the surge was affected, an observation previously reported by (Fabre-Nys and Martin, 1991). The foregoing discussion thus leads to the suggestion that progesterone pre-treatment delays the occurrence of the LH surge in response to estrogen or ram introduction and may amplify the estrogen-induced $\mathrm{GnRH}$ surge. Unlike the situation during the breeding season, progesterone treatment and withdrawal alone, does not modify the secretion of gonadotropins. However the latter needs further investigation as previous measurements were conducted long after progesterone withdrawal and possibly after the occurrence of an LH surge. 
Types of progestogens. Adoption of the use of progestogens for the control of the estrous cycle of the ewe and induction of estrus in anestrous ewes required simplification of the progesterone injection procedure, development of a sharp end-point to progestogen treatment and an understanding of the factors that affect fertility (Robinson, 1967). Development of intravaginal pessaries for the application of progestogens, the first two objectives could be met. However owing to the problems associated with the incorporation of adequate amounts of progesterone in sponges a need existed for the development of progestogens that were more active than progesterone but with similar physiological effects including a short and predictable duration of activity (Robinson, 1967). In a series of experiments Robinson and coworkers evaluated the effectiveness of several such progestogens. Robinson et al. (1967a) evaluated the effectiveness of five progestogens on the control of estrus and ovulation when used in intravaginal sponges during spring. The authors reported that the most effective were SC-9880 (fluorogestone acetate (FGA); $17 \alpha$-acetoxy-9 $\alpha$-fluoro-11 $\beta$ hydroxypregn-4-ene-3, 20-dione; 10-40mg), which was 25 times more potent than progesterone, MAP (17 $\alpha$-acetoxy-6 $\alpha$-methylpregn-4-ene-3, 20-dione; 20-80 $\mathrm{mg}$ ), and SC-9022 (17- $\beta$-hydroxy-21-methyl-21-methylene-19-nor-17 $\alpha$-pregn-4en-3-one; > $80 \mathrm{mg}$ ). These progestogens induced estrus in $85 \%$ of ewes days after sponge withdrawal, and 43 percent of ewes lambed to $\mathrm{Al}$ at the induced estrus.

Lindsay et al. (1967) observed that treatment with daily progesterone injections or feeding MAP were equally effective in blocking estrus during the 
treatment period $(98 \%)$, but more ewes synchronized with progesterone displayed estrus within 7 days (80.3\%) than ewes synchronized with MAP (58.3\%). More MAP than progesterone-synchronized ewes ovulated without displaying estrus during (6.3 and $1.3 \%$ ) and after (29.7 and $14.3 \%)$ the synchronization treatment. The estrous response was more synchronized, and conception rate and lambing percentages were greater in progesterone than MAP treated ewes. Ewes bred by Al and synchronized with MAP showed the lowest conception rate and lambing percentages. No differences were observed between a 14 day treatment with a progesterone releasing inserts (CIDR; 550 $\mathrm{mg}$ ) or FGA sponges $(40 \mathrm{mg})$ in their relative efficiency to synchronize estrus during the breeding season (Ainsworth and Downey, 1986). The two treatments, both resulted in a high estrous response ( $91 \%$ within 72 h) and pregnancy rate (67\%). In a similar study, Rhodes and Nathanielsz (1988) observed no difference in the estrous response in ewes treated with CIDR (366 mgprogesterone) and MAP sponges (60 mg) although the estrous response was more synchronized in CIDR-treated ewes. MAP and FGA sponges were also found to be equally effective in synchronizing estrus and ovulatory responses in cyclic ewes (Boland et al., 1978/79). No difference was observed in the effectiveness of FGA (Cronolone sponges; $30 \mathrm{mg}$ ) or progesterone (CIDR; 400 $\mathrm{mg}$ ) in their ability to induce estrus in anestrous ewes (Hamra et al., 1989).

The progestogen, SC-21009, (Norgestomet; 17-hydroxy-11 $\beta$-methyl-19norpregn-4-ene-3, 20-dione acetate) administered as an ear implant was effective in synchronizing estrus in heifers (Burrell et al., 1972) and cows 
(Whitman et al., 1972). A 3-mg norgestomet ear implant used for 14 days (Boland et al., 1978/79) or a 3-mg implant for 10 days plus $1.5 \mathrm{mg}$ norgestomet and $0.5 \mathrm{mg}$ estradiol (Spitzer and Carpenter, 1979; 1981) was effective in synchronizing estrus in ewes during the breeding season. The estrous response and pregnancy rate to the first service was comparable to responses observed in FGA-synchronized ewes (Spitzer and Carpenter, 1981). The effectiveness of norgestomet implants to induce estrus in anestrous ewes has been evaluated (Carpenter and Spitzer, 1981; Alifakiotis et al., 1982; Tritschler II et al., 1991). Carpenter and Spitzer (1981) reported that the estrous response and conception rate were 79 and $51 \%$, respectively in anestrous ewes following treatment with 3-mg implant for 10 days plus $1.5 \mathrm{mg}$ norgestomet and $0.5 \mathrm{mg}$ estradiol. In a comparison between ewes treated with MAP sponges (60 mg), FGA sponges (40 $\mathrm{mg})$ or norgestomet implants $(1.3 \mathrm{mg})$ for 14 days with eCG $(500-1000 \mathrm{IU})$ at progestogen withdrawal no differences in the estrous response and percentage of ewes lambing to the first service (98 and $54 \%$, in norgestomet treated ewes respectively) were observed among the treatment groups.

Melengestrol acetate (MGA; 17 $\alpha$-hydroxy-6-methyl-16-methylene-4,6pregnadiene-3,20-dione acetate) is one of the most potent orally active progestagens in ruminants (Zimbelman, 1963). MGA is capable of synchronizing estrus in cattle (O'Brien et al., 1968) and has been used to induce fertile estrus in anestrous ewes (Safranski et al., 1992; Jabbar et al., 1994; Powell et al., 1996; Keefe et al., 2000). Safranski et al. (1992) observed a 63\% estrous response and a $41 \%$ lambing percentage in anestrous ewes fed $0.125 \mathrm{mg} \mathrm{MGA}$ twice per 
day for 9 days. In another study in which ewes were similarly fed $80 \%$ of ewes displayed estrus by $84 \mathrm{~h}$ and $75 \%$ lambed after a $21 \mathrm{~d}$ breeding period (Powell et al., 1996). Treatment of anestrous ewes for 10 days with norgestomet ear implants (SMB; 3mg) or MGA (0.3 mg/ewe/day) resulted in more SMB than MGA-treated ewes mating within the first 5 days and conceiving to the first service (Jabbar et al., 1994). However, the overall percentage of ewes mated and lambing over the 30 day mating period did not differ between treatments. There seems to be little difference in the efficacy of the various progestogens (progesterone, FGA, SMB, MAP, MGA) to induce fertile estrous in anestrous ewes. The use of a particular progestogen may therefore be more related to other factors such as availability, ease of use, and approval by regulatory agencies.

Methods of progestogen administration. Early approaches to simplify the procedure for induction of estrus involved injections of microcrystalline progesterone or the use of a single large dose. These approaches failed to produce comparable results to that of daily progesterone injections over 5-6 days (Gordon, 1958; 1963d).

Robinson (1965) first reported the use of progestogen-impregnated sponges that could be applied intravaginally or subcutaneously. The use of intravaginal sponges impregnated with several different progestogens were later observed to be effective in blocking estrus and ovulation in cyclic ewes (Robinson et al., 1967a) and induction of estrus in anestrous ewes (Moore and 
Holst, 1967; Robinson and Moore, 1967; Robinson and Smith, 1967). Intravaginal pessaries were subsequently manufactured with FGA and MAP, and utilized for the induction of estrus in anestrous ewes (Alifakiotis et al., 1982) and the synchronization of estrus in cyclic ewes (Spitzer and Carpenter, 1981; Rhodes and Nathanielsz, 1988).

Evans et al. (1962) and Hogue et al. (1962) successfully used oral progestogens to synchronize estrus in cyclic sheep. Evans et al. (1962) fed cyclic ewes 50,60 or $90 \mathrm{mg}$ MAP daily for $15-18$ days and observed estrus in $80-100 \%$ of all ewes, and $63.2 \%$ of all ewes lambed to the first post treatment service period. The estrous response was not different in ewes synchronized with MAP (60 mg/daily for 20 days) and unsynchronized ewes. The conception rates were also not different among control ewes bred naturally or with $\mathrm{Al}$ and synchronized ewes bred naturally. However, synchronized ewes bred with Al had a lower conception rate than all other groups (Hogue et al., 1962). Lindsay et al. (1967) fed MAP to cyclic ewes for 16 days, almost $60 \%$ of ewes exhibited estrus within 7 days of completion of feeding. Safranski et al. (1992) and Powell et al. (1996) evaluated the effectiveness of the orally active progestogen, Melengesterol acetate (MGA), in the induction of fertile estrus in anestrous ewes. Ewes were fed $0.125 \mathrm{mg}$ MGA twice per day for 9 (Safranski et al.1992), 811 or 14 days (Powell et al., 1996). The mean estrous response, percentage of ewe lambing, and lambing rate were 55 and 90,41 and 75 , and 71 and $100 \%$ for both studies, respectively. 
The progestogen norgestomet in an ear implant was effective in controlling estrus in the cycling ewe and resulted in pregnancy rates to the first service that were equal to those of non-treated controls (Spitzer and Carpenter, 1979). Carpenter and Spitzer (1981) treated anestrous ewes in February through June with a 3-mg norgestomet ear implant for 10 days with an additional $1.5 \mathrm{mg}$ and $0.5 \mathrm{mg}$ estradiol valerate i.m. at time of placement of the implant and 750 IU eCG at implant removal. The estrous response, conception and pregnancy rates were $79,40,40 \%$, respectively and were higher than that observed in control ewes after a 16 day breeding period. The estrous response, percentage of ewes lambing to the first service and overall was not different in anestrous ewes treated with norgestomet ear implants $(1.3 \mathrm{mg})$, FGA (40 mg) or MAP (60 mg) sponges for 14 days (Alifakiotis et al., 1982).

Welch et al. (1984) first reported the use of controlled internal drug release dispensers (CIDRs) for synchronization of estrous in ewes. These intravaginal devices were constructed of a progesterone impregnated medical silicone elastomer molded over a nylon core (Wheaton et al., 1992; 1993). CIDR devices were developed as an alternative to intravaginal progestogen sponges. The advantages of these devices included the ability to incorporate greater concentrations of progesterone that proved to be difficult with sponges (Robinson, 1965), elimination of foul-smelling mucus that discharges upon removal of sponges and the incorporation of synthetic progesterone similar in structure to the natural hormone (Wheaton et al., 1992; 1993). The use of the natural hormone makes CIDR devices more attractive to licensing authorities 
such as the U.S. Food and Drug Administration. In a series of experiments Wheaton and co-workers evaluated the effectiveness of CIDR devices. Carlson et al. (1989) obtained an average serum concentration of progesterone of 1.9 $\mathrm{ng} / \mathrm{ml}$ over a 13 day period in ovariectomized ewes treated with CIDR devices containing $9 \%(\sim 366 \mathrm{mg})$ and $12 \%(\sim 488 \mathrm{mg})$ of total weight which was higher than ewes treated with progesterone sponges $(400 \mathrm{mg} ; 1 \mathrm{ng} / \mathrm{ml})$. As there were no apparent differences in the 9 and $12 \%$ devices and because $12 \%$ devices were more expensive to produce, the $9 \%$ devices were selected for commercial production (Wheaton et al., 1992). CIDRs with 9\% progesterone elevated the serum concentrations of progesterone in ovariectomized ewes to $2.8 \mathrm{ng} / \mathrm{ml}$ by 3 days after which concentrations declined to $0.3 \mathrm{ng} / \mathrm{ml}$ by day 36 . These devices were able to block estrus and ovulation for 27 to 31 days (Carlson et al., 1989). Treatment of cyclic ewes with CIDR devices resulted in an estrous response of $91 \%$ within 5 days after insert removal and $\sim 68 \%$ of the 129 CIDR treated ewes lambed within 6 days of each other (Carlson et al., 1989). CIDR devices were as effective as FGA sponges (Ainsworth and Downey, 1986) or MAP sponges (Rhodes and Nathanielsz (1988) in synchronizing estrus during the breeding season.

Anestrous ewes treated with FGA sponges or CIDR devices and eCG at progestogen withdrawal showed a similar estrous response (92 and 93\%), percentage of ewes lambing ( $69 \%)$, and lambing rate ( 104\%, respectively; Hamra et al., 1989). These findings support those of Crosby et al. (1991) and Maxwell and Barnes (1986) who observed no differences in reproductive 
variables following treatment with CIDR devices or progestogen sponges. CIDR devices therefore seems to be as effective as other delivery systems in the induction of estrus in anestrous ewes and synchronization of estrus during the breeding season, and offers advantages that may prove beneficial to its acceptance by the U.S. Food and Drug administration and sheep producers.

Effect of Duration of progestogen treatment. Treatment with progesterone for 3 days, either $30 \mathrm{mg}$ s.c. every 3 days (Dutt, 1953) or $12.5 \mathrm{mg} 2$ times per day (Robinson, 1954ab;1955; Gordon, 1958;1963bcde) with eCG (Robinson, 1954; Gordon, 1958ab;1963bcde) or estrogen (Robinson, 1955) after the last progesterone injection induced estrus and ovulation in anestrous ewes. Increasing the duration of treatment to six days ( 3 injections, 3 days apart) increased the percentage of ewes displaying estrus, and the percentage of fertilized ova, however increasing the period of progesterone pre-treatment up to 12 days did not improve estrous response or fertility further (Dutt, 1953). Gordon (1958) also observed a high estrous response (80-90\%) when progesterone was administered for 5 or 6 days ( $12.5 \mathrm{mg}$ at $12 \mathrm{~h}$ intervals or $25 \mathrm{mg} 1 \mathrm{x}$ day), while the lowest response ( $31-50 \%)$ were observed in ewes treated for 3 days (12.5 $\mathrm{mg}$ at $12 \mathrm{~h}$ intervals). All ewes were treated with eCG $24 \mathrm{~h}$ after the final progesterone injection. Ewes treated with single injections of 50 to $200 \mathrm{mg}$ of progesterone followed by eCG 3,5 or 7 days later also showed a low estrous response (9.7\%; Robinson, 1955; 31.8\%; Gordon, 1958). The duration of progesterone pre-treatment may affect the sensitivity of the behavioral centers to 
estradiol, or the duration of progesterone treatment may affect the gonadotropin effects on follicular development and estrogen production (Hunter and Southee, 1987; Hunter et al., 1988; Leyva et al., 1998; Noël et al., 1999). Robinson et al., (1956) reported that the median effective dose to induce estrus was reduced from 16 to $12 \mu \mathrm{g}$ by increasing the duration of progesterone treatment from 6 to 12 days. Further, Robinson (1955) found that administration of estrogen (15 $\mu \mathrm{g}$ ) to ewes pre-treated with progesterone for three days and injected with eCG 1 day after the last progesterone injection increased the percentage of ewes that displayed estrus. When the duration of progesterone pre-treatment was extended to six days all ewes displayed estrus and as such treatment with estrogen was not required.

In estrous synchronization protocols the period of progestogen treatment has been often equal to or greater than the luteal phase (14-17 days; Robinson, 1968; Gordon, 1972; 1977). This allows a synchronized decline in progestogen with removal of the delivery device (Robinson, 1965; 1968). It is now generally accepted that these long periods of progestogen treatment may contribute to the decline in fertility observed with progestogen-synchronized estrus (Robinson, 1968; Gordon, 1972; 1977). Morgan et al. (1967) noted that $16 \%$ of the progestogen (FGA) present in a sponge was absorbed each day so that the duration of effective suppression of estrus and ovulation is dependent on the initial concentration. Allison and Robinson (1970) also showed that beyond day 12 very little progestogen is released and or absorbed from FGA sponges regardless of the initial dose, suggesting that the relationship observed by 
Morgan et al. (1967) may only be relevant for the first 12 days of treatment. The interaction between initial dose and duration of treatment is therefore relevant. In addition to the quadratic response to increasing dose and duration of treatment on fertility, Morgan et al. (1967) observed a significant interaction between initial dose and duration of treatment. Low dosages were as effective as high dosages over a short ( 8 days) but less effective over a longer duration of treatment (16 days).

A similar relationship may not exist for the anestrous ewe. Increasing the duration of treatment from 12 to 17-18 days did not affect estrous responses and conception rates (ewes lambed of ewes mated; Moore and Holst, 1967; Robinson and Smith, 1967). Anestrous ewes treated with FGA sponges (20 mg) for 8 or 16 days and eCG (750 IU) 1 day after sponge withdrawal also showed comparable estrous responses and conception rates (80 and 37\%, and 89 and 37\%, respectively; Christenson, 1976). More recently studies by Powell et al. (1996) using MGA (0.25 mg/ewe/day) for 8,11 , or $14 \mathrm{~d}$ and Ungerfeld and Rubianes (1999) using MAP sponges (60 mg) for 6,9 , or 13 days, or 6 and 12 days also failed to show an effect of duration of progestogen pre-treatment. In the study by Ungerfeld and Rubianes (1999) ewes treated for 3 days had a numerically lower estrous response and pregnancy rate (72 and 50\%) compared to ewes treated for 6 or 12 days (91 and $72 \%$ ). Ewes treated for 1 or 2 days had the poorest estrous response and pregnancy rate (29 and 16.5\%), confirming the earlier findings of Dutt (1953) and Gordon (1958). The data are suggestive of a at least a 5-6 day progestogen pre-treatment requirement to allow for adequate 
sensitivity to be developed in the behavioral brain centers to the amounts of estrogen secreted as a result of gonadotropin treatment and or ram introduction. Prolongation of the progestogen pre-treatment of anestrous ewes, unlike the situation during the breeding season, probably does not affect fertility.

Effect of Dosage of Progestogen. A variable and generally low fertility has been associated with synchronization of estrous with progestogens (Dutt and Casida, 1948; O’Mary et al., 1950; Robinson, et al., 1967a). Robinson (1968) showed that the fertilization rate and percentage of ewes lambing falls from 86 and $80 \%$, respectively in controls during the breeding season, to 62 and 56 , and 54 and $41 \%$ for ewes treated with progestogens during the breeding season and anestrous, respectively. Lamond (1964) suggested that high fertility at the time of a controlled estrous period is associated with minimal dosage of progestogen capable of blocking ovulation. Robinson et al. (1967a) and Robinson and Smith (1967b) later refuted this hypothesis when they observed that fertility at the induced estrus was greater in ewes synchronized with the higher dosages of progestogen for 19-21 days during the breeding season.

Conception rate was greater in ewes treated with a 6 than a $3 \mathrm{mg}$ norgestomet implant during the breeding season (Woody et al., 1983). Further, treatment with the higher dosage of progestogen prevented the decline in fertility observed when ewes were treated late in the cycle (d 12-13) with the low dose (3 $\mathrm{mg}$ ) of norgestomet.

Robinson (1968) suggested that a dose of progestogen adequate to suppress ovulation and increase the sensitivity to estrogen might not be 
adequate for maximal fertility. Gordon (1972) suggested that inadequacies in intravaginal progestogen treatment might arise due an inadequate initial dose, sub-optimal dispersion in the delivery device resulting in inadequate release, using a long rather a short period of treatment or due to the inherent characteristics of the progestogen.

Inadequate progestogen in the synchronization procedure may reduce fertility in a number of ways. Quinlivan and Robinson (1967) reported that sperm transport in the female reproductive tract following estrus was reduced in progestogen treated compared to that observed in untreated ewes. Allison and Robinson (1970) compared the effects of various dosages of progestogen and observed a reduction in the number of spermatozoa and percentage of ova fertilized when the lower dosage of progestogen $(10 \mathrm{mg})$ was used to synchronize estrus during the breeding season. Further, a positive relationship between the number of spermatozoa in the fallopian tube and fertilization rate was observed, confirming the earlier observations of Quinlivan and Robinson (1967).

Alterations in the timing of events involved in the periovulatory cascade have also been observed in ewes in which estrus is synchronized with progestogens. Ewes treated with low doses of progestogen during the breeding season show a high incidence of breakthrough ovulation during the progestogen treatment period (Shelton and Robinson, 1967), and express estrus earlier after progestogen withdrawal (Robinson et al., 1967b; Van Cleeff et al., 1998). In ewes treated with a low dose of FGA (20 mg), estrus occurred earlier relative to 
the LH surge at the synchronized than at the subsequent follicular phase (Lewis et al., 1974). The asynchrony between the time of mating/insemination and the occurrence of ovulation in addition to reduced sperm transport may reduce fertility at the progestogen-synchronized estrus.

Gordon (1972) noted that one consequence of inadequate progestogen dosage is the failure to inhibit gonadotropin secretion from the pituitary. The author suggested that the increase in gonadotropin secretion might stimulate a rise in estradiol prior to progesterone withdrawal based on the occurrence of estrus as early as 12 hours after progestogen withdrawal. Regression of the CL on day 6 and replacement with exogenous progesterone allowed Johnson et al. (1996) to study the effects of differing concentrations of progesterone. Ewes with low serum concentrations of progesterone $(\leq 1 \mathrm{ng} / \mathrm{ml})$ had a premature rise in estrogen that was associated with a persistent ovulatory follicle. Further ewes in the low progesterone treatment group and those with the highest concentration of estradiol on the day prior to progesterone treatment had lower conception rates. A variable and higher concentration of estradiol was also observed prior to progesterone withdrawal in ewes treated with 1 vs 2 CIDR devices during the breeding season. Elevated concentrations of estradiol for prolonged periods of time may reduce fertility by affecting the quality of the ovulated oocyte and implantation as observed in rats (Butcher, 1972).

The effect of varying dosages of progestogen on the induction of fertile estrus in the anestrous ewe has not been investigated to the same extent as during the breeding season. However, some evidence exist that the minimal 
dosage for a consistent estrous response and conception rate in anestrous ewes may be lower than that for cyclic ewes. Robinson and Smith (1967) treated anestrous ewes with $10 \mathrm{mg}$ FGA sponges for 17-19 days followed by eCG (750 IU). The estrous response (95\%) and the conception rate (ewes lambing to the first service period; 41\%) was not different from that observed when $30 \mathrm{mg}$ sponges were used prior to eCG injection (82 and $37 \%$, respectively; Moore and Holst, 1967). Sponges with less than $30 \mathrm{mg}$ FGA were shown to suppress fertility in ewes during the breeding season (Quilivan and Robinson, 1967; Allison and Robinson, 1970).

Rodriquez-Iglesias et al. (1997) compared the response of anestrous Corriedale ewes to increasing concentrations of MAP in intravaginal sponges. The percentage of ewes marked was not different among dosages, and the percentage of 'non-returns' to estrus and lambing rate tended to be higher in ewes treated with the 15 than the 30,45 or $60 \mathrm{mg}$ sponges. Greyling et al. (1994) also observed no difference in the conception rate (Mean, 68\%) and lambing rate (mean, $82 \%$ ) in anestrous ewes treated with 30,40 or 60 mg MAP impregnated sponges and $300 \mathrm{IU}$ eCG at sponge withdrawal.

Alifakiotis et al. (1982) noted that the pregnancy rate of anestrous ewes treated with a $1.3 \mathrm{mg}$ norgestomet implant $(54 \%)$ was similar to that observed by Carpenter and Spitzer (1981), (51\%) using a total of $4.5 \mathrm{mg}$ norgestomet (1.5 mg at insertion and a $3 \mathrm{mg}$ implant). However, the conception rate was consistently lower with a 3 than a $6 \mathrm{mg}$ norgestomet implant in ewes synchronized during the breeding season (Woody et al., 1983). 
In contrast, when Ungerfeld and Rubianes (1999) treated anestrous ewes for 6 days with previously used ( 6 or 11 days) or new CIDRs and eCG 1 day after insert removal, no differences in the estrous response was observed. However, ewes receiving CIDRs previously used for 11 days had lower conception and pregnancy rates. The reason for the difference in this study is not apparent. However plasma concentrations of progesterone in ovariectomized ewes treated with CIDR devices decline to $0.3 \%$ of peak values by day 10 (Wheaton et al., 1992). The changes in circulating progesterone induced by a 6 day treatment with CIDRs previously used for 11 days while adequate to prime and so elicit estrous behavior in response to eCG may be inadequate to prevent the formation of short-lived CL (Cognie et al., 1982). Therefore, it is apparent that the threshold dosage of progestogen beyond which fertility is compromised is lower for induction of fertile estrus in anestrous ewes than synchronization of estrus during the breeding season. Also the minimal dosage needed to induce estrus in anestrous ewes must be presented long enough to adequately prime the brain for the estrous response and be high enough to prevent the occurrence of shortlived CL.

\section{Progestogen and Gonadotropin Treatment.}

Gonadotropin treatment as part of the estrous induction protocol in anestrous ewes has two main goals, increase in the percentage of ewes bred 
and subsequently lambing and increase in the ovulation rate and number of lambs born per ewe lambing.

\section{Use of eCG}

Cole and Miller (1933) first showed that ovulation could be induced in anestrous ewes with a single injection of pregnant mare serum gonadotropin (eCG), and estrus accompanying ovulation could be induced if two injections were administered 16 days apart. Estrus and ovulation could be induced at the first injection if estrogen alone or estrogen with eCG or eCG and pituitary extracts were used (McKenzie and Terrill, 1937; Bell et al., 1941). Hammond Jr. et al. (1942) noted that estrus and ovulation could be induced at the first injection of gonadotropin if the ewe possessed a regressing $\mathrm{CL}$. The authors suggested that estrogenic substances induce ovulation by evoking secretion of gonadotropins and gonadotropic hormones act by stimulating estrogen secretion.

Dutt (1953) first used progesterone pre-treatment and eCG to induce synchronous estrus and ovulation. Ewes artificially inseminated at the synchronized estrus subsequently lambed. Robinson (1954a) was able to successfully induce estrus and ovulation with a treatment of 3 days of progesterone followed by 1000 i.u. eCG but also noted that successful induction of estrus and ovulation also occurred in the absence of eCG. Gordon (1958) observed that the percentage of ewes exhibiting estrus and the number of multiple of births was increased with higher dosages of gonadotropins. Thereafter, the standard treatment for induction of estrus and ovulation involved 
progestogen pre-treatment with eCG at progestogen withdrawal (Gordon, 1963bcde; Robinson and Smith, 1967a; Gordon, 1971; Carpenter and Spitzer, 1981; Lunstra and Christenson, 1981; Alifakiotis et al., 1982; Ainsworth and Downey, 1986; Hamra et al., 1986; Hamra et al., 1989; Tritschler II et al., 1991; Reviewed in Robinson, 1968; Gordon, 1977; Thimonier and Cognie, 1977; Wheaton et al., 1992).

\section{Dosages and timing of eCG application}

Early studies that utilized progesterone injections frequently used eCG two days after the final progesterone injection (Robinson, 1950; Gordon, 1958; 1963bcde). Gordon (1963b) administered eCG between 1 and 4 days after the final injection of progesterone. Conception rate but not the estrous response was depressed as time from final progesterone injection increased. Similarly Moore and Holst (1967), observed no difference in the percentage of ewes displaying estrus but the percentage of ewes lambing to the induced estrus was highest $(52.7 \%)$ when eCG injection was given at sponge removal and lowest $(17.2 \%)$ when given 48 hours later. Subsequently, with the application of progestogens via implants or intravaginal devices which resulted in a rapid removal of the progestogen and the need to simplify the synchronization procedure, a single injection of eCG was used at progestogen withdrawal (Robinson and Smith, 1967; Gordon, 1971; Carpenter and Spitzer, 1981; Hamra et al., 1989, and others). Gordon (1958) observed an increase in the percentage of multiple births as the dosage of eCG increased from $250 \mathrm{IU}$ to $500 \mathrm{IU}$ with no observable 
difference in 500 and $1000 \mathrm{IU}$. Gordon (1971) compared the effects of increasing concentrations $(0-750 \mathrm{IU})$ of eCG on fertility in out-of-season bred ewes. Among eCG-treated ewes, conception rate was lowest in ewes treated with 750 IU, while the highest percentage of ewes lambing was observed with in groups injected with 500 IU. Since then, several researchers have used a dosage of 500-750 IU in progesterone-eCG protocols for induction of estrus in anestrous ewes (Carpenter and Spitzer, 1981; Lunstra and Christenson, 1981; Alifakiotis et al., 1982; Ainsworth and Downey, 1986; Hamra et al., 1986; Hamra et al., 1989; Tritschler II et al., 1991).

\section{Estrous response to eCG}

The majority of eCG-treated anestrous ewes (85-100\%) display estrus (Moore and Holst, 1967; Robinson and Smith, 1967; Gordon, 1971; Alifakiotis et al., 1982; Hamra et al., 1989; Tritschler II, 1991) once adequate progestational priming occurs and eCG is administered around the time of progestogen removal (Robinson, 1950; Gordon, 1958; 1963bcd). Neither the age (Gordon, 1958; 1963) nor the lactation status (Gordon, 1958; Alifakiotis et al., 1982) seems to affect the estrous response.

\section{Progestogen Pre-treatment and Ram Introduction Without Gonadotropins.}

Several authors have suggested that there is a need for gonadotropin (eCG) application in order to induce a consistently high mating response (Gordon and Keane, 1967; Foote, 1968; Gordon, 1971). These early reports were 
supported by the findings of Cunningham et al. (1980) and Hamra et al. (1989) who observed a poor estrous response (2 of 19 and 1 of 25 in heat, respectively), in progesterone pre-treated ewes not treated with eCG. However, reports also exist that support the hypothesis that ram introduction coincident with progesterone withdrawal may be sufficient to induce fertile estrus in anestrous ewes. Treatment with progesterone for 12 days ( $30 \mathrm{mg}$ once every 3 days; Dutt, 1953), or for 3 days (12.5 mg, twice per day; Robinson, 1955), resulted in synchronous estrus and ovulation. Rams were either joined one-day after progesterone pretreatment (Robinson, 1955) or introduced daily for the detection of estrus (Dutt, 1953). Gordon (1971) induced fertile estrus in anestrous ewes pre-treated with progestogen for 12 days and introduced to rams only. However, the author observed higher percentages of ewes bred, conception and prolificacy rates when eCG was used. Robinson and Smith (1967) found no significant differences between ewes treated with eCG at the end of progestogen pretreatment and progestogen pre-treated ewes only on the overall reproductive performance. Wheaton et al. (1992) observed an estrous response of $91 \%$ and lambing percentage of $73 \%$ in ewes (Columbia, 0.25Finn X 0.25 Targhee $\times 0.5$ Suffolk, and Polypay) treated with CIDR devices and abruptly exposed to rams at insert removal. All ewes were weaned after a lactation period of $7-10$ weeks and had been isolated from rams. The percentage of ewes mated, lambing rate and prolificacy was also not different in anestrous ewes treated with MGA for 8 days alone and ewes treated with MGA and PG-600 (Safranski et al. 1992). The two divergent views on the requirement for gonadotropins may be related to 
timing of ram introduction. Abrupt ram introduction to previously isolated anestrous ewes increases LH pulse frequency and induces an LH surge (Knight et al., 1978; Oldham et al., 1978/79; Martin et al., 1983), thus providing an endogenous source of gonadotropin. Ewes that were not previously isolated will not show the ram effect following progesterone pre-treatment; further, ewes may become refractory to the ram after an initial response (Oldham and Cognie, 1980; Philips et al., 1984; Oldham and Fisher, 1992). The elimination of the ram induced increase in gonadotropin secretion, or the separation of the sensitizing effect of progesterone pre-treatment and the ram induced gonadotropin secretion that drives follicular development and estrogen secretion will reduce the estrous and ovulation responses. In support of this hypothesis, Hamra et al. (1989), observed only 1 of 25 ewes in heat when rams were joined 2 days after progesterone (CIDR-S) removal, the same group, Wheaton et al. (1992) treated ewes at a comparable time in spring and observed an estrous response of $91 \%$ when rams were joined at insert removal. Similarly, analysis of the data presented by Cunningham et al. (1980) in which rams were introduced 5 days prior to progesterone removal indicates that less than $10 \%$ of progesterone treated ewes showed a gonadotropin surge or exhibited estrus, while $95 \%$ of ewes also treated with eCG at progesterone removal showed an $\mathrm{LH}$ surge and estrous response. Boland et al. (1981) showed that the estrous response and lambing percentage in ewes joined with rams was higher in eCG-treated than non-treated ewes when rams were introduced $48 \mathrm{~h}$ after progesterone removal. However, when rams were joined at progesterone removal similar values for all 
reproductive variables were observed for ewes treated with and without eCG. Therefore, introduction of rams at progesterone withdrawal may be adequate to induce a consistent fertile estrous response if conditions are appropriate to allow a "ram effect" response.

Factors that Modify the Ovulation Rate and Prolificacy of Ewes Bred Out-ofSeason

The ovulation rate during the anestrous period is lower than at the rest of the year (McKenzie and Terrill, 1937; Dermody et al., 1970; Mallampati et al., 1971; Land et al., 1973; Hulet et al., 1974; Hall et al., 1986). These changes are in general independent of changes in nutrition or live weight as they were still observed in studies in which animals were on a constant diet (Radford, 1959; Dunn et al., 1960). Other factors may affect the seasonal response, for example changes in ovulation rate are not observed in maiden ewes (Fletcher et al., 1970) or in adult ewes with low live weights (Fletcher, 1971). For this reason attempts to breed ewes out of season has focused on both increasing the percentage of ewes bred as well as increasing prolificacy. Factors affecting ovulation rate include genetic variation, nutrition, age and parity and season (reviewed in Scaramuzzi and Radford, 1983; Cahill, 1984; Signoret, 1990). Approaches to increasing ovulation rate have been previously reviewed (Scaramuzzi and Radford, 1983; Cahill, 1984; Boland and Crosby, 1993; Findlay et al., 1993) and include breeding and selection, nutritional, immunological and hormonal manipulation. This review will briefly address some of the approaches used to 
increase ovulation rate and possible explanations for the reduced ovulation rate during seasonal anestrous.

\section{Factors involved in the reduced ovulation rate during seasonal anestrous.}

Although some reports suggest there is little change in the secretion of FSH between the estrous and anestrous seasons (Walton et al. 1977; Bister and Paquay, 1983; Bartlewski et al., 1998; 2000), others have observed lower concentrations of FSH in the ewe (Findlay and Cumming, 1976; Legan and Karsch, 1980) and at a time equivalent to anestrous in the ram (Lincoln et al., 1977; 1982). Oussaid et al. (1993) observed a higher concentration of FSH during early than mid-anestrous and suggested that the contrasting results obtained in comparisons between seasons may be a result of the time (early vs mid vs late) within anestrous when samples were taken. Suppression of LH pulse frequency that is needed to drive final stages of follicular maturation and lower concentrations of FSH may reduce the number of ovulatory follicles during seasonal anestrous.

Legan et al. (1985) suggested that a decline in ovarian follicular sensitivity to gonadotropins might occur at the onset of anestrous in ewes, and Bartlewski et al. (2000) suggested that individual ewes or breeds that enter anestrous earlier may have a higher threshold for $\mathrm{LH}$ or a greater reduction in ovarian responsiveness to gonadotropins compared to ewes that continue to cycle later. Similarly, a reduction in the responsiveness to gonadotropins might explain the 
lower ovulation rate in anestrous ewes. In support of this hypothesis Gherardi and Lindsay (1980) showed that the ovulation rate response in Merinos to eCG was lowest in spring and highest in autumn mimicking seasonal variation in the number of large follicles reported by Kammerlade et al. (1952). Further, the differences in ovulation rate between different genotypes after hCG induced ovulation were maintained during anestrous and was lower compared to that observed during the breeding season (Boulton et al. 1995). Basal and LH/FSH induced estradiol secretion was lower in follicles $(4-5.5 \mathrm{~mm})$ collected at the end of the breeding season and during anestrus than during the follicular phase at the beginning or middle of the breeding season (Bister et al., 1999; Noël et al., 1999). Long-term GnRH administration maintained cyclic activity during anestrous in Romney ewes (McNatty et al., 1982) but LH alone failed to do so beyond two consecutive cycles (McNatty et al., 1984b). A decrease in the responsiveness to LH also occurs from early to middle anestrus (Oussaid et al. 1993). During early anestrus repeated LH administration alone (10 ug i.v. every $2 \mathrm{~h}$ for $48 \mathrm{~h}$ ) was sufficient to evoke an immediate rise in estradiol secretion, an LH surge, and ovulation. However, during mid-anestrus treatment with FSH (50 $\mu$ i.v. every $2 \mathrm{~h}$ for the first $24 \mathrm{~h}$ ) was also necessary to induce ovulation in response to LH administration (Oussaid et al., 1993). The authors thus suggested that an increase in estradiol negative feedback on FSH occurs gradually during anestrus and this is associated with a gradual decline in responsiveness to LH. FSH and estradiol are needed to ensure that the developing follicle has a full compliment of LH receptors (Kessel et al., 1995). 
The greater ovulation rate and responsiveness to FSH and hCG have been associated with the higher concentration of $\mathrm{LH}$ and $\mathrm{FSH}$ receptors in Romanov than Ile-de-France ewes (Abdennebi et al., 1999) . The lower ovulation in anestrous ewes may be due to lower ovarian follicular sensitivity to gonadotropins as a result of lower concentrations of gonadotropin receptors. However confirmation of this hypothesis is needed.

\section{Approaches to increasing ovulation rate and prolificacy.}

Breed and genetic selection: Most domestic sheep have ovulation rates of between 1 and 2 (Scaramuzzi and Radford, 1983; Cahill, 1984). However 5 breeds of sheep are known to have ovulation rates that approach 3 . These prolific breeds, which have ovulation rates as high as 5-6, include the Booroola Merino, Dahman, Finn, Hu Yang, and Romanov (Scaramuzzi and Radford, 1983; Cahill, 1984). Mahieum et al. (1989) has suggested that the "Creole ewe" of the West Indies should be considered prolific based on the high repeatable ovulation rates observed ( $27 \%$ have ovulation rates of at least 5$)$. The increase in ovulation rate is associated with increase variability in the number of ovulations (Scaramuzzi and Radford, 1983; Cahill, 1984; Mahieum et al. 1989). Based on the high degree of genetic variation and the estimates of heritability (Hanrahan, 1980), it may be possible to increase ovulation rates by cross breeding (Scaramuzzi and Radford, 1983). 
Nutritional manipulation. Marshall (1903) was one of the first researchers to document the increase in prolificacy associated with an enhanced plane of nutrition prior to mating. Knight et al. (1975) observed feeding lupin grains could result in a $30 \%$ increase in twin ovulations within 1 week. This short-term nutritional response, 'flushing' is rapid, reversible and independent of season (Radford et al., 1982). Oldham (1980) fed Lupin supplement (750 g/ewe/day) to unsynchronized ewes for 14 days and determined ovulation rate in ewes that came into estrus 1 week later. The author observed an increase in ovulation rate of about $30 \%$ in ewes fed for 6 days, with no further increase when feeding was continued beyond 6 days. Further, the increase in ovulation rate was not associated with changes in live weight, suggestive of a direct response to nutrient supply (Lindsay, 1976). Protein intakes of $200 \mathrm{~g} /$ day produced a maximal ovulation rate response (Smith, 1981). Ewes in a good body condition or on a good quality basal ration will not respond to additional feeding (Scaramuzzi and Radford, 1983). The association between nutrition and ovulation rate is further complicated by relationships between increase in body weight and ovulation rate (Coop, 1966). For example, Morely et al. (1978) reported a $2-2.5 \%$ increase in ovulation rate per $\mathrm{kg}$ increase in body live weight. Additionally, ovulation rate has been associated with body weight changes occurring months earlier (Cahill, 1981). Nonetheless, short-term flushing perhaps during the period of progestogen pre-treatment is one possible mechanism of increasing ovulation rate in anestrous ewes. 
Immunological approaches. Immunological approaches to increasing ovulation rate have focused on passive or active immunization against estrogens and androgens (reviewed by Boland and Crosby, 1993) or inhibin (reviewed by Findlay et al., 1993). Ewes passively immunized against oestradiol over the last 5 days of the estrous cycle doubled their ovulation rate (Scaramuzzi, 1976). Active immunization against most sex steroids have reportedly increased ovulation rate; testosterone, estrone, estradiol-17 $\beta$ (Scaramuzzi et al., 1980ab, 1981), progesterone (Hoskinson et al., 1982), and androstenidione (Scaramuzzi et al., 1977). The latter has been the basis for the commercial preparation, Fecundin $\AA$. While it was initially thought that the immunological approaches act to increase ovulation rate by reducing the negative feedback effect on gonadotropins, most reports have shown no increase in serum concentrations of gonadotropins (Findlay et al., 1993; Boland and Crosby, 1993). Additionally, Philipon et al., 1989) observed a suppression of FSH in response to immunization against androstenedione. A correlation between ovulation rate and circulating concentrations of gonadotropins was not observed in prolific and non-prolific breeds (Scaramuzzi and Radford, 1983). This has led to the suggestion that mechanisms operating locally at the level of the ovary play an important role in regulating ovulation rate (Signoret, 1990).

Hormonal approaches. Ovulation rate can be increased by administration of gonadotropins such as eCG (Robinson, 1951; Gherardi and Lindsay, 1980), FSH (Laster, 1973; Wright et al., 1981), hCG (Radford et al. 1984) and gonadotropin 
preparations such as PG 600 (Keisler, 1992). In general the use of gonadotropins for increasing prolificacy has been hampered by the great variability in the ovulatory response (Cahill et al., 1984; Lopez-Sebastian et al. 1993). Cahill (1984) suggested therefore that gonadotropins are more useful in super-ovulating ewes rather than increasing twin ovulations. With respect to increasing ovulation rate and prolificacy during the seasonal anestrous, the response to a given dose of gonadotropins may be lower and more variable due to a decreased and variable sensitivity of the ovarian follicles (Oussaid et al., 1993; Noël et al., 1999). An ovulation rate of between 2.3-3 (1-5 range) ovulations per ewe in progestogen-eCG treated ewes has been reported (Gordon, 1958; Moore and Holst, 1967).

The wide variability in responses reported among studies or flocks within studies is probably associated with differences in breed, age, lactation and nutritional status as well as other prevailing environmental conditions. Another source of variation may be related to the mating management practice, specifically whether rams or Al were used, and if rams were used whether they are introduced at the time of eCG injection/progestogen withdrawal or prior to this. The ovulation rate of anestrous ewes at the ram-induced ovulation is 0.27 and 0.48 ovulations above that observed in spontaneous ovulating flock mates without or with progestogen pre-treatment prior to ram introduction, respectively (Cognie et al., 1980; Pearce and Oldham, 1984). Therefore, when ram introduction and eCG occur at progestogen withdrawal the resultant ovulation rates are not independent of either effect. Whether the effects of ram introduction 
and eCG on ovulation rates are additive and whether the degree of stimulation affects ovulation rate as it affects the percentage of ewes ovulating has not been determined, but differences in the use of rams and timing of ram introductions may determine if significant increases due to eCG are observed. Nonetheless, prolificacy values reported for progestogen-eCG treated anestrous ewes are lower than that observed in cyclic ewes treated with (Gordon, 1958; 1963b; 1977; Hulet, 1977; Thimonier and Cognie, 1977) or without (Gordon, 1958; 1963b) eCG at progesterone withdrawal.

While use of eCG at dosages 500-750 IU administered at progesterone withdrawal may increase the estrous response and ovulation rate to that commonly observed in the cyclic untreated ewe, several factors limit its adoption. First, increases in ovulation rate do not always translate to increases in prolificacy. Gordon (1958) examined ovulation rate and embryo numbers in 48 anestrous ewes treated with progesterone for 5 days and injected with 700-750 IU eCG. The author observed an ovulation rate of 1.83 but the embryonic rate was only 1.02 on day $20-22$ after mating. Prolificacy rates of 1.3 (range 1-1.83; Gordon 1958), 1.59 (range 1.39-1.72; Gordon, 1963b), 1.01 (Moore and Holst, 1967), 1.52, 1.35, and 1.2 for three flocks (Robinson and Smith, 1967) were observed. Gordon (1977), and Wheaton (1992) also reported similar values. These rates are lower than that observed in the untreated ewe during the breeding season. Second, as pointed out earlier a wide variability in the response may be observed at dosages required to achieve improvements. Third, repeated use of eCG may induce antibodies that may render the gonadotropin 
ineffective as has been observed in goats (Cognie, 1990). Fourth, eCG is no longer approved for use in sheep production, nor has its application for approval been pursued due to questionable return-on-investments (Wheaton, 1992). Alternative gonadotropins and treatment regimen is therefore needed in order to enhance reproductive performance of anestrous ewes.

Other gonadotropins and gonadotropin preparations have been used in out-of-season breeding. The gonadotropin preparation PG-600 administered after an 8-day treatment with MGA resulted in a higher ovulation rate (2.32) than controls (1.79) and ewes treated with MGA only (1.83) and increased the percentage of ewes ovulating (99.1\%; Safranski et al., 1992). Ahmad et al. (1996) reported that in anestrous ewes treated with $25 \mathrm{mg}$ progesterone and joined with rams a single injection of FSH-P (8 mg i.m.) in propylene glycol increased ovulation rates when injected $12 \mathrm{~h}$ before induction of luteolysis with $20 \mathrm{mg}$ prostaglandin $\mathrm{F}_{2 \alpha}$ on d 14 . However treatment regimen using $\mathrm{FSH}$ where progesterone pre-treatment is used to induce synchronous estrus with the initial ram induce ovulation has not been determined.

Effect of Season on the Occurrence of Reproductive Cycles in the Fall Born Ewe Lamb and Approaches to Induce Fertile Estrus During Seasonal Anestrus.

Age of puberty in fall born ewe lambs. 
Ewes which lamb at one year of age produce 20 percent more lambs and 14 percent more kilograms of lamb than their flock mates bred first as yearlings (Spencer, 1942; Hohenboken et al., 1977). Notter (1992) suggested that 'it may be very difficult to get fall-born ewe lambs to lamb at 12 months of age', and indicated that no satisfactory system exist for introducing ewe lambs to an out-ofseason production system. Ewe lambs born in fall experience a period of seasonal anestrus prior to them achieving puberty. The fall born ewe lamb reaches a breed specific weight and age at puberty of their spring born flock mates during the seasonal anoestrous period. As a result, puberty in fall born ewe lambs is delayed until their first fall (Vesely and Swiersta, 1987; Forcada et al., 1991). Similarly, ewe lambs that were nutritionally restricted from June to February did not initiate reproductive cycles until the next breeding season although they had attained an appropriate weight by April (Foster et al., 1988). However, nutritionally restricted lambs that were fed ad libitum beginning in the middle of the breeding season attained puberty during their first breeding season. The inhibitory photoperiod that fall born ewe lambs are exposed to during seasonal anestrous is thought to repress the attainment of puberty due to the retardation of sexual development (Foster, 1981), or, through the inhibition of the expression of already achieved sexual competence (Land, 1978; Foster, 1981).

\section{Photoperiodic requirements for the attainment of puberty in fall born ewe} lambs. 
Ewe lambs that are born in the fall do not attain puberty before the following autumn at nearly one year of age. In contrast spring born lambs attain puberty in the fall of the same year. Exposure of spring born ewe lambs to a continuous long or short photoperiod delayed the first normal luteal cycle beyond 1 year. However, exposure of ewe lambs 12 weeks or older (but not before) to long days (15L: 9D) for as little as 5 weeks followed by exposure to short days (9L: 15D) was effective in inducing normal cycles (Yellon and Foster, 1985; Ebling and Foster, 1988). Additionally, treatment of spring born ewe lambs with melatonin beginning in July but not before, advances the onset of puberty (Nowak and Rodway, 1985). These findings have lead to the suggestion that, a decline in photoperiod after exposure to the long days was necessary for the attainment of puberty in spring born ewe lambs. In contrast, continuous exposure of anestrous ewes to LD only from spring resulted in the resumption of reproductive activity synchronously at the expected time in fall (Ebling and Foster, 1988). This suggests that the photoperiodic requirements for induction of puberty in spring born ewe lambs probably differs from those for the onset of the adult breeding season (Ebling and Foster, 1988).

Photoperiodic manipulations (long day followed by short days) have also been used to induce puberty during the anoestrous period in fall born ewe lambs (Foster and Ryan, 1981; Ainsworth and Shrestha, 1987; Ainsworth et al., 1991). Such treatments reduce the age of puberty to that observed in spring born lambs. However, under natural photoperiod fall born lambs initiate reproductive cycles early in the breeding season and before significant decline in day length (Lopez- 
Sebastian, 1985ab; Forcada et al., 1991). This suggest, that the breeding season of fall-born ewe lamb may be initiated by a short period of small decreases in day length, or that lambs may become refractory to inhibitory long day photoperiod like the adult ewe.

\section{Induction of fertile estrus during seasonal anestrus in fall born ewe lambs.}

In order for the age at first lambing in fall and spring lambing systems to be comparable, fall born ewe lambs must be bred during the period of seasonal anestrous. Treatment with long days (from 5 to 20 weeks) followed by a period of short days (20-32 weeks) with progestogen-eCG treatments commencing towards the end of the short day photoperiod induced fertile estrus in fall born lambs during seasonal anestrous (Ainsworth and Shrestha, 1987; Ainsworth et al., 1991). The percentage of ewe lambs lambing and the litter size to two service periods after synchronization treatments were $58 \%$ and 1.6 , respectively. Although photoperiod treatments induced puberty in $60 \%$ of ewe lambs prior to progestogen-eCG administration, the pubertal state did not affect fertility.

Burfening and Van Horn (1970) treated 11-12 month old ewe lambs with progestogen (6-chloro-6-dehydro-17 $\alpha$ acetoxyprogesterone; CAP) for 13 days with or without estradiol $(1 \mathrm{mg})$ prior to progestogen treatment and eCG (800 IU) 1-4 days following progesterone withdrawal. A total of $84 \%$ of ewe lambs treated with eCG displayed estrus and $67 \%$ conceived to the induced estrus. Injection with estradiol prior to progestogen treatment increased the percentage of ewe lambs in heat and conceiving by 30 and 15\%, respectively. Ewe lambs 
that were not treated with eCG did not display estrus. Robinson and Smith (1967) reported similar estrous responses for Dorset Horn maiden yearlings treated in late anestrous with progestogen-eCG. Although the response in yearlings not treated with eCG was better than that observed by Burfening and Van Horn (1970), both the estrous response (92 and 60\%) and the percentage of ewes lambing (58 and 20\%) were better in yearlings treated with eCG than those that were untreated. In contrast, Suffolk crossbred and Romney Marsh yearling ewe lambs treated during the early anestrous period with progesterone for 3 days with or without eCG ovulated but the estrus response was poor (8\%; Robinson, 1955). This was probably related to the inability of the short-term treatment with progesterone to adequately sensitize the brain to the ram and or eCG-induced increases in estradiol (Robinson, 1955; Gordon, 1958). Administration of estradiol $(25 \mu \mathrm{g})$ with or without eCG induced an estrous response in all yearling ewes although the occurrence of ovulation with the induced estrous was reduced.

The lack of response of ewe lambs and maiden yearlings (Robinson, 1955; Burfening and Van Horn, 1970) pre-treated with progestogens without gonadotropins may be due to the inability of rams to stimulate increases in $\mathrm{LH}$ secretion in these females. Spring born Suffolk cross ewe lambs did not show an increase in LH pulse frequency until September at a mean age and weight of 136 \pm 1.2 days and $32.7 \mathrm{~kg}$, respectively, and ram introduction did not induce ovulation until October (166 \pm 1.2 days and 35.6 kg; Al-Mauly et al., 1991). While this data set is suggestive of an increased response to ram introduction as the 
breeding season progresses, clear interpretation is difficult since age and time of year is confounded. Lopez-Sebastian et al. (1985b) examined the responsiveness of fall born ewe lambs to the ram effect in relation to the start of the breeding season. Rams were introduced to fall born ewe lambs born in late October-early November, ( $\geq 6$ months of age) at the end of May (5/26), and at the beginning (7/4) and end of July (7/26). Increases in the concentration of LH and an LH surge were only detected after rams were introduced in late July approximately 1 month prior to the period in which control lambs were observed to initiate puberty. The authors thus suggested that the ram effect only occurs as the ewe lambs approaches puberty. While this experiment does not eliminate the confounding of age and season, the ewe lambs at the beginning of the experiment (5/26) were older than the spring born ewe lambs of (Al-Mauly et al., 1991) or as old as those of (Dýrmundsson and Lees (1972) in which the ram effect was observed. The findings of this study may also explain why Robinson and Smith (1967) were able to induce fertile estrus in yearlings during late anestrous when they did not use eCG. Therefore the lower response to estrous induction procedures in ewe lambs and yearlings especially in the absence of gonadotropin treatment may be related to the failure of these females to respond to ram introduction with increases in LH pulse frequency, and LH surge and ovulation. 


\section{STATEMENT OF THE PROBLEM}

The survival and development of the sheep industry depends on the development of markets for the products, increases in the production efficiency and reduction in cost of production. The seasonal nature of reproduction of sheep under temperate conditions as characterized by periods of low estrous response and ovulation rates limits the development of the industry and the efficiency at which it operates. Although the gestation period of sheep is only 5 months the normal production cycle is annual but could be shortened if lambings occurs twice per year or even 3 times in two years. Additionally, production and marketing activities are concentrated to specific times of the year as reflected by the large non-random price and supply swings. The development of a market is no doubt dependent on products that are of a high quality and that could be supplied in adequate quantities consistently throughout the year. If the sheep industry is to achieve these objectives it would entail shifting the breeding season to periods associated with low reproductive activity, additionally the relative reproductive efficiency must not be unduly compromised by this shift.

Attempts to breed ewes out-of-season has relied on ram introduction only and or progestogen (MAP, FGA, Norgestomet) and the gonadotropin eCG. As pointed out in the literature review, the response to ram introduction is low and variable, further there is a positive correlation between the amount of progestogen used in synchronizing estrus and subsequent fertility. Synthetic progesterone analogues are advantageous, because they are more potent than 
the natural hormone and could be more readily incorporated in delivery systems because of the smaller quantities needed. Approval for use of these compounds in the sheep industry would be difficult due to the requirement for additional efficacy and safety data. The development of a new intravaginal insert made with polycapralactone (PCL) that incorporates twice the amount of progesterone as previous devices may be as effective as those devices using synthetic analogues and may increase the percentage of ewes breeding out-of-season to ram introduction alone. Follicle stimulating hormone, a gonadotropin, is currently approved for use in super-ovulation of cattle. While approaches for superovulation in cattle and sheep have been determined, treatment regimens that would increase the ovulation rate of sheep by only 1 or 2 ovulations during seasonal anestrous has not been demonstrated. The objectives of the first experiment were to determine whether these new PCL inserts would induce fertile estrus, if the duration of progestogen treatment modified the response and if $\mathrm{FSH}$ applied one day before insert removal would increase prolificacy in anestrous ewes.

Because the delivery of progesterone by the PCL insert was not better than previous devices (CIDRs) and because delivery and uptake of progesterone declines overtime the second experiment was designed to determine if a 5-d treatment with a CIDR-G device would induce fertile estrus and whether FSH before insert removal would increase ovulation rate and prolificacy in anestrous ewes. 
Puberty in fall-born lambs is not observed before 10-12 months of age and at the beginning of the next breeding season. This is $3-5$ months later than their spring born flock mates. This delay represents a potential decrease in production efficiency in fall lambing systems as more time and expenses are invested before the first lamb crop is marketed and through a decline in the lifetime productivity of the ewe. Attempts to breed ewe lambs and maiden yearlings during seasonal anestrous especially in the absence of gonadotropin treatments have not been as successful as in mature ewes. The third experiment was aimed at determining if ram introduction would induce an LH surge and ovulation in fall born ewe lambs and if estrogen would improve the estrous response in progesterone pre-treated fall born ewe lambs. 
EFFECTIVENESS OF INTRAVAGINAL PROGESTERONE INSERTS AND FSH FOR INDUCING SYNCHRONIZED ESTRUS AND INCREASING LAMBING

RATE IN ANESTROUS EWES 


\section{INTRODUCTION}

Progesterone was first used to synchronize estrus five decades ago (Dutt and Casida, 1948; O'Mary et al., 1950), and fertile estrus was induced in anestrous ewes by progesterone and gonadotropin (Dutt, 1953) shortly thereafter. Despite advances, an effective method to enhance the response of anestrous ewes to the introduction of rams (Underwood, 1944) is not available to shepherds in the United States

Fertility at estrus induced in anestrous ewes by progestogens with gonadotropin (Dutt, 1953; Hogue et al., 1962; Robinson and Smith, 1967), or

progestogens alone (e.g., Wheaton et al., 1990; Safranski et al., 1992), was lower than in cycling ewes (Crosby et al., 1991). Increased fertility with higher concentrations of progestogen (Robinson et al., 1968) probably resulted from more appropriate: follicular development (Johnson et al., 1996), synchrony of estrus and the LH surge (Lewis et al., 1974; Van Cleeff et al., 1998), and sperm transport (Quinlivan and Robinson, 1967; Hawk and Conley, 1971).

Ovulation rate is low during anestrus (Mallampati et al., 1971; Hulet et al., 1974; Hall et al., 1986). Prolificacy was increased by eCG (Hackett 1982; Ainsworth and Shrestha, 1985; Hamra et al., 1989) or by FSH (Ahmad et al., 1996) at progestogen withdrawal in anestrous ewes.

Controlled internal drug-releasing devices (CIDR; Welch et al., 1984) have been used in anestrous ewes (e.g., Hamra et al., 1989). Delivery of progesterone from CIDRs declines over time. However, treatment for only $5 \mathrm{~d}$ in 
anestrous cows (Smith et al., 1983) and $6 \mathrm{~d}$ in anestrous ewes (RodriguezIglesias, 1996) has been effective.

A polycapralactone CIDR device contains more progesterone (0.82 g; PCL insert) than the original CIDR ( $<0.4 \mathrm{~g}$ progesterone in silicone elastomer). The primary objectives were to determine whether PCL inserts would induce fertile estrus and whether $\mathrm{FSH}$, in combination with the inserts, would increase prolificacy in anestrous ewes introduced to rams. Effects of progesterone for 5 vs $12 \mathrm{~d}$ in FSH-treated ewes changes in follicular growth and ovulatory follicles also were examined.

\section{MATERIALS AND METHODS}

\section{General}

The study was conducted from May to July, 1998 on six farms in West Virginia, one university farm in Hardy county and five private farms in Hardy, Lewis, Pendleton and Preston Counties. A total of 382 non-lactating ewes of mixed breeding were available for the study. Ewes varied in relative proportions of black-faced (mainly Suffolk) and white-faced (mainly Dorset) breeding, and on two farms, some ewes were 50 to $100 \%$ North Country Cheviot. Ewes were managed on native grass and white clover pastures, but brought into barns or holding lots to initiate treatment and during the synchronized estrus. In general, animals were managed in a manner typical of eastern commercial farm flocks. Ewes $(n=84)$ with serum concentrations of progesterone $>0.6 \mathrm{ng} / \mathrm{mL}$ in either of two samples collected $3 \mathrm{~d}$ apart were not considered anestrous and were not 
assigned to the study. Three ewes were not used due to poor body condition or health.

The remaining 295 ewes were assigned to randomized treatments within face color (white, black, or mottled) in each flock, to one of four treatment groups. Ewes served as controls (ram introduction only; $C, n=73$ ), or were assigned to one of three progesterone-treated groups. Ewes in the first treatment group received the $P C L$ insert for $12 d(P 12, n=73)$. To determine whether $F S H$ given $24 \mathrm{~h}$ before insert removal would increase ovulation rate or prolificacy, another group received the PCL insert for $12 \mathrm{~d}$ and a single injection of FSH (Folltropin, $55 \mathrm{mg} \mathrm{NIH-FSH-P1}$ dissolved in saline/propylene glycol 1:4, vol:vol; $2 \mathrm{~mL}$ was injected i.m.; Lopez-Sebastian et al., 1993) $24 \mathrm{~h}$ before insert removal (P12F, n = 71). To test whether a short-term treatment was as effective as a 12-d treatment, a fourth group of ewes received the PCL insert for $5 \mathrm{~d}$ plus FSH $24 \mathrm{~h}$ before insert removal (P5F, $n=77$ ). Raddled, intact rams that had passed a breeding soundness examination, were introduced to all ewes at insert removal. Ewes on each farm were run together initially with all rams, at a ewe:ram ratio not exceeding 15:1; on one farm, one ram larger than the others was isolated with 15 ewes.

Ewes were observed for raddle marks (estrus) every $12 \mathrm{~h}$ from $24 \mathrm{~h}$ after ram introduction and insert removal (d 0) until d 5. As ewes were marked or observed being mated, they were separated from unmated ewes into another lot; rams were then rotated among lots, so that the ewe:ram ratio was maintained at less than 15:1 throughout the synchronized breeding period (d 5). After each 
observation for estrus, briskets of rams were repainted to ensure that mounted ewes were clearly detectable. After synchronized breeding, ewe:ram ratio was increased to no more than $25: 1$, and rams remained with ewes for 26 to $30 \mathrm{~d}$, to allow a second service period.

All ewes marked by rams during d 1 through 5 were examined for pregnancy on d 26 to 30 using transrectal ultrasonography (Schrick and Inskeep, 1993). Ovaries of all pregnant ewes were scanned and numbers of corpora lutea (CL) were recorded. At pregnancy diagnosis, all rams were removed. All ewes that were not diagnosed pregnant on $d 26$ to 30 were reexamined 20 to $25 \mathrm{~d}$ later (d 46 to 51 after insert removal) to detect pregnancies from matings subsequent to $\mathrm{d} 5$ (second service period).

Lambing dates and numbers of lambs born were recorded. Two ewes in the control group $(\mathrm{C})$, and one each in groups P12F and P5F died before the lambing period. Pregnancy retention was determined by expressing ewes lambing as a percentage of ewes diagnosed pregnant and alive at lambing time.

To evaluate release of progesterone from the PCL insert, blood samples $(5 \mathrm{ml})$ from a subset of five ewes per group in each replicate were collected by jugular venipuncture at 2-d intervals from $d-12$ through $d 0$. Samples were stored in glass tubes at $4^{\circ} \mathrm{C}$ and allowed to clot. Serum samples were collected within $12 \mathrm{~h}$ and frozen $\left(-20^{\circ} \mathrm{C}\right)$ until assayed for progesterone as described by Sheffel et al. (1982). The limit of detection was $0.1 \mathrm{ng} / \mathrm{ml}$, and the intra and interassay coefficients of variation were 7.1 and $18 \%$, respectively. 
Follicular growth and ovulation in the same subset of ewes were monitored during the periestrous period using transrectal ultrasonography (Schrick et al., 1993). Ewes were examined on d 0, and at 36, 48, 72, and $96 \mathrm{~h}$ after insert removal. On d 0 , all follicles greater than $3 \mathrm{~mm}$ in diameter were recorded and the subsequent growth and atresia or disappearance of these follicles were monitored. The largest, second largest, and third largest follicles on both ovaries on $\mathrm{d} 0$ were referred to as the $\mathrm{F} 1, \mathrm{~F} 2$, and $\mathrm{F} 3$ follicles, respectively. Follicles of the same size were assigned randomly to the higher or lower rank. Follicles $\geq 4 \mathrm{~mm}$ were judged to have ovulated if they were not present on the ovary at the subsequent examination (Schrick et al., 1993). Growth rate of an ovulatory follicle was determined retrospectively as the daily change in diameter from $\mathrm{d} 0$ or the time at which the ovulatory follicle was first recorded, to the time when the follicle was last seen.

\section{Statistics}

Analysis of variance was conducted using the GLM procedures of SAS (SAS Inst. Inc., Cary, NC), using farms as blocks to evaluate the fixed effects of treatments. Orthogonal contrasts tested were control vs treated with progesterone, $\mathrm{FSH}$ vs no $\mathrm{FSH}$, and 12 vs $5 \mathrm{~d}$ of progesterone with $\mathrm{FSH}$. Response variables included proportion of ewes exhibiting estrus, conception and pregnancy rates at diagnosis, proportion of ewes lambing to the first and second service periods, interval from ram introduction to lambing, lambing rate for all ewes treated, prolificacy for ewes lambing, and pregnancy retention. For 
prolificacy, additional comparisons were made between the first service period for FSH-treated ewes and the second service period for control ewes and all ewes. Conception and pregnancy rates to the first service period were defined as ewes pregnant as a percentage of ewes exhibiting estrus on $\mathrm{d} 0$ through 5 and ewes pregnant as a percentage of all ewes treated, respectively. The effects of interval from insert removal to estrus ( $\leq 24,25$ to 36,37 to $48, \geq 49 \mathrm{~h})$ and interactions of that interval with treatment contrasts on conception rate also were assessed in the progesterone-treated ewes. Effect of treatment on concentrations of progesterone was examined by analysis of variance for a splitplot with treatment as the main plot and time as the sub-plot (Gill and Hafs, 1971).

\section{RESULTS AND DISCUSSION}

\section{Progesterone profiles}

Highest concentrations of progesterone were observed on $d-10$ (1.2 $\mathrm{ng} / \mathrm{mL}), \mathrm{d}-8(1.4 \mathrm{ng} / \mathrm{mL})$ and $\mathrm{d}-4(1.1 \mathrm{ng} / \mathrm{mL})$ for P12, P12F, and P5F ewes, respectively, (Figure 1). Concentrations of progesterone at insert removal were highest in ewes treated for $5 \mathrm{~d}(\mathrm{P}<0.05 ; 0.1 \pm 0.1,0.4 \pm 0.1,0.5 \pm 0.1$, and $0.9 \pm$ $0.2 \mathrm{ng} / \mathrm{mL}$ for ewes in $\mathrm{C}, \mathrm{P} 12, \mathrm{P} 12 \mathrm{~F}$, and P5F groups, respectively. Greater peak values of 2.8 to $3.4 \mathrm{ng} / \mathrm{mL}$ have been reported 3 to $4 \mathrm{~d}$ after treatment of ovariectomized ewes with CIDRs containing $550 \mathrm{mg}$ progesterone (Ainsworth and Downey, 1986; Carlson et al.,1989; Wheaton et al.,1993), or with 470 and $620 \mathrm{mg}$ progesterone (Hamra et al., 1986) impregnated in a silicone elastomer. 
Concentrations of progesterone in serum throughout the treatment period averaged $0.2 \pm 0.1,0.8 \pm 0.1,0.7 \pm 0.1$, and $0.9 \pm 0.2 \mathrm{ng} / \mathrm{mL}$ for $\mathrm{C}, \mathrm{P} 12, \mathrm{P} 12 \mathrm{~F}$, and P5F, respectively, and did not differ among locations. Concentrations of serum progesterone at insert removal were similar to the $0.4 \mathrm{ng} / \mathrm{mL}$ on $\mathrm{d} 11$ of treatment reported by Barnes (1987), but lower than the $1.7 \mathrm{ng} / \mathrm{mL}$ in ewes treated with CIDRs for $14 \mathrm{~d}$ (Ainsworth and Downey, 1986). The PCL insert used in this study did not release sufficient progesterone to elevate serum concentrations to within the range observed during the luteal phase of the estrous cycle (Hauger et al., 1977; Van Cleeff et al., 1998).

\section{Estrous response}

Treatment with progesterone increased $(P<0.01)$ the percentage of ewes marked by rams during the first $5 \mathrm{~d}$ after ram introduction (Table 1). In FSHtreated ewes, more ewes $(P<0.05)$ were marked after 5 than after $12 \mathrm{~d}$ of progesterone treatment. This result is consistent with the elevated concentrations of progesterone at insert removal (Figure 1) in ewes treated for 5 $d$ and the results of Shelton et al. (1967). Treatments for $6 \mathrm{~d}$ with $6 \alpha$-methyl$17 \alpha$-acetoxy-progesterone (MAP; Rodriguez Iglesias et al., 1996) or for $8 d$ with melengesterol acetate (MGA; Powell et al., 1996) have induced fertile estrus in anestrous ewes. The number of ewes showing estrus (marked by raddled rams) in this study was similar to the number observed by Carpenter and Spitzer (1981) and slightly lower than the number reported in other studies using CIDRs (Maxwell and Barnes, 1986; Hamra et al., 1989), MGA (Safranski et al., 1992; 
Figure 1. Mean concentrations of progesterone prior to ram introduction for control ewes (C, 2 ), ewes pre-treated with PCL inserts for $12 \mathrm{~d}$ without $(\mathrm{P} 12, \square)$ ) or with FSH $24 \mathrm{~h}$ before insert removal $(\mathrm{P} 12 \mathrm{~F},-\backsim)$ ) and ewes treated with PCL inserts for $5 \mathrm{~d}$ with $\mathrm{FSH} 24 \mathrm{~h}$ before insert removal (P5F,-- -). Treatment $X$ Time $(P<0.05)$ 


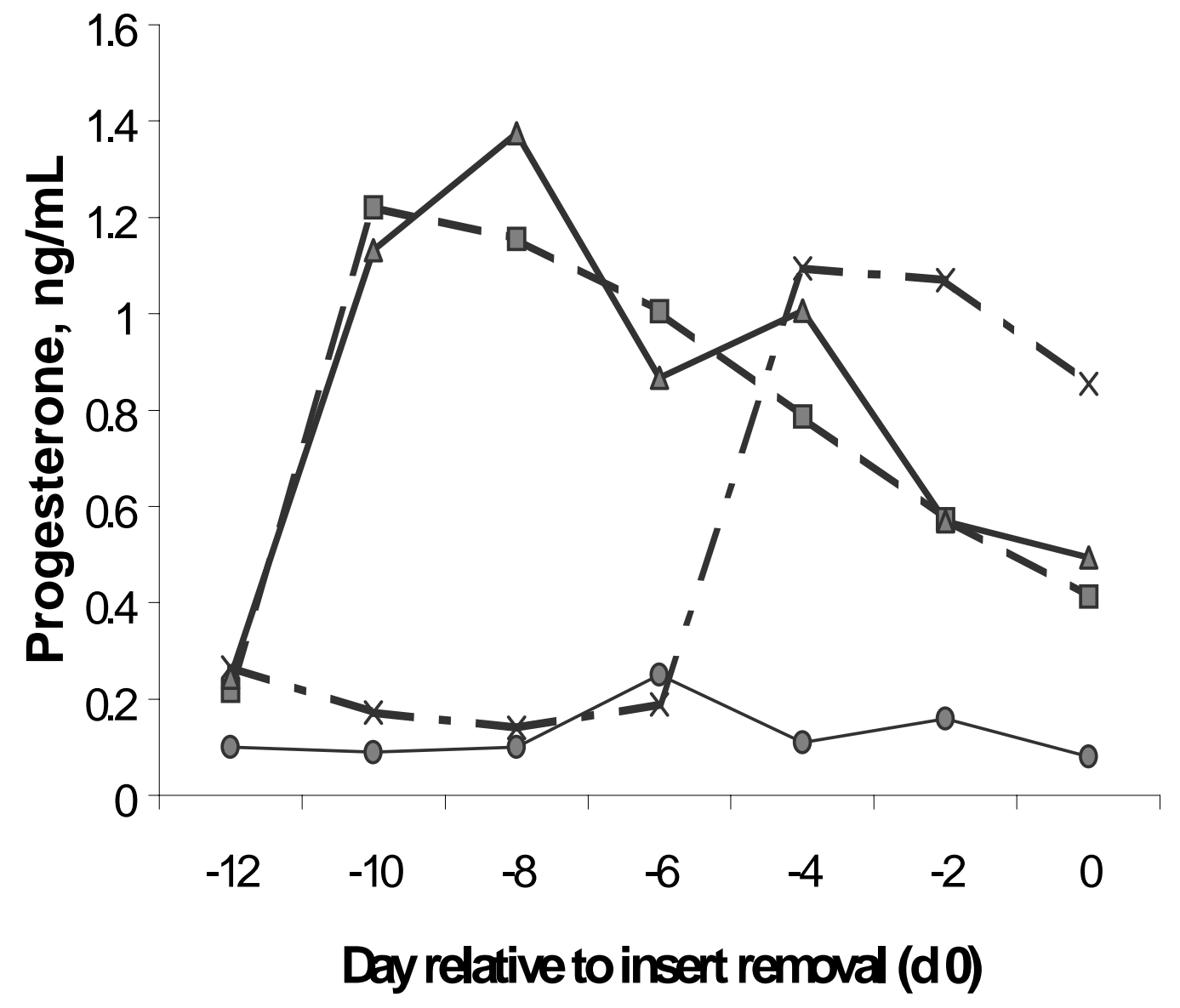


Figure 2. Distribution of estrus over the first $2.5 \mathrm{~d}$ after insert removal for control ewes (C, $\square$ ), ewes pre-treated with PCL inserts for $12 \mathrm{~d}$ without (P12, $\square$ ), or with FSH $24 \mathrm{~h}$ before insert removal (P12F, $\square$ ), and ewes treated with PCL inserts for $5 \mathrm{~d}$ with $\mathrm{FSH} 24 \mathrm{~h}$ before insert removal (P5F, $\square$ ). 


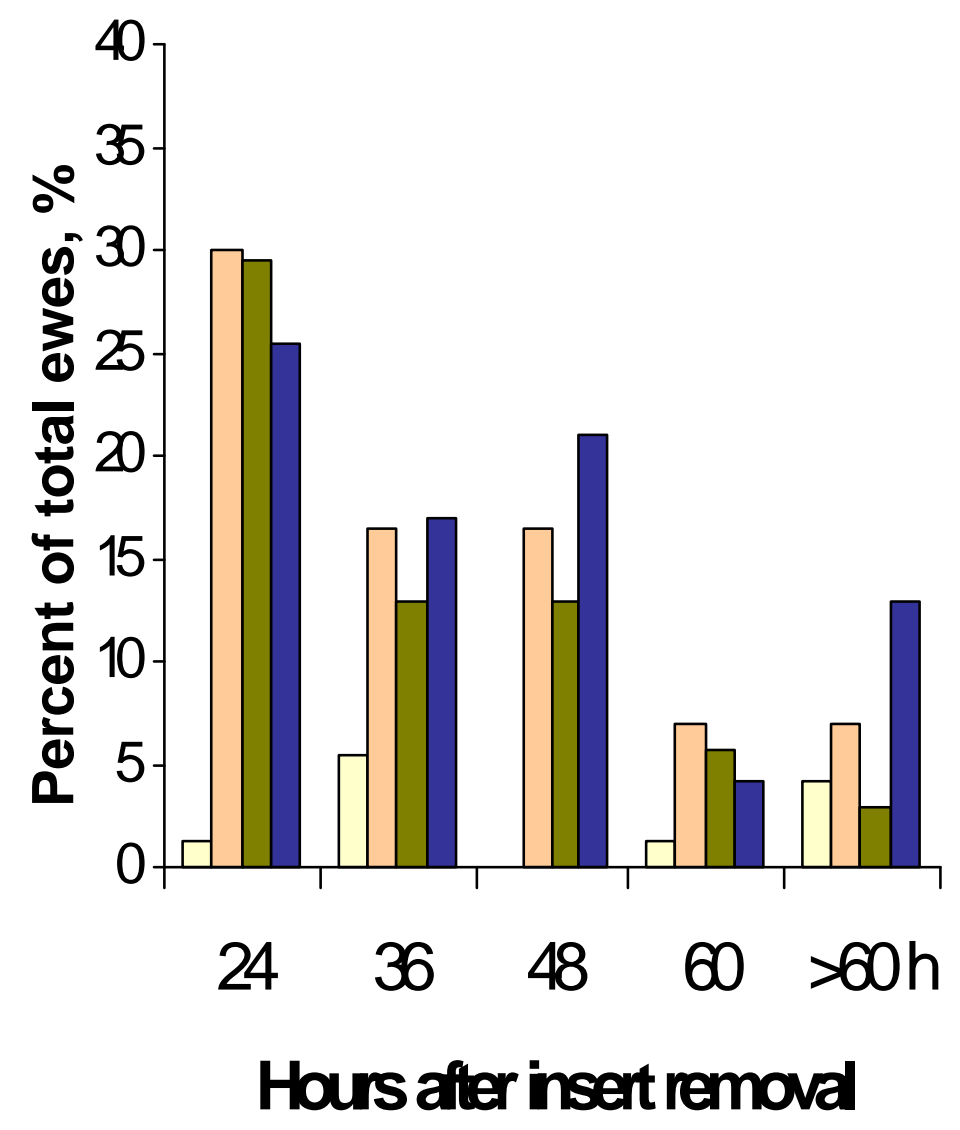


Jabbar et al., 1994), flurogestone acetate (Gordon, 1971; Hamra et al., 1989; Wheaton et al., 1993), or norgestomet (Carpenter and Spitzer, 1981; Alifakiotis et al., 1982) for 12 to $14 \mathrm{~d}$ with eCG.

The time from ram introduction and insert removal to estrus averaged $42 \pm$ $5 \mathrm{~h}$ and did not differ among groups of progesterone-treated ewes (Figure 2). Maxwell and Barnes (1986) observed a similar pattern; 50\% of CIDR-treated ewes that exhibited estrus did so by $36 \mathrm{~h}$, and the remainder exhibited estrus by $48 \mathrm{~h}$ after insert removal. In the present study, in which all ewes were joined with rams abruptly at insert removal, no differences were observed in occurrence of estrus between ewes treated with inserts only or inserts and FSH. Foote (1968) reported that frequencies of estrus, ovulation, and pregnancy were greater in anestrous ewes treated with progestogen and eCG than in ewes treated with only progestogen. Ram introduction alone at progestogen withdrawal was as effective as gonadotropins in stimulating estrus (Boland et al., 1981; Welch et al., 1984; Wheaton et al., 1992). Gonadotropins may be required when rams are joined before (Cunningham et al., 1980) or after (Boland et al., 1981; Hamra et al., 1989) progestogen withdrawal, or in artificial insemination protocols if rams are not joined with ewes (Langford et al., 1983; Husein et al., 1998). 
Table 1. Reproductive performance of anestrous ewes in response to ram introduction (C), or ram introduction + 12-d progesterone pre-treatment (P12), 12-d progesterone pre-treatment + FSH (P12F) or 5-d progesterone pre-treatment +FSH (P5F).

\begin{tabular}{|c|c|c|c|c|}
\hline \multirow[t]{2}{*}{ Variable } & \multicolumn{4}{|c|}{ Treatment } \\
\hline & C & P12 & $\mathrm{P} 12 \mathrm{~F}$ & P5F \\
\hline Number of ewes & 73 & 73 & 71 & 77 \\
\hline Number of ewes marked by rams $(\%)^{c}$ & $9(12)^{a}$ & $56(77)$ & $47(66)^{b}$ & $61(79)$ \\
\hline Ram introduction to raddle marks, $\mathrm{h}$ & $56 \pm 0.6^{a}$ & $42 \pm 0.2$ & $40 \pm 0.2$ & $43 \pm 0.2$ \\
\hline Ewes pregnant to first service $(\%)^{c, d}$ & $1(1)^{a}$ & $35(48)$ & $30(42)$ & $36(47)$ \\
\hline Ewes conceived to first service $(\%)^{\mathrm{c}, \mathrm{e}}$ & $1 / 10(10)^{a}$ & $35 / 56(63)$ & $30 / 47(64)$ & $36 / 64(56)$ \\
\hline Pregnancy rate $2^{\text {nd }}$ service period $(\%)^{\dagger}$ & $36 / 72(50)$ & $24 / 38(63)$ & $23 / 41(56)$ & $25 / 41(61)$ \\
\hline Ovulation rate ${ }^{g}$ & - & $1.9 \pm 0.1$ & $2.2 \pm 0.2$ & $2.2 \pm 0.2$ \\
\hline \multicolumn{5}{|l|}{ Number of ewes lambing ${ }^{c}$ : } \\
\hline (a) From $1^{\text {st }}$ service period (\%) & $0 / 71(0)^{a}$ & $33 / 73(45)$ & $27 / 70$ (39) & $32 / 76(42)$ \\
\hline (b) Both service periods, \% & $29 / 71(41)^{\mathrm{a}}$ & $48 / 73(66)$ & $45 / 70(64)$ & $48 / 76(63)$ \\
\hline \multicolumn{5}{|l|}{ Lambing rate ${ }^{\mathrm{h}}$, mean $\pm \mathrm{SE}$ : } \\
\hline (a) Lambing to $1^{\text {st }}$ service period & - & $0.74 \pm 0.9$ & $0.72 \pm 1.0$ & $0.75 \pm 1.1$ \\
\hline (b) Both service periods & $0.6 \pm 0.1^{a}$ & $1.0 \pm 0.1$ & $1.1 \pm 0.1$ & $1.1 \pm 0.1$ \\
\hline \multicolumn{5}{|l|}{ Prolificacy', mean \pm SE: } \\
\hline (a) Lambing to $1^{\text {st }}$ service period & - & $1.6 \pm 0.1$ & $1.9 \pm 0.1$ & $1.8 \pm 0.1$ \\
\hline (b) Lambing to both service periods & $1.5 \pm 0.1$ & $1.5 \pm 0.1$ & $1.6 \pm 0.1$ & $1.8 \pm 0.1$ \\
\hline Ram Introduction to lambing, $d$ & $165 \pm 2^{\mathrm{a}}$ & $152 \pm 1$ & $153 \pm 1$ & $153 \pm 1$ \\
\hline
\end{tabular}

a Progesterone vs control, $\mathrm{P}<0.01,{ }^{\mathrm{b}} \mathrm{P} 12 \mathrm{~F}$ vs $\mathrm{P} 5 \mathrm{~F}, \mathrm{P}<0.05$.

${ }^{c}$ Three ewes in $\mathrm{P} 5 \mathrm{~F}$ and one in the $\mathrm{C}$ treatment groups that were detected pregnant at the first PD were not detected in heat. Two ewes in C and one each in P12F and P5F were removed because of death or lost ear tags before lambing.

${ }^{\mathrm{d}}$ Number of ewes diagnosed pregnant on $\mathrm{d} 26$ to 31 as a percentage of all ewes in a treatment group.

${ }^{e}$ Number of ewes diagnosed pregnant on $\mathrm{d} 26$ to 31 as a percentage of ewes marked by rams.

${ }^{f}$ Number of ewes pregnant on d 46 to 51 expressed as a percentage of ewes not pregnant on d 26 to 31 .

${ }^{g}$ Number of CL observed in ewes diagnosed pregnant on d 26 to 31 .

${ }^{\mathrm{h}}$ Lambs born per ewe exposed.

' Lambs born per ewe lambing. 
Progesterone priming is necessary for expression of estrus, due to increased sensitivity to estrogen (Robinson, 1954; Fabre-Nys and Martin, 1991), and to maximize the ability of estrogen to trigger the preovulatory surge of $\mathrm{GnRH}$ (Caraty and Skinner, 1999). Introduction of rams to anestrous ewes increases the frequency of pulses of LH (Oldham et al., 1978/1979; Martin et al., 1980, Signoret, 1990), which in turn drives increases in estradiol-17ß (Signoret, 1990). Separation of progestogen withdrawal and introduction of rams may preclude maximal secretion of $\mathrm{LH}$, reducing the occurrence of estrus and ovulation. The present results support those of Welch et al. (1984) that abrupt ram introduction at insert removal stimulated fertile estrus in progesterone-treated, anestrous ewes.

\section{Follicular Dynamics and Ovulation}

Diameters of the largest follicles (F1, F2 and F3) at d 0 were greater in progesterone-treated ewes than in controls $(P<0.05$; Table 2$)$, however, no differences in follicular diameter were detected among groups treated with progesterone. The proportion of $\mathrm{F} 1$ follicles that ovulated did not differ in control and progesterone-treated ewes, or due to $\mathrm{FSH}$. However, within $\mathrm{FSH}$-treated ewes, those receiving progesterone for $5 \mathrm{~d}$ ovulated more $\mathrm{F} 1$ follicles $(100 \%)$ than those receiving progesterone for $12 \mathrm{~d}(63 \% ; \mathrm{P}<0.05)$. Progesterone treatment increased the proportion of $\mathrm{F} 2$ follicles ovulated (69\%) compared with control ewes $(17 \% ; \mathrm{P}<0.01)$. 
Diameters of the ovulatory follicles at $d 0$ and when last observed were 4.6 and $5.6 \mathrm{~mm}$, respectively (Table 2), and did not differ among treatments. The ovulatory follicles tended to grow more slowly in progesterone-treated $(0.5 \pm 0.1$ $\mathrm{mm} / \mathrm{d})$ than in control ewes $(0.8 \pm 0.2 \mathrm{~mm} / \mathrm{d} ; \mathrm{P}=0.09)$ and in $\mathrm{FSH}$-treated ewes receiving progesterone for $5 \mathrm{~d}(0.3 \pm 0.1 \mathrm{~mm} / \mathrm{d})$ than for $12 \mathrm{~d}(0.5 \pm 0.1 \mathrm{~mm} / \mathrm{d} ; \mathrm{P}$ $=0.07)$. Ovulatory follicles observed in the present study were similar in diameter to those observed in anestrous ewes by Leyva et al. (1998). However, ovulatory follicles were smaller than in cyclic ewes with normal $(6.9 \pm 0.2 \mathrm{~mm})$ or low $(7.8 \pm$ $0.3 \mathrm{~mm}$ ) luteal phase concentrations of progesterone (Johnson et al., 1996). Concentrations of progesterone achieved using the PCL inserts over 12 or $5 \mathrm{~d}$, although insufficient to mimic the luteal phase during the breeding season (Van Cleeff et al.,1998), prevented development of persistent follicles in anestrous ewes.

Ovulation rate as determined by the number of $C L$ present in ewes diagnosed pregnant (Table 1), did not differ among treatment groups. However, in ewes that were subjected to frequent ultrasonography, number of follicles $>3$ $\mathrm{mm}$ (Figure 3 ) was increased $(\mathrm{P}<0.01)$ by pre-treatment with progesterone compared with introduction of rams only. The number of follicles $>3 \mathrm{~mm}$ also was greater in $\mathrm{FSH}$-treated ewes than in ewes receiving progesterone only, and greater in FSH-treated ewes receiving progesterone for 5 rather than for $12 \mathrm{~d}(\mathrm{P}$ $<0.05$; Figure 3). More follicles disappeared and apparently ovulated in progesterone-treated than in control ewes $(P<0.05$; Table 2$)$. Treatment with 
Table 2. Characteristics of the ovarian follicular population during the periestrous period in control ewes $(C)$, ewes pre-treated with progesterone inserts for $12 \mathrm{~d}$ without (P12), or with FSH 24 h before insert removal (P12F) and ewes treated with progesterone inserts for $5 \mathrm{~d}$ with $\mathrm{FSH} 24 \mathrm{~h}$ before insert removal (P5F).

\begin{tabular}{|c|c|c|c|c|c|}
\hline \multirow[t]{2}{*}{ Characteristic } & \multicolumn{5}{|c|}{ Treatment } \\
\hline & Control & $\mathrm{P} 12$ & $\mathrm{P} 12 \mathrm{~F}$ & P5F & SE \\
\hline $\mathrm{N}$ & 15 & 15 & 16 & 13 & \\
\hline Ewes observed to ovulate, \% & 33.3 & 73.3 & 68.8 & 46.2 & 10 \\
\hline \multicolumn{6}{|l|}{ Follicle population: } \\
\hline Diameter $\mathrm{F} 1$ at $\mathrm{d} 0$ & $4.8^{a}$ & 5.6 & 5.5 & 5.4 & 0.2 \\
\hline Diameter F2 at d 0 & $3.7^{\mathrm{a}}$ & 4.4 & 4.9 & 4.5 & 0.2 \\
\hline Diameter F3 at d 0 & $3.0^{\mathrm{a}}$ & 3.6 & 4.0 & 3.9 & 0.3 \\
\hline \multicolumn{6}{|l|}{ Ovulatory follicles: } \\
\hline Diameter at $\mathrm{d} 0, \mathrm{~mm}$ & 4.4 & 4.6 & 4.6 & 4.8 & 0.4 \\
\hline Diameter at ovulation ${ }^{\mathrm{b}}, \mathrm{mm}$ & 5.9 & 5.7 & 5.4 & 5.4 & 0.2 \\
\hline Growth rate, $\mathrm{mm} /$ day & 0.8 & 0.6 & 0.5 & 0.3 & 0.2 \\
\hline Time of disappearance $^{c}, \mathrm{~h}$ & 55.2 & 64.8 & 55.2 & 65 & 11 \\
\hline Number disappeared/ewe & $1.3^{\mathrm{a}}$ & 2.6 & 2.2 & 3.3 & 0.6 \\
\hline
\end{tabular}


Figure 3. Population of follicles $(>3 \mathrm{~mm}$ ) during the periestrous period for control ewes (C, ـ ـ ), ewes pre-treated with PCL inserts for $12 \mathrm{~d}$ without $(\mathrm{P} 12, \square)$ ) or with FSH $24 \mathrm{~h}$ before insert removal $(\mathrm{P} 12 \mathrm{~F}, \triangle$ ) ) and ewes treated with PCL inserts for $5 \mathrm{~d}$ with $\mathrm{FSH} 24 \mathrm{~h}$ before insert removal (P5F, - - .). Number of follicles $>3 \mathrm{~mm}$ was greater in progesterone-treated than in control ewes $(\mathrm{P}<0.01)$, in $\mathrm{FSH}$-treated ewes than in ewes receiving progesterone only and in FSH-treated ewes receiving progesterone for 5 than for $12 \mathrm{~d}(\mathrm{P}<0.05)$ 


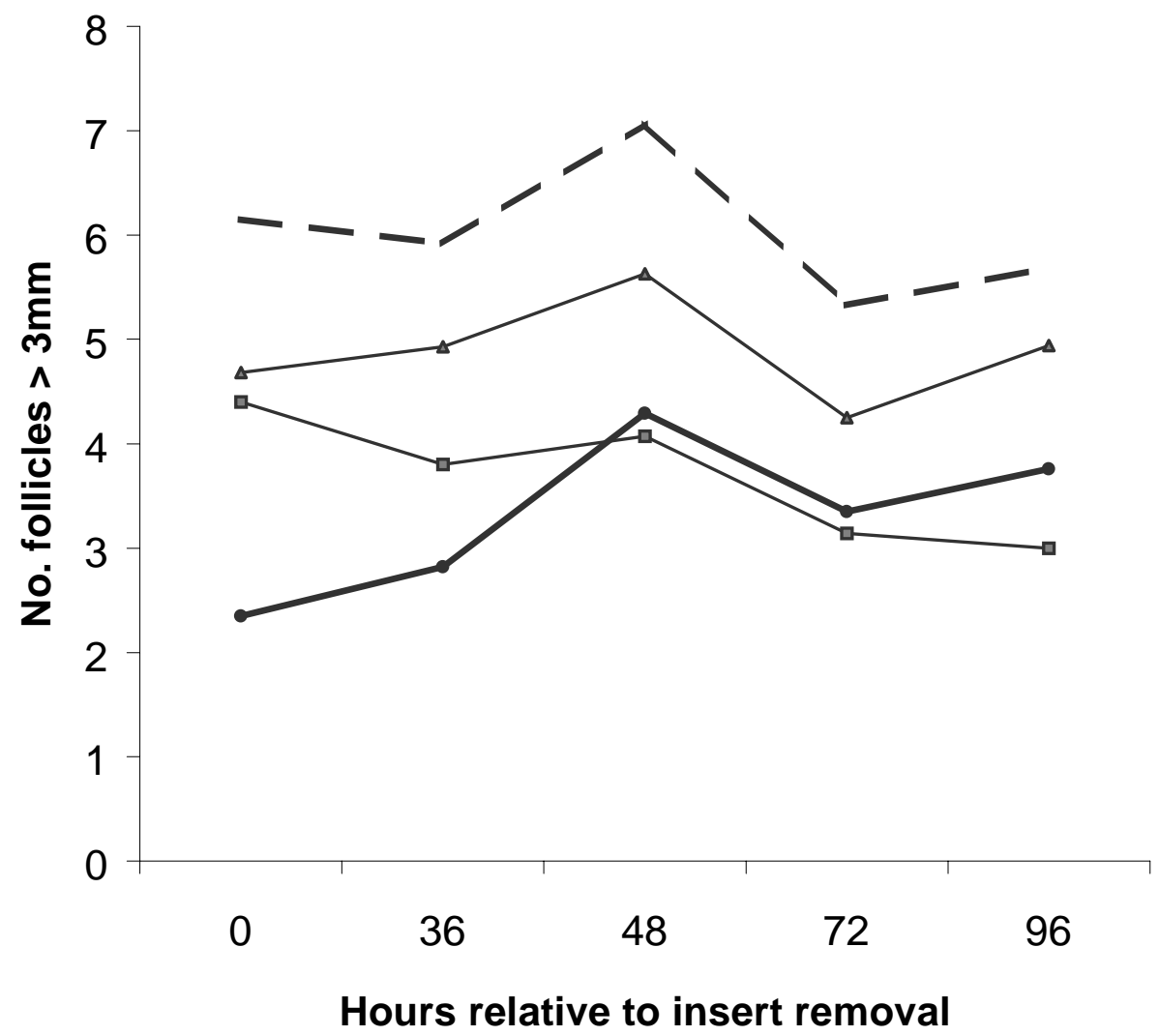


FSH did not increase ovulation rate, but ovulation rate tended to be greater $(\mathrm{P}=$ $0.09)$ in $\mathrm{FSH}$-treated ewes treated with progesterone for $5 \mathrm{~d}(3.3 \pm 0.6)$ as opposed to $12 \mathrm{~d}(2.2 \pm 0.4$; Table 2$)$. The numerically smaller proportion (46\%, Table 2) of P5F ewes that were observed to have ovulated from ultrasonographic scanning does not fit with the high proportion of ewes in estrus and pregnant in that group. The discrepancy may indicate that the scanned ewes were not a random sample or that the larger number of follicles $>3 \mathrm{~mm}$ in these ewes (Figure 3) reduced the accuracy of observation of disappearance of follicles.

Greater concentrations of progesterone in ewes treated for 5 rather than for $12 \mathrm{~d}$ before treatment with FSH may explain in part the trend for greater ovulation rate in ewes treated for $5 \mathrm{~d}$. This explanation is consistent with the observation of greater ovulation rates in response to eCG in ewes pre-treated with MAP (Leyva et al., 1998) and the increased binding of hCG to granulosal cells in progesterone pre-treated anestrous ewes (Hunter and Southee, 1987). Unilaterally ovulating ewes showed greater follicular development on the ovary that contained the CL (Dufour et al., 1972). Similarly, intraovarian progesterone increased ovulation rate in ewes treated with eCG (Rexroad and Casida, 1977). More small follicles grew beyond $3 \mathrm{~mm}$ after than before the first ovulation of the breeding season (Bartlewski et al., 1999b), and pre-treatment with progesterone increased secretion of testosterone, estradiol, and IGF-I from follicles collected from anestrous ewes in response to a GnRH challenge (Khalid et al., 1997). All of these observations support the conclusion that elevated concentrations of progesterone may enhance responsiveness of follicles to supplemental 
gonadotropins (Walton et al., 1977; Leyva et al., 1998; Bartlewski et al., 1999a,b).

\section{Conception and Pregnancy rates}

Conception and pregnancy rates (Table 1) were greater in progesteronetreated than in control ewes $(P<0.01)$ but did not differ among progesteronetreated ewes. Similar results have been obtained in anestrous ewes inseminated artificially at estrus following treatment with CIDR + eCG (Maxwell and Barnes, 1986) and in ewes treated with progestogens + eCG (Gordon, 1971; Carpenter and Spitzer, 1981; Tritschler et al., 1991). In the present study, pregnancy rates in progesterone-treated ewes were similar to those observed in cyclic ewes treated with MAP or CIDRs (Rhodes and Nathanielsz, 1988), but lower than those observed in control ewes during the natural breeding season (Inskeep et al., 1983; Carlson et al., 1989). Observed conception rates fit with the inability of new PCL inserts to deliver adequate progesterone to mimic a normal luteal phase. It has been shown that ewes receiving lower dosages of progestogen have higher concentrations of estrogen (Hunter and Southee, 1987; Johnson et al., 1996; Van Cleeff et al., 1998), come into estrus earlier (Lewis et al., 1974; Van Cleeff et al., 1998), have a shorter interval from progestogen withdrawal to LH peak (Lewis et al., 1974; McLeod et al., 1982; Van Cleeff et al., 1998), and ovulate older follicles and are less fertile than ewes on higher dosages of progestogen (Johnson et al., 1996). Elevated estrogen may indicate a failure to inhibit progression of follicular development (Van Cleeff et al., 1998), and may 
interfere with sperm transport (Quinlivan and Robinson, 1967) and fertilization (Allison and Robinson, 1970).

Percentages of ewes lambing from the first or to both service periods were greater $(P<0.01)$ in progesterone-treated than in control ewes but did not differ among progesterone-treated groups (Table 1). Overall, treatment with progesterone increased ewes lambing by $23 \%(P<0.01)$. In contrast, Jabbar et al. (1994) and Wheaton et al. (1992) found no difference in the percentage of ewes lambing between ewes pre-treated with progestogen and control ewes during the anestrous period. Wheaton et al. (1992) used lower ewe to ram ratios, and smaller group sizes, which resulted in greater contact among control ewes, rams, and treated ewes in estrus. These added stimuli might have enhanced reproductive activity in control ewes (Martin et al., 1986; Nugent and Notter, 1990). In contrast, Waller et al. (1988) observed a poorer response in a study with a ram:ewe ratio of 1:50 anestrous ewes. Breed differences and selection for or use of out-of-season breeding also may explain variation in observed responses.

In ewes treated with $\mathrm{FSH}$, no differences were observed due to treatment with progesterone for 5 or $12 \mathrm{~d}$ in the number of ewes lambing (Table 1). The effects of short intervals of progestogen treatment have been reported previously (Dutt, 1953; Christenson, 1976; Powell et al., 1996; Rodriguez-Iglesias, 1996). Dutt (1953) injected progesterone at 3-d intervals to anestrous ewes for periods of 3 to $15 \mathrm{~d}$ and found no difference in the percentage of ova fertilized at estrus after periods of 6 through $15 \mathrm{~d}$. A 2-d progesterone treatment (McLeod and 
Haresign, 1984) or a single injection of $20 \mathrm{mg}$ of progesterone at ram introduction (Cognie et al., 1982) were adequate to stimulate normal luteal function following ovulation in response to rams, but estrus did not occur in association with first ovulation. The percentages of anestrous ewes exhibiting estrus and lambing in response to treatment with MGA for 8,11 or $14 \mathrm{~d}$ were not different (Powell et al., 1996). Based on the present and previous studies, $5 \mathrm{~d}$ of elevated progesterone before ram introduction is adequate to prevent the occurrence of short-lived $\mathrm{CL}$ following ovulation, and to induce an immediate fertile estrus in anestrous ewes.

Conception rates for ewes detected in estrus at $24,36,48$, and after $48 \mathrm{~h}$ from insert removal were $58 \pm 8,70 \pm 9,62 \pm 9$, and $25 \pm 19 \%$, respectively, with a lower conception rate after $48 \mathrm{~h}(\mathrm{P}<0.05)$. The decline in conception rate at this time may be associated with increasing asynchrony between time of estrus and time of ovulation. Ewes bred on the second day after progestogen withdrawal had greater conception rates than ewes bred later in the service period (Gordon, 1975). Ovulation and conception rates declined as the interval from administration of eCG and progesterone withdrawal to estrus increased (Lunstra and Christenson, 1981a). A decrease in ram fertility may be a possible explanation. Fertility of rams is greater during fall than during spring (Fitzgerald and Stelfflug, 1991). The number of services per ram decreased during the first few days of intense breeding (Hulet et al., 1962; Bryant and Tomkins, 1975). In rams under conditions of continual mating, number of sperm per ejaculate (Jennings and McWeeney, 1976; Synnott et al., 1981) and number of ejaculates per $24 \mathrm{~h}$ (Synnott et al., 1981) decreased over time. Lower ram fertility in the 
ewes mated later in the service period could be exacerbated by the reduced sperm transport (Allison and Robinson, 1970; Hawk and Conley, 1971), and asynchrony of onset of estrus and release of LH (Lewis et al., 1974) in ewes treated with low dosages of progestogens.

\section{Pregnancy retention}

Only one ewe in the $\mathrm{C}$ group was diagnosed pregnant to the first service period. Therefore, comparisons of pregnancy retention for ewes conceiving to the first service period, were made only among progesterone-treated groups. Percentages of ewes diagnosed pregnant to the first service period that lambed were not different (Figure 4; $94 \pm 5,90.5 \pm 4$, and $89 \pm 5 \%$ for ewes in treatment groups $\mathrm{P} 12, \mathrm{P} 12 \mathrm{~F}$, and $\mathrm{P} 5 \mathrm{~F}$, respectively). Pregnancy retention rate for ewes conceiving at the second service period did not differ among treatment groups and these rates were $76.3 \pm 7$ and $70.4 \pm 4.3$ for ewes in $C$ and progesteronetreated groups, respectively (Figure 4). To compare pregnancy retention at first versus second service periods, data for all groups were pooled. Ewes conceiving to the first service period had a greater $(P<0.01)$ pregnancy retention rate $(90.9 \pm 3.7)$ than ewes conceiving at the second service period $(72.5 \pm 4.3)$. Embryonic mortality rate in sheep was suggested to be approximately $30 \%$ regardless of whether fertilization rate was considered (Bolet, 1986). However, Lunstra and Christenson (1981b) estimated that losses of fertilized ova to first and second service were 15 and $40 \%$, respectively, in ewes synchronized out-ofseason, and 35 and $38 \%$, respectively, in ewes synchronized in season, 
compared with $16 \%$ in non-synchronized ewes bred in season. In their study, fertilization rate was lower out-of-season. In sheep mated during the early breeding season, maximal loss of embryos immediately preceded d 18 of pregnancy (Hulet et al., 1956), accounting for almost $50 \%$ of total embryonic mortality (Quinlivan et al., 1966; Bolet, 1986). Embryonic losses were estimated to be $9.3 \%$ after $d 18$ (Hulet et al., 1956) and 1.3 and $5.3 \%$ after $d 30$ in parous and non-parous ewes, respectively (Quinlivan et al., 1966). Elevated temperatures affecting rams before mating (Mieusset et al., 1992) or ewes during pregnancy (Bell et al., 1987;1989; Vatnick et al., 1991) may be responsible for high embryonic mortality.

\section{Lambing rate and prolificacy}

Overall lambing rate per ewe treated was greater in progesterone-treated than in control ewes $(P<0.01)$, primarily due to the failure of control ewes to lamb from the first service period (Table 1). Prolificacy to the first $(1.6,1.9$, and $1.8 \pm 0.1$ for P12, P12F and P5F, respectively) or to both service periods (1.5, 1.5, 1.6, and $1.8 \pm 0.1$ for $\mathrm{C}, \mathrm{P} 12, \mathrm{P} 12 \mathrm{~F}$, and P5F, respectively) did not differ among individual treatment groups (Table 1). Ovulation and lambing rates during the anestrus period have been improved by stimulation with eCG (Robinson and Smith, 1967; Gordon, 1971) or FSH (Ahmad et al., 1996). Ahmad et al. (1996) reported that a single injection of $8 \mathrm{mg}$ of $\mathrm{FSH}-\mathrm{P}$ in propylene glycol $12 \mathrm{~h}$ before injection of $20 \mathrm{mg}$ of prostaglandin $F_{2 \alpha}$ i.m.,on d 14 after ram introduction 
increased ovulation rates in anestrous ewes treated with $25 \mathrm{mg}$ of progesterone and joined with rams. 
Figure 4. Pregnancy retention rate: Percentages of ewes lambing as a percentage of ewes diagnosed pregnant as a result of matings at the first ( $\square$ ), second ( $\square$ ), or both ( $\square$ ) service periods after ram introduction, for control ewes (C), ewes pre-treated with PCL inserts for $12 \mathrm{~d}$ without (P12), or with $\mathrm{FSH} 24 \mathrm{~h}$ before insert removal (P12F), and ewes treated with PCL inserts for $5 \mathrm{~d}$ with FSH $24 \mathrm{~h}$ before insert removal (P5F). 


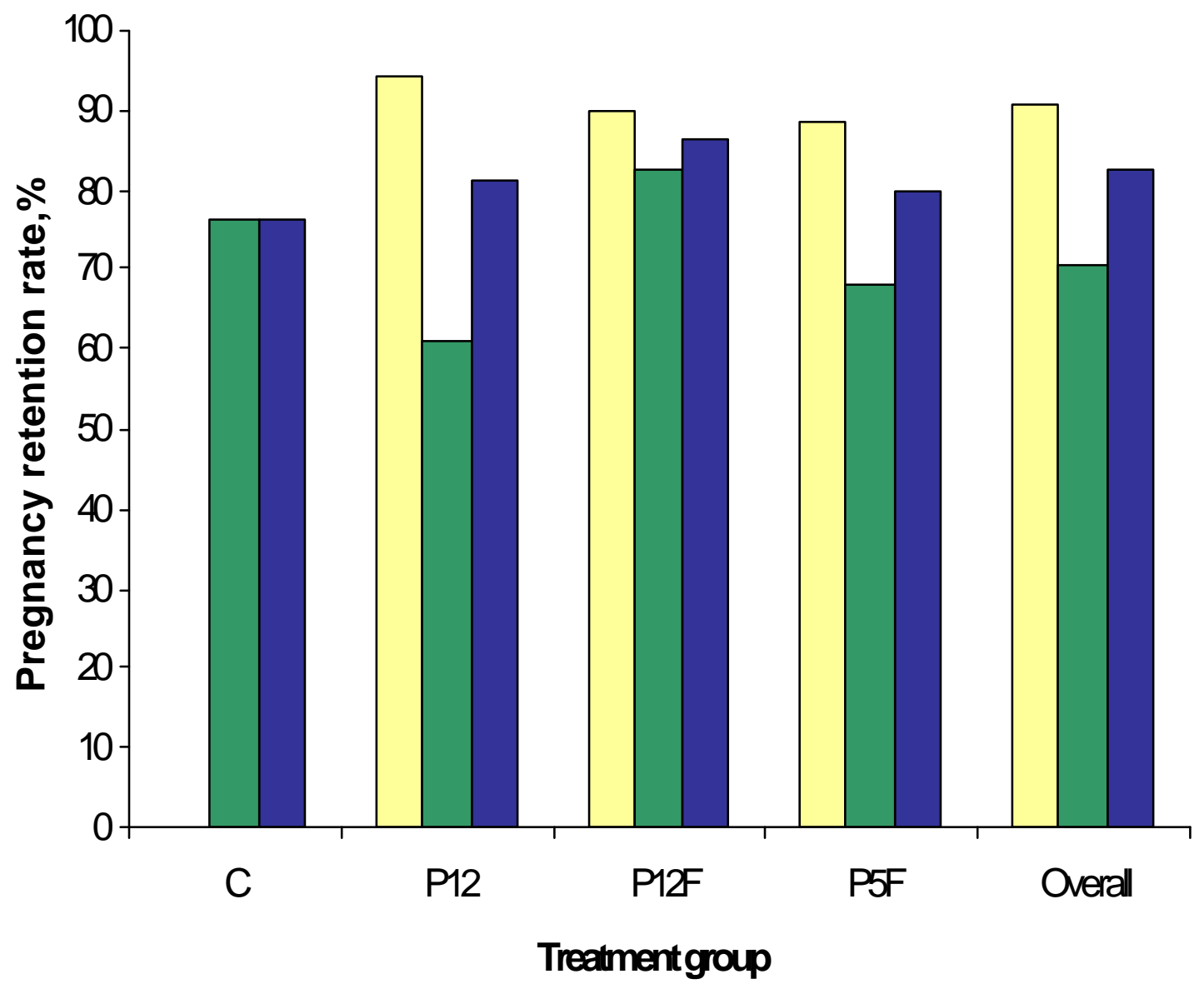


In the present study, we anticipated a more rapid decline in peripheral progesterone after insert removal and used a similar dosage of FSH $24 \mathrm{~h}$ before removal of PCL inserts. The effect of FSH on prolificacy was assessed in three ways. First, groups P12F and P5F were compared with group P12 at the first service period, a completely contemporary comparison. Second, groups P12F and P5F at the first service period were compared with control ewes at the second service period (which was actually the first estrus for most control ewes), a chronologically contemporary comparison. Finally, groups P12F and P5F at the first service period were compared with all ewes at the second service period, during which no FSH were given in any group. The means for prolificacy of ewes lambing to the first service period, that were treated with (P12 F and P5F) or without FSH (P12) were 1.85 and $1.64 \pm 0.1$, respectively, and for control ewes and all ewes lambing to the second service period were 1.5 and $1.4 \pm 0.1$, respectively. Ewes treated with $\mathrm{FSH}$ did not have a higher prolificacy or overall lambing rate to the first service than ewes treated with progesterone only. However, prolificacy of ewes conceiving to the first service was greater in $\mathrm{FSH}$ treated ewes than in control ewes $(P<0.05)$ or in all ewes lambing to the second service period $(P<0.01)$.

In other studies, approaches to increasing prolificacy in anestrous ewes have been effective only when control values were less than the genetic potential for the breed. Lopez-Sebastian and Inskeep (1991) observed breed differences in response to melatonin; maximal responses occurred in a breed with an ovulation rate of 1.2 in control ewes. Treatment of anestrous ewes with melatonin 
for 4 to $5 \mathrm{wk}$ increased prolificacy to estrus synchronized with ram introduction and prostaglandin $F_{2 \alpha}$ in flocks in which prolificacy of control ewes was less than 1.6 (E. K. Inskeep, A. Lopez-Sebastian, P. S. Blackwood, and P. E. Lewis, unpublished data). Prolificacy was not improved by the gonadotropin preparation PG-600 in anestrous ewes, in which prolificacy was 1.9 in ewes receiving progestogen alone or 1.82 in control ewes (Safranski et al., 1992). Prolificacy to the first service period in the FSH-treated, anestrous ewes in the present study was similar to that in anestrous ewes in which eCG was used (Hamra et al., 1989; Tritschler et al., 1991; Safranski, et al., 1992). Further, prolificacy in the present study was comparable to (Ainsworth and Downey, 1986; Carlson et al., 1989) or higher than (Greyling and Brink, 1987) that obtained in cyclic ewes synchronized with CIDRs.

\section{Lambing pattern}

The mean interval from ram introduction to lambing was shorter by 12 to $13 \mathrm{~d}(\mathrm{P}<0.05$; Table 1$)$ in progesterone-treated ewes than in the control group. The majority of progesterone-treated ewes that lambed did so during the first $8 \mathrm{~d}$ (60 to $70 \%$ ) of the lambing period with a secondary peak in lambing between $d$ 16 and 25 (30\%; Figure 5). Carlson et al. (1989) reported a similar pattern of lambing; in their study, 74\% of progesterone-treated ewes lambed within $6 \mathrm{~d}$, with a second period of lambing an average of $16 \mathrm{~d}$ later. Ram introduction without pre-treatment with progestogen leads to two peaks of estrous activity in anestrous ewes (Oldham and Martin, 1978/1979; Oldham et al., 1978/1979) 
because of the development of some normal and some short-lived corpora lutea (Oldham and Martin, 1978/1979; Oldham et al., 1985). This phenomenon explains the more scattered pattern of lambing in control ewes lambing from the second service period (Figure 5). The existence of a second lambing peak in progesterone-treated ewes in the present study indicates that the combination of PCL inserts and ram introduction stimulated occurrence of at least 2 consecutive fertile estrous periods during the anestrous season.

In conclusion, the intravaginal inserts studied did not deliver adequate progesterone to mimic luteal phase peripheral concentrations during the breeding season. However, amounts delivered were able to induce fertile estrus when combined with ram introduction and increased proportions of ewes lambing to the first service and overall, compared with ram introduction alone. Treatment for 5 $\mathrm{d}$ was as effective as $12 \mathrm{~d}$ and may be more practical under field conditions. Treatment with $\mathrm{FSH} 24 \mathrm{~h}$ before insert removal at the dosage and timing used did not increase prolificacy to the first service over that observed in ewes treated with progesterone only. The FSH-treated ewes had more lambs from matings at the first service period than either control ewes or all ewes lambing to the second service period. Therefore, FSH may ensure that lambing rates of ewes bred during anestrus towards that seen during the breeding season. 
Figure 5. Cumulative percentages of ewes lambing in control ewes $(C,-C)$, ewes pre-treated with PCL inserts for 12 d without ( $\mathrm{P} 12, \square$ ), or with $\mathrm{FSH}$ $24 \mathrm{~h}$ before insert removal $\left(\mathrm{P} 12 \mathrm{~F}, \ldots \_\right.$) and ewes treated with PCL inserts for $5 \mathrm{~d}$ with $\mathrm{FSH} 24 \mathrm{~h}$ before insert removal (P5F, _ _. ). 


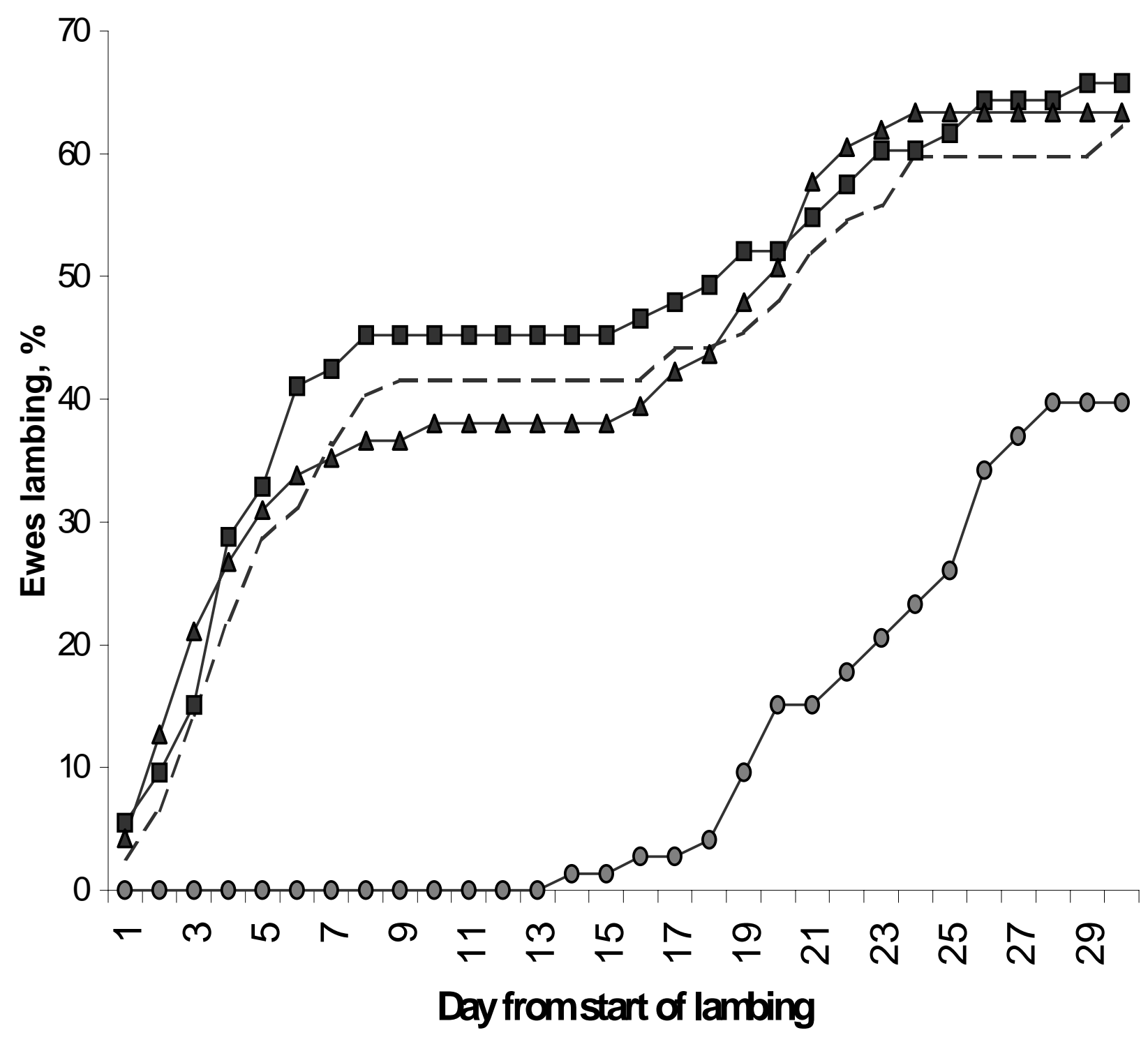


SHORT-TERM TREATMENT WITH A CONTROLLED INTERNAL DRUG RELEASING (CIDR) DEVICE AND FSH TO INDUCE FERTILE ESTRUS AND INCREASE PROLIFICACY IN ANESTROUS EWES 


\section{INTRODUCTION}

Breeding ewes during the anestrous period has relied on two general approaches, use of the "ram-effect" (Underwood, 1944; Schinckel, 1954) and progestogen-based therapies (Dutt, 1953; Boland et al., 1981; Wheaton, 1990). The efficacy of the ram effect alone in inducing out-of-season breeding is variable (Oldham and Cognie, 1980; Oldham and Fisher, 1992). More ewes lamb when the ram effect is combined with progesterone (Knights et al., 2000). Progestogens either alone (Wheaton, 1990; Jabbar et al., 1994; Knights et al., 2000) or with gonadotropin at the end of progestogen pretreatment (Dutt, 1953; Powell et al., 1996; Knights et al., 2000) have been used to induce fertile estrus in anestrous ewes. However, pregnancy rates of progestogen-synchronized ewes were lower during anestrus than during the breeding season (Crosby et al., 1991). Fertility was related positively to concentrations of progesterone during treatment (Robinson and Smith, 1967; Robinson et al., 1968; Pearce et al., 1985; Johnson et al., 1996), probably as a result of increased sperm transport (Hawk and Conley, 1971), more appropriate patterns of follicular development (Johnson et al., 1996), and timing of the LH surge in relation to the onset of estrus (Lewis et al., 1974; Van Cleeff et al., 1998). Release of progestogen from delivery devices declines over time (Morgan et al., 1967; Allison and Robinson, 1970). Therefore, a short-term treatment provides exposure to higher average concentrations of progestogen during the treatment period. Such treatments (5 to 8 d) have been effective in anestrous ewes (Christenson, 1976; Rodriguez- 
iglesias, 1997). Because ovulation rate and prolificacy (litter size) are lowest during the spring/summer period (Mallampati et al. 1971; Hall et al., 1986), gonadotropin treatment at the end of progestogen treatment has been used to increase prolificacy of ewes bred out-of-season (Hacket et al., 1982; Hamra et al., 1989; Safranski et al., 1992).

Recently, Knights et al. (2000) reported that a 5-d treatment with a redesigned intravaginal progesterone insert $\left(\begin{array}{lll}0.8 & \mathrm{~g} & \text { progesterone in }\end{array}\right.$ polycapralactone) with $\mathrm{FSH}$ at insert removal, stimulated fertile estrus as effectively as a 12-d treatment with $\mathrm{FSH}$, and resulted in prolificacy comparable to that observed during the normal breeding season. In that study, no comparison was made to a 5-d treatment without FSH. Because release of progesterone was less with the newer prototype (Knights et al. 2000) than with the original CIDR-G device (0.3 g progesterone in silicone; Ainsworth et al., 1986; Carlson et al., 1989), the newer prototype was abandoned. The effectiveness of a short-term treatment using the original CIDR-G had not been evaluated. Therefore, the objectives of this study were to determine whether a 5-d treatment with progesterone, delivered by a CIDR-G device, induces fertile estrus and whether FSH in combination with the insert increases ovulation rate and prolificacy in anestrous ewes. 


\section{MATERIALS AND METHODS}

\section{General}

The study was conducted during the period May to early August 1999. Ewes of mixed breeding, mostly involving Suffolk and Dorset, on 7 farms were available for the study $(n=729)$. Ewes were managed on mixed grass pastures, and were brought into barns or holding lots during treatment and the first service period. Ewes with serum concentrations of progesterone $>0.6 \mathrm{ng} / \mathrm{mL}$ in a sample collected $3 \mathrm{~d}$ before the start of the experiment were considered not to be in anestrus and were not assigned to the study $(n=71)$. Five ewes were excluded due to poor body condition or health.

The remaining 653 ewes were assigned at random within face color (white, black or mottled) to one of three treatment groups. Ewes served as controls (C, $n=125)$, or were assigned to one of two progesterone-treated groups. Each ewe in one progesterone-treated group received a CIDR-G® device (Interag, Hamilton, New Zealand) for $5 \mathrm{~d}(\mathrm{P} 5, \mathrm{n}=257)$. Ewes in the second group received the CIDR-G and a single dose of FSH (Folltropin®); Vetrepharm, Ottawa, Canada) im, $24 \mathrm{~h}$ before insert removal (P5F, $\mathrm{n}=271)$. The dosage of

$\mathrm{FSH}$ was equivalent to $55 \mathrm{mg} \mathrm{NIH}-\mathrm{FSH}-\mathrm{P} 1$ and was dissolved in saline/propylene glycol 1:4, v:v, the dosage used previously by Knights et al. (2000). Raddled rams that had been tested for breeding soundness (Kimberling and Marsh, 1991) were introduced to all ewes at insert removal (IR). Ewes on each farm were run together initially with all rams, at a ewe:ram ratio not exceeding 15:1 throughout the synchronized breeding period (Days 0 through 3). 
Ewes were observed for estrus every $24 \mathrm{~h}$ on Days 1 through 3 . After each observation for estrus, briskets of rams were repainted to ensure that mounted ewes were clearly marked. After the synchronized breeding period, the ewe:ram ratio was increased to not more than $25: 1$, and rams remained with ewes for 26 to $30 \mathrm{~d}$. Ewes were expected to have two peaks of breeding activity, a first service period (Days 1 through 3 ) during which progesterone-treated ewes would show estrus and a second service period (Days 16 through 24) during which control ewes and progesterone-treated ewes that did not conceive to the first service period would be mated.

Progesterone-treated ewes marked by rams during days 1 through 3 were examined by transrectal ultrasonography on Days 10 to 14 to determine ovulation rate (Schrick et al., 1993), and on Days 26 to 31 for pregnancy determination (Schrick and Inskeep, 1993). At pregnancy diagnosis, all rams were removed. All ewes were reexamined 20 to 25 days later (Days 46 to 51 after IR) to detect pregnancies from the second service period and any pregnancy losses that had occurred after the initial pregnancy diagnosis.

Lambing dates and numbers of lambs born were recorded. Pregnancy retention was determined by expressing ewes lambing as a percentage of ewes diagnosed pregnant on either Days 26 to 31 or 46 to 51 .

\section{Statistics}

Analysis of variance was conducted using GLM procedures of SAS, with farms as blocks, to evaluate the fixed effects of treatments. Orthogonal contrasts 
tested were (a) treated with progesterone vs control, and (b) FSH vs no FSH. Response variables for the first service period included proportion of ewes marked by rams (estrous response), ewes diagnosed pregnant of ewes marked (conception rate) and of ewes treated (pregnancy rate), ewes lambing of ewes diagnosed pregnant (pregnancy retention rate), lambs born per ewe treated (lambing rate) and lambs born per ewe lambing (prolificacy). For the second service period, pregnancy rate, lambing rate, pregnancy retention rate and prolificacy were compared. For prolificacy, additional comparisons were made between the first service period for FSH-treated ewes and the second service period for $\mathrm{C}$ ewes and all ewes. The pattern of estrous response relative to time after ram introduction and the effect of time of onset of estrus on conception rate and interactions of time with treatment were assessed in progesterone-treated ewes using orthogonal polynomial comparisons. 


\section{RESULTS}

\section{Retention of Progesterone Inserts}

The retention rate for the CIDR devices was 97.3\%. Eight of the 14 ewes in which CIDR devices were not found were marked by rams. Data for these ewes were included in all analyses to assess the overall effectiveness of the CIDR device.

\section{Estrous Response and Distribution}

The percentage of ewes marked by rams was higher in progesterone-treated $(77 \pm 1.5 ; \mathrm{P}<0.01)$ than in $\mathrm{C}$ ewes $(20 \pm 3.6$; Table 3$)$, but did not differ due to $\mathrm{FSH}$. The estrous response was quadratic relative to time after ram introduction $(P<0.05)$, and the treatment $\times$ time interaction was not significant $(P>0.10)$. The percentages of ewes treated with progesterone that exhibited estrus at 24, 48 and $72 \mathrm{~h}$ after ram introduction were 9, 48 and $19 \%$, respectively.

\section{Conception and Pregnancy Rates}

Conception and pregnancy rates to the first service period in progesterone-treated ewes (66-70 and $52-53 \%$, respectively) were significantly higher $(P<0.01)$ than those in control ewes $(0$ and $0 \%$, respectively). Conception and pregnancy rates to the first service period did not differ between ewes treated with progesterone alone (70 and 53\%, respectively) and ewes 
receiving progesterone and FSH (66 and 52\%, respectively). Conception rate varied quadratically $(P<0.05)$ with time from ram introduction to onset of estrus. Mean conception rates were $58.5 \pm 6.1,70.9 \pm 2.9$, and $61.7 \pm 5.1$ for ewes detected in estrus 24,48 and $72 \mathrm{~h}$ after ram introduction, respectively. Mean pregnancy rate to the second service period was $52.6 \pm 1.2$ and did not differ among treatment groups.

\section{Percentage of Ewes Lambing}

The percentages of ewes lambing to the first and both service periods were higher $(P<0.01)$ in progesterone-treated ewes than in control ewes but did not differ between progesterone-treated groups (Table 3). Within progesterone-treated groups, more ewes conceived and lambed during the second service period if they had expressed estrus but did not conceive at the first service period $(62.5 \pm 4.3$ and $54.2 \pm 4.3 \%$; $P<0.01)$, than if they did not exhibit estrus at the first service period ( $37.7 \pm 4.4$ and $27 \pm 4.1 \%$, respectively). Ovulation Rate, Lambing Rate and Prolificacy

Ovulation rate $(1.95 \pm 0.04$; Table 3$)$ did not differ between ewes receiving progesterone alone and ewes receiving both progesterone and $\mathrm{FSH}$. None of the control ewes lambed from mating during the first service period, so lambing rate and prolificacy to the first service period were compared only among progesterone-treated groups. The lambing rate to the first service period $(0.72 \pm$ 0.04) did not differ between progesterone-treated groups. The overall lambing rate was higher in progesterone-treated $(P<0.05)$ than in control ewes, and 
tended to be higher $(P=0.07)$ in ewes treated with $\mathrm{FSH}$ and progesterone than in ewes treated with progesterone alone (Table 3). Prolificacy in ewes lambing to the first service period tended to be higher in FSH-treated ewes $(1.67 \pm 0.06)$ than in ewes receiving only progesterone $(1.50 \pm 0.05 ; P=0.06)$. The $\mathrm{FSH}$-treated ewes lambing to the first service period tended to have higher prolificacy than all ewes lambing to the second service period $(1.48 \pm 0.04 ; \mathrm{P}=$ 0.06; Table 3). Neither prolificacy to the second service period $(1.48 \pm 0.04)$ nor overall prolificacy $(1.54 \pm 0.03)$ differed significantly among treatment groups. 
Table 3. Summary of reproductive performance of anestrous ewes in response to ram introduction (C), or ram introduction + 5-d CIDR pre-treatment without (P5) or with FSH (P5F).

\begin{tabular}{|c|c|c|c|}
\hline Variable/Treatment & $\mathrm{C}$ & P5 & P5F \\
\hline Total number of ewes & 125 & 257 & 271 \\
\hline Ewes in estrus ${ }^{1}, \%$ & 20 & $75^{a}$ & $79^{a}$ \\
\hline Ovulation rate & - & $1.95 \pm 0.1$ & $1.96 \pm 0.1$ \\
\hline Conception rate $^{2}, \%$ & 0 & $70^{a}$ & $66^{a}$ \\
\hline \multicolumn{4}{|l|}{ Pregnancy rate, \% } \\
\hline First service period ${ }^{3}$ & 0 & $53^{a}$ & $52^{\mathrm{a}}$ \\
\hline Second service period ${ }^{4}$ & 57 & 45 & 54 \\
\hline
\end{tabular}

Percent ewes lambing, \%

First service period

Both service periods

Lambing rate ${ }^{5}$, (mean $\pm \mathrm{SE}$ )

First service period

Both service periods

Prolificacy $^{6}$, (mean \pm SE)

First service period

Second service period

Overall
0

45 $46^{a}$

$63^{\mathrm{a}}$ $46^{a}$

$67^{a}$

${ }^{a}(P<0.01),{ }^{b}(P<0.05)$ progesterone vs control.

${ }^{1}$ Number of ewes marked by raddled rams as a percentage of all ewes treated.

${ }^{2}$ Number of ewes diagnosed pregnant on Days 26 to 31 as a percentage of ewes exhibiting estrus.

${ }^{3}$ Number of ewes diagnosed pregnant on Days 26 to 31 as a percentage of all ewes treated.

${ }^{4}$ Number of ewes pregnant on Days 46 to 51 expressed as a percentage of ewes not pregnant on Days 26 to 31 .

${ }^{5}$ Lambs born per ewe exposed to rams.

${ }^{6}$ Lambs born per ewe lambing. First service period P5 vs P5F ; P $=0.06$. 
Figure 6. Pregnancy retention rate: Ewes lambing as a percentage of ewes diagnosed pregnant as a result of matings at the first, second, or both service periods after ram introduction, for control ewes (C), and ewes pre-treated with CIDR devices for $5 \mathrm{~d}$ without (P5), or with FSH $24 \mathrm{~h}$ before insert removal (P5F). 


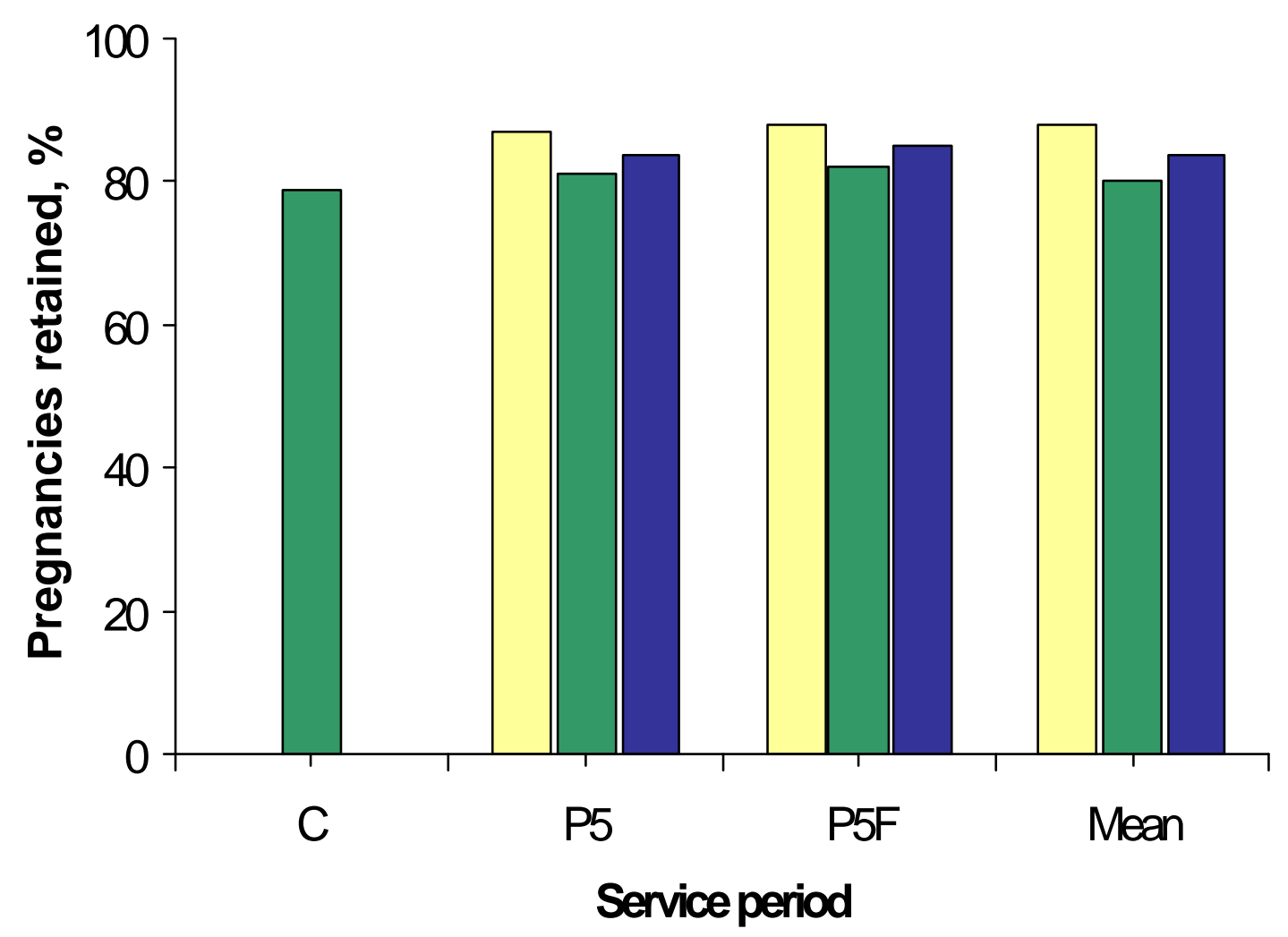

$\square$ 1st $\square$ 2nd $\square$ Both 


\section{Retention of Pregnancy}

Pregnancy retention rates are shown in Figure 6. The pregnancy retention rate averaged $84.6 \pm 1.7 \%$ for both service periods and tended to be higher in ewes conceiving at the first service period $(87.6 \pm 2.0 \%)$ than at the second service period $(80.4 \pm 2.8 \% ; \mathrm{P}=0.07)$. Of the ewes diagnosed pregnant to the first service period on Days 26 to $31,93.8 \pm 1.0 \%$ were still pregnant when examined on Days 46 to 51 . 


\section{DISCUSSION}

Treatment of anestrous ewes with progesterone for 5 days before ram introduction was adequate to induce fertile estrus, confirming our earlier results (Knights et al. 2000). Similarly, anestrous ewes that received progesterone injections for 3 to $6 \mathrm{~d}$ (25 to $30 \mathrm{mg} / \mathrm{d}$; Dutt; 1953; Robinson, 1955), medroxy-progesterone-acetate (MAP) sponges for $6 \mathrm{~d}$ (10 or $60 \mathrm{mg} ; 37$ ) or feed containing melengesterol acetate for $8 \mathrm{~d}(0.25 \mathrm{mg} / \mathrm{d}$; 30$)$ showed estrus after ram introduction. Pretreatment with progesterone increased the sensitivity of behavioral centers in the brain to estradiol (Robinson, 1955; Fabre-Nys and Martin, 1991) and prevented the formation of short-lived corpora lutea (CL) after ram introduction (Cognie et al., 1982; McLeod and Haresign, 1984; Pearce et al., 1985). The minimum time of progesterone exposure needed to increase the behavioral response of ewes to estrogen is probably 3 to 5 days (Dutt, 1953; Robinson, 1955; Knights et al., 2000, present study). Increasing the duration of progesterone pretreatment probably offers little advantage in terms of estrous response (Dutt, 1953; Robinson, 1955; Christenson, 1976; Powell et al., 1996; Knights et al., 2000). The estrous response did not differ in ewes exposed to different dosages of MAP incorporated in sponges (15 to $60 \mathrm{mg}$ for $9 \mathrm{~d}$ ); near maximal estrous response was observed at the lowest dosage (RodriguezIglesias, 1997).

Improved fertility in ewes synchronized with higher dosages of progestogen is probably due to improved sperm transport (Hawk and Conley, 1971), synchrony of onset of estrus and LH surge (Lewis et al., 1974; Van Cleeff et al., 1998), or patterns of follicular development (Johnson et al., 1992). More ewes 
were marked between 24 and $48 \mathrm{~h}$ after ram introduction than any other period. This is consistent with a mean time from ram introduction to estrus of 40 to $50 \mathrm{~h}$ (Robinson and Smith, 1967; Robinson et al., 1968) and with peak estrous response on Day 2 after withdrawal of progestogen and ram introduction (Gordon, 1971). However, higher dosages of progestogen may increase the interval from ram introduction to estrus (Lewis et al., 1974; Rodriguez-Iglesias, 1997).

The conception rate in progesterone-treated ewes was comparable to that observed during the breeding season (Ainsworth and Downey, 1986; Greyling and Brink, 1987; Rhodes and Nathanielsz, 1988). The conception rate responded quadratically in relation to time of estrus after ram introduction and was highest in ewes detected in estrus at $48 \mathrm{~h}$. Gordon (1971) also reported the highest conception rates on the second day after ram introduction. The higher conception rates in ewes detected in estrus at $48 \mathrm{~h}$ may be due to a greater synchrony of time of ovulation and mating. The majority of anestrous ewes ovulate between 36 and $62 \mathrm{~h}$ after ram introduction (Oldham et al., 1978/79), which coincides with the time when the most ewes are in estrus.

Among progesterone-treated ewes, ewes expressing estrus but failing to conceive at the first service period were twice as likely to become pregnant and to lamb from the second service period as ewes that were not detected in heat at the first service period. Introduction of rams to anestrous ewes increases LH pulse frequency, which in turn drives increases in estrogen (Oldham and Fisher, 1992). Increasing concentrations of estrogen stimulate the progesterone-primed 
brain, inducing estrus (Robinson, 1954; Fabre-Nys and Martin, 1991) and triggering the LH surge and ovulation (Martin et al., 1986; Signoret, 1990; Oldham and Fisher, 1992). Ewes that failed to ovulate at the first service period lacked progesterone, which could preclude them from expressing estrus at the second service period. Ewes that fail to show estrus may not be secreting adequate amounts of estrogen to stimulate both estrus and ovulation. In a previous study (Knights et al., 2000), measurement of estradiol-17 $\beta$ in serum samples that were collected at 12-h intervals during the first $48 \mathrm{~h}$ after ram introduction in progesterone pre-treated ewes demonstrated that both the mean and peak concentrations of estrogen were lower in ewes that did not express estrus than in ewes that expressed estrus $(4.0 \pm 0.1$ and $4.2 \pm 0.3$, vs $4.7 \pm .1$ and $5.1 \pm 0.3 \mathrm{pg} / \mathrm{mL}$, respectively; M. Knights, unpublished observations).

The overall percentage of ewes lambing was 20 points higher in progesterone-treated than in control ewes. Abrupt introduction of rams to anestrous ewes induces one or two ovulations without estrus before an ovulation associated with estrus (Schinckel, 1954; Oldham et al., 1978/79; Martin et al., 1986). Reversion to an anestrous state usually follows the second induced ovulatory activity and estrus, however some ewes may never re-ovulate or exhibit estrus (Oldham and Fisher, 1992). The higher percentage of ewes lambing in treated groups probably reflects the ability of progesterone pretreatment and ram introduction to stimulate potentially fertile (ovulatory) estrus at least twice before reversion to an anestrous/anovulatory state. 
The pregnancy retention rate tended to be higher in ewes conceiving at the first $(88 \%)$ than at the second service period $(80 \%)$. In our previous study (Knights et al. 2000), the pregnancy retention rate was $91 \%$ to the first service period and $73 \%$ to the second service period. In the ewes diagnosed pregnant to the first service period, approximately half (6.2 percentage points) of the pregnancy losses occurred between Days 26 to 31 and 46 to 51 with the other half occurring after this period. The overall pregnancy loss observed in ewes bred out-of-season in the two studies (15\%) was higher than that reported for parous and non-parous ewes bred during the natural breeding season (1.3 and 5.3\% after Day 30, respectively; Quinlivan et al., 1966). Decreased placental supply of nutrients, elevated temperatures during pregnancy (Bell et al., 1987; Vatnick et al., 1991) and elevated scrotal temperatures of rams (Mieusset, 1992) have been associated with late embryonic mortality. Progressively higher ambient temperatures during the spring/summer months may explain pregnancy losses overall as well as the greater loss to the second service period. Further studies to determine the time of pregnancy loss in ewes bred out-of-season and its relationship to ambient conditions are warranted.

Lambing rates were higher in progesterone-treated than in control ewes. This was due primarily to a higher percentage of ewes lambing, as overall prolificacy did not differ between progesterone-treated and control ewes. Ewes treated with FSH and lambing to the first service period tended to have higher prolificacy than ewes treated with only progesterone and lambing to the first service period and all ewes lambing to the second service period. The 
pregnancy loss observed may only partially reflect overall embryonic and fetal mortality. In ewes carrying multiple embryos or fetuses, high ambient temperatures and decreased nutrient supply to the fetus may cause the selective loss of some embryos (Bell et al., 1987; Vatnick et al., 1991). Losses of individual embryos without total loss of pregnancy have been documented during the breeding season (Schrick and Inskeep, 1993). Such an occurrence will limit potential benefits of $\mathrm{FSH}$-treatments.

It can be concluded that a $5-\mathrm{d}$ treatment with progesterone before ram introduction is sufficient to induce fertile estrus in anestrous ewes. The FSH administered $24 \mathrm{~h}$ before withdrawal of progesterone tended to increase lambing rates and prolificacy. 
ABILITY OF RAM INTRODUCTION TO INDUCE LH SECRETION, ESTRUS AND OVULATION IN FALL-BORN EWE LAMBS DURING ANESTRUS. 


\section{INTRODUCTION}

The sheep industry benefits from fall lambing by being able to provide annually a consistent supply of fresh product to the consumer. A source of inefficiency in fall lambing systems is the later age at first lambing for fall-born ewe lambs relative to spring-born lambs. Ewes bred as lambs produce more lambs and more kilograms of lamb than their flock mates bred first as yearlings (Spencer, 1942; Hohenboken et al., 1977). A critical photoperiod required for the normal timing of puberty is the exposure to long days followed by short days (Yellon and Foster, 1985). Fall-born ewe lambs are first exposed to this photoperiodic regimen during late summer and early fall. Therefore the attainment of puberty in fall-born lambs is delayed until they are between 10 and 12 months of age (Vesely and Swiersta, 1987; Forcada et al., 1991). Ewe lambs born in fall reach the age and weight that are associated with the commencement of puberty in their spring-born counterparts during the anestrous period. In order for the ages at first lambing in fall and spring lambing systems to be comparable, fall-born ewe lambs must therefore be bred during the period of seasonal anestrous. Some success has been achieved in breeding fall-born ewe lambs during the anestrous period using equine eCG after progestogen priming alone (Burfening and Van Horn, 1970) and in combination with manipulation of photoperiod (Ainsworth and Shrestha, 1987; Ainsworth et al., 1991). However, attempts to induce fertile mating during anestrus in fall-born ewe lambs with ram introduction alone (Lopez-Sebastian et al. 1985) or with progestogen pre- 
treatment independent of exogenous gonadotropins (Burfening and Van Horn, 1970) have not been successful. Only 11 percent of fall-born ewe lambs were bred when exposed to rams during spring/early summer (Al-Shorepy and Notter, 1996). Notter (1992) suggested that it may be very difficult to get fall-born ewe lambs to lamb at 12 months of age (an industry goal), and indicated that no satisfactory system exists for introducing fall born ewe lambs into an out-ofseason production system.

Ram introduction increased LH pulse frequency in anestrous ewes (Atkinson and Williamson, 1985; Martin et al., 1986; Goodman, 1994). Increases in LH pulse frequency probably promote follicular development (Atkinson and Williams, 1985) and increase estrogen secretion, which in turn triggers an LH surge and ovulation (Oldham et al., 1978/79). Anestrous ewes pre-treated with progestogens expressed estrus at the ram-induced ovulation (Knights et al., 2000). Secretion of $\mathrm{LH}$ increases and becomes more variable 1-5 weeks before the first pubertal rise in progesterone (Foster and Ryan, 1979; Keisler et al., 1983; 1985; Huffman et al., 1987). Increases in both the basal concentration of $\mathrm{LH}$ and LH pulse frequency are presumably required to stimulate increases in estrogen secretion and to trigger the LH surge and ovulation (Foster and Ryan, 1981; Keisler, 1983). Ewe lambs born in March (spring) did not show an increase in LH pulse frequency until September or ovulate until October in response to ram introduction (Al-Mauly et al., 1991). Further, Lopez-Sebastian et al. (1985) did not observe increases in the concentration of LH or an LH surge in response to ram introduction before the transition from anestrus to the breeding 
season (i.e. August/September) in ewe lambs born in November (fall). Therefore, the lower response to estrous induction procedures in ewe lambs and yearlings in the absence of gonadotropin treatment may be related to the failure of ram introduction to induce increases in LH pulse frequency, and ovulation. The aim of the present study was to determine if ram introduction could induce increases in LH pulse frequency, follicular development, an LH surge and ovulation in fall-born ewe lambs. A second objective was to determine if progesterone pre-treatment with or without estrogen could induce estrous behavior and ovulation in fall-born ewe lambs introduced to rams during seasonal anestrus.

\section{MATERIALS AND METHODS:}

\section{Animals and Treatments}

The study was conducted in early July 2000 , using crossbred ewe lambs of mixed breeding that were not exposed to rams prior to the study. Ewe lambs were born the previous November and averaged $251 \mathrm{~d}$ of age and $41.8 \pm 0.6 \mathrm{~kg}$ body weight, respectively.

Lambs were assigned randomly to receive no treatment $(C, n=7)$, to be introduced to rams $(R, n=7)$, to be pre-treated with progesterone for five days ( $P$, $n=5)$, treated with progesterone and introduced to rams $(P R, n=11)$ to receive the latter treatment plus an injection of estradiol benzoate $(25 \mu \mathrm{g}$, i.m.) one day 
(d1) after ram introduction/progesterone withdrawal $(P E R, n=11)$. Progesterone was provided with CIDR devices previously used for five days in mature ewes. Used CIDR devices ( six days) were shown to be effective in inducing fertile estrus in anestrous ewes (Ungerfeld and Rubianes, 1999). To ensure that ewe lambs were stimulated properly by ram introduction, rams were joined continuously with them, at a ram to ewe lamb ratio of $1: 7$, and while confined inside a holding lot $\left(74 \mathrm{~m}^{2}\right)$.

\section{Blood Collection}

Blood samples for the determination of LH pulse frequency were collected via jugular venipuncture every 15 minutes for $8 \mathrm{~h}$ from 12 through $20 \mathrm{~h}$ after ram introduction ( $T=0$ ) from lambs in $C$ and $R$ treatment groups. Blood samples were collected every $4 \mathrm{~h}$ for $60 \mathrm{~h}$ beginning at ram introduction/progesterone withdrawal for determination of the mean concentration of $\mathrm{LH}$ and the $\mathrm{LH}$ surge profile in all lambs.

\section{Follicular Development, Estrus and Ovulation}

Follicular development was monitored utilizing transrectal ultrasonography (Schrick et al., 1993) at 0,36 and $60 \mathrm{~h}$ after ram introduction/progesterone withdrawal. All follicles greater than $3 \mathrm{~mm}$ in diameter were recorded and the subsequent growth, atresia or disappearance of these follicles were monitored. Follicles $\geq 4 \mathrm{~mm}$ were judged to have ovulated if they were not present at the subsequent examination (Schrick et al., 1993). Growth rate of the largest follicle 
was determined retrospectively as the change in diameter between 0 and $36 \mathrm{~h}$. Lambs were observed for raddle marks (estrus) every $4 \mathrm{~h}$ from 0 to $60 \mathrm{~h}$.

\section{LH Determination}

Concentration of LH was measured in 100 to $200 \mu \mathrm{l}$ aliquots of serum by RIA as previously described by (Whisnant and Goodman, 1988) using anti-ovine LH (oLH) serum CSU204 (Estienne et al., 1989). The average minimal detectable dose was $0.1 \mathrm{ng} /$ tube (NIH-S24). The interassay and average intraassay coefficients of variation were 13.6 and $13 \%$, respectively.

\section{Analysis}

LH pulses were detected by PC Pulsar analysis (Gitzen and Ramirez, 1986). The onset of the LH surge was defined as the time of the first sample in which the concentration of $\mathrm{LH}$ exceeded the base line (mean of first three samples) by two standard deviations and remained elevated for at least two consecutive samples. The amplitude of the surge was defined as the highest value minus the baseline. The duration of the surge was defined as the period when concentration of $\mathrm{LH}$ remained elevated over the baseline by two standard deviations. The characteristics of the LH surge profile (initiation, amplitude, duration, area under the curve (AUC) and the relationship of these characteristics to patterns of follicular development were analyzed by ANOVA using the GLM procedure of SAS. The proportion of ewes showing an LH surge, ovulating or displaying estrus was analyzed by the CATMOD procedure of SAS. Differences 
in the LH pulse frequency (pulses/8h) of lambs in treatment groups $\mathrm{R}$ and $\mathrm{C}$ were analyzed using the Student's t-test.

\section{RESULTS}

\section{Follicular Development}

No differences were detected in the diameter of the largest follicle before ram introduction (mean, $3.2 \pm 0.2 \mathrm{~mm}$ ) and at $60 \mathrm{~h}$ after ram introduction (4.3 \pm $0.6 \mathrm{~mm}$ ) among treatment groups. At $36 \mathrm{~h}$ the diameter of the largest follicle was greater $(P<0.05)$ in $R$ or $P R$ than in $C$ or $P$ groups, and in $R$ than $P E R$ treatment groups $(P<0.05 ;$ Table 4$)$. The growth rate of the largest follicle between 0 and $36 \mathrm{~h}$ did not differ among groups exposed to rams but was greater $(P<0.05$; Table 4) in all ram-exposed ewe lambs than in C lambs and in lambs exposed to rams alone $(R)$ than in lambs treated with progesterone only $(P)$.

The number of follicles $\geq 3 \mathrm{~mm}$ was not different among treatment groups at $0 \mathrm{~h}$. At $36 \mathrm{~h}$, the number of follicles $\geq 3 \mathrm{~mm}$ was greater in lambs in group $\mathrm{R}$ than in group $C(P<0.05)$. At $60 \mathrm{~h}$ the number of follicles $\geq 3 \mathrm{~mm}$ was greater in group $C$ than in all groups introduced to rams $(P<0.05$; Table 4).

\section{LH Pulse Frequency and Profile of the LH Surge}

During the $8 \mathrm{~h}$ sampling period between 12 and $20 \mathrm{~h}$ after ram introduction, ewe lambs introduced to rams had a higher mean concentration of $\mathrm{LH}(\mathrm{P}<0.01 ;$ Table 5) than lambs in the control group. LH pulse 
Table 4. Follicular development and ovulatory and estrous responses in control (C), ram-exposed $(\mathrm{R})$, progesterone-pre treated $(\mathrm{P})$ and ram-exposed, progesterone-pre treated lambs without $(\mathrm{PR})$ or with estrogen (PER).

\begin{tabular}{llllll}
\hline \hline & & \multicolumn{3}{c}{ Treatment } \\
\hline Variable & $\mathrm{C}$ & $\mathrm{R}$ & $\mathrm{P}$ & $\mathrm{PR}$ & PER \\
\hline $\mathrm{N}^{1,2}$ & 7 & 7 & 5 & 11 & 11
\end{tabular}

Diameter of the largest

follicle $(\mathrm{mm})$ :
a. $0 \mathrm{~h}$
$3.3 \pm 0.2$
$3.3 \pm 0.2$
$3.2 \pm 0.2$
$3.1 \pm 0.3 \quad 3 \pm 0.0$
b. $36 \mathrm{~h}$
$3.3 \pm 0.9^{b}$
$5.6 \pm 0.2^{\mathrm{a}}$
$3.8 \pm 0.4^{b}$
$5.1 \pm 0.5^{\mathrm{ac}}$
$4.3 \pm 0.4^{b c}$
c. $60 \mathrm{~h}$
$4.4 \pm 0.4$
$4.8 \pm 0.8$
$3.3 \pm 1.3$
$4.0 \pm 1.0$
$4.0 \pm 0.6$
d. Estrus
Growth rate $(\mathrm{mm} / \mathrm{d})^{3}$
$0.0 \pm 0.6^{b}$
$1.5 \pm 0.2^{\mathrm{a}}$
$5.8 \pm 0.2 \quad 5.0 \pm 0.5$

No. follicles $\geq 3 \mathrm{~mm}$
a. $0 \mathrm{~h}$
$1.3 \pm 0.2$
$1.6 \pm 0.3 \quad 1 \pm 0.0$
$1.7 \pm 0.4 \quad 2 \pm 0.4$
b. $36 \mathrm{~h}$
$0.8 \pm 0.4^{\mathrm{a}}$
$1.9 \pm 0.3^{\mathrm{b}} \quad 1 \pm 0.0^{\mathrm{ab}}$
$1.6 \pm 0.3^{b}$
$1.3 \pm 0.2^{b}$
c. $60 \mathrm{~h}$
$1.7 \pm 0.4^{b}$
$0.7 \pm 0.2^{\mathrm{a}} \quad 1 \pm 0.3^{\mathrm{ab}}$
$0.6 \pm 0.2^{a}$
$0.3 \pm 0.2^{\mathrm{a}}$

No. follicles $\geq 4 \mathrm{~mm}$ (at

onset of estrus)

Lambs in estrus (\%)

Lambs ovulating (\%)

$\begin{array}{lllll}\mathrm{ND}^{4} & - & \mathrm{ND} & 1.2 \pm 0.2 & 1.1 \pm 0.3 \\ \mathrm{ND} & 0^{\mathrm{b}} & \mathrm{ND} & 45.5^{\mathrm{a}} & 81.8^{\mathrm{c}} \\ 0^{\mathrm{c}} & 85.7^{\mathrm{a}} & 0^{\mathrm{c}} & 33.3^{\mathrm{bc}} & 71.4^{\mathrm{ab}}\end{array}$

\footnotetext{
${ }^{1}$ Number of lambs per treatment group

${ }^{2}$ Follicular development and ovulation were monitored in 9 lambs in treatment group PR and 7 lambs in treatment group PER and in all lambs in the other groups

${ }^{3}$ Growth rate of the largest follicle measured between 0 and $36 \mathrm{~h}$

${ }^{4} \mathrm{ND}=$ not determined

a, b, c, Means in the same row with different superscripts differ significantly $(P<0.05)$.
} 
frequency increased $(P<0.05)$ from $2.7 \pm 0.8$ (range 1-5) pulses/8h in control lambs to $7.7 \pm 0.5$ (range $4-10$ ) pulses/8h in lambs introduced to rams (Table 5).

During the $60 \mathrm{~h}$ following ram introduction, the mean concentration of $\mathrm{LH}$ was higher $(P<0.01 ;$ Table 6$)$ in ewe lambs introduced to rams compared to control lambs and lambs pre-treated with progesterone alone. Among groups introduced to rams mean concentration of $\mathrm{LH}$ was higher $(P<0.05)$ in lambs receiving estrogen than in lambs pre-treated with progesterone and introduced to rams only (Table 6).

The percentage of lambs in which a detectable LH surge was induced was 0, 0, 100, 72.7 and $100 \%$, for treatment groups C, P, R, PR and PER, respectively (Table 6). As none of the lambs in groups $\mathrm{C}$ or $\mathrm{P}$ showed an $\mathrm{LH}$ surge, characteristics of the LH surge profile were only analyzed in groups introduced to rams.

Among ram-exposed groups there were no differences in the percentage of ewe lambs in which an LH surge was induced. The time to initiation of the LH surge was greater in ewe lambs pre-treated with progesterone and introduced to rams than in lambs that also were treated with estrogen $(P<0.01)$ or those introduced to rams alone $(P<0.05$; Table 6$)$. 
Table 5. Mean concentration of LH and LH pulse frequency and amplitude during 12 to $20 \mathrm{~h}$ after ram introduction in control $(\mathrm{C})$ ewe lambs and ewe lambs introduced to rams $(\mathrm{R})$.

\begin{tabular}{lll}
\hline Variable & Control (C $)$ & Ram-exposed (R) \\
\hline Mean LH (ng/mL) & $1.8 \pm 0.18^{\mathrm{a}}$ & $2.8 \pm .14^{\mathrm{b}}$ \\
Pulse Frequency (Pulses $/ 8 \mathrm{~h})$ & $2.7 \pm 0.8^{\mathrm{c}}$ & $7.7 \pm 0.5^{\mathrm{d}}$ \\
Mean Pulse Amplitude $(\mathrm{ng} / \mathrm{mL})$ & $4.3 \pm 1.0$ & $4.8 \pm 0.3$ \\
\hline Means with different superscripts in the same row differ significantly a, b $(\mathrm{P}<0.05) ; \mathrm{c}, \mathrm{d}(\mathrm{P}<$ \\
0.01).
\end{tabular}


Table 6. Mean concentrations of $\mathrm{LH}$, percentages of ewe lambs with a detectable LH surge and characteristics of the LH surge profile during the first 60 $h$ after ram introduction for control $(C)$, ram-exposed $(R)$, progesteronepretreated $(\mathrm{P})$, and ram-exposed progesterone-pretreated lambs without $(\mathrm{PR})$ or with estrogen (PER).

\begin{tabular}{lccccc}
\hline & \multicolumn{5}{c}{ Treatment } \\
\cline { 2 - 5 } \multicolumn{1}{c}{ Variable } & $\mathrm{C}$ & $\mathrm{R}$ & $\mathrm{P}$ & $\mathrm{PR}$ & PER \\
\hline \multicolumn{1}{c}{$\mathrm{N}^{1}$} & 7 & 7 & 5 & 11 & 11 \\
Mean LH $(\mathrm{ng} / \mathrm{mL})$ & $2.7 \pm 0.3^{\mathrm{a}}$ & $14.2 \pm 2.8^{\mathrm{bc}}$ & $3.7 \pm 0.4^{\mathrm{a}}$ & $9.7 \pm 1.8^{\mathrm{bc}}$ & $17.6 \pm 3.2^{\mathrm{bd}}$ \\
Lambs with an LH surge (\%) & $0^{\mathrm{a}}$ & $100^{\mathrm{b}}$ & 0 & $72.7^{\mathrm{b}}$ & $100^{\mathrm{b}}$ \\
Start of LH surge $(\mathrm{h})$ & - & $32.6 \pm 4.6^{\mathrm{bd}}$ & - & $43.5 \pm 3.8^{\mathrm{ac}}$ & $33 \pm 1.2^{\mathrm{b}}$ \\
Duration of LH surge $(\mathrm{h})$ & - & $13.7 \pm 0.8$ & - & $12.5 \pm 1.2$ & $11.6 \pm 0.8$ \\
AUC $(\mathrm{ng})^{2}$ & - & $176.3 \pm 24.2$ & - & $156.3 \pm 46.1$ & $223.9 \pm 28.3$ \\
Amplitude of LH surge $(\mathrm{ng} / \mathrm{mL})$ & - & $112.2 \pm 23.6^{\mathrm{cd}}$ & - & $89.6 \pm 19.3^{\mathrm{d}}$ & $151.6 \pm 19.8^{\mathrm{c}}$ \\
\hline
\end{tabular}

\footnotetext{
${ }^{1}$ Number of lambs per treatment group

${ }^{2}$ Area under the curve, estimated as the sum of the concentration of all samples collected during the LH surge

$a, b$ means in the same row with different superscript differ significantly $(P<0.01) c, d(P<0.05)$.
} 
The mean amplitude of the LH surge was greater in estrogen-treated, progesterone primed lambs $(P<0.05 ; 151.6 \pm 19.8 \mathrm{ng} / \mathrm{mL})$ than lambs primed with progesterone and introduced to rams $(89.6 \pm 19.3 \mathrm{ng} / \mathrm{mL})$, but did not differ from that observed in lambs introduced to rams only $(112.2 \pm 23.6 \mathrm{ng} / \mathrm{mL}$; Table 6). Among lambs in the PR treatment group, 2 lambs showed an earlier start to the LH surge ( $30 \pm 2$ vs $48 \pm 3.3 \mathrm{~h}$ ) and the amplitudes of their LH surges were greater $(161.4 \pm 3.31 \mathrm{vs} 60.46 \pm 6.67 \mathrm{ng} / \mathrm{ml} ; \mathrm{P}<0.05)$ than those of the other 5 lambs that had an LH surge.

\section{Estrus and ovulation}

Only progesterone-pretreated lambs expressed estrus (Table 4). Estrogen increased the percentage of lambs that exhibited estrus $(P<0.05 ; 82$ and $46 \%$ for lambs in PER and PR groups, respectively). Estrogen had no effect on the mean time to onset of estrus $(40 \pm 3.1$ and $41.6 \pm 4.1 \mathrm{~h}$ for lambs in PER and PR treatment groups, respectively. Neither the size of the largest follicle or the number of follicles $\geq 4 \mathrm{~mm}$ at estrus differed among treatment groups.

Ovulation was detected only in ewe lambs exposed to rams (Table 4). Among groups joined with rams the percentage ovulating by 60 hours after ram introduction was greater $(P<0.05)$ in lambs exposed to rams alone $(86 \%)$ than those also pre-treated with progesterone (33\%). Although the percentage of lambs ovulating in the PER group (71\%) was more than twice that observed in the PR, group the difference did not achieve statistical significance. 


\section{DISCUSSION}

Fall-born ewe lambs are not likely to breed during seasonal anestrus. For example in a line selected for fall lambing, the fertility of ewe lambs bred out-ofseason was 11 compared to $59 \%$ for adults (Al-Shorepy and Notter, 1996). Further, progestogen priming alone failed to stimulate estrus (Robinson, 1955; Burfening and Van Horn, 1970) and conception (Burfening and Van Horn, 1970) in fall-born ewe lambs. Induction of fertile estrus during seasonal anestrus in the absence of gonadotropin treatments presumably depends on the ability of ram introduction to stimulate a "follicular phase" (Martin et al., 1986). Introduction of rams failed to increase LH secretion and ovulation in spring (Al-Mauly et al., 1991) or fall-born ewe lambs (Sebastian et al., 1985) until just prior to the time when un-exposed, control lambs attained puberty. These findings led to the suggestion that fall-born ewe lambs may not be capable of responding to the ram effect during seasonal anestrus.

In the present study introduction of rams to fall-born ewe lambs increased the growth rate of the largest follicle between 0 and $36 \mathrm{~h}$ and resulted in a larger follicle at $36 \mathrm{~h}$. Atkinson and Williams (1985) reported increased follicular development during the first $40 \mathrm{~h}$ when anestrous ewes were joined with rams. The number of follicles $\geq 3 \mathrm{~mm}$ at $60 \mathrm{~h}$ was greater in control lambs than in all ram-exposed groups. Depletion of the large follicle population via ovulation or atresia probably explains the reduced number of follicles $\geq 3 \mathrm{~mm}$ in ram-exposed compared to control lambs at $60 \mathrm{~h}$. 
Introduction of rams to fall-born lambs in the present study increased the mean concentration of LH and the LH pulse frequency. The increased pulsatile secretion of $\mathrm{LH}$ in ram-exposed groups presumably stimulated follicular development and increased estrogen secretion, triggering the observed LH surge (Foster and Ryan, 1981; Goodman, 1994). In contrast, introduction of rams to fall-born ewe lambs elevated concentrations of $\mathrm{LH}$ and induced ovulation in late July, close to the time at which puberty occurred in control lambs, but a similar response was not observed in late May or early July (Lopez-Sebastian et al., 1985). The normal timing of puberty requires lambs to be exposed to a long day photoperiod followed by short days (Foster and Ryan, 1981; Yellon and Foster, 1985). Prior to ram introduction, the lambs in this study were exposed to long days and had a brief exposure to declining photoperiod. It is tempting to suggest that either refractoriness to long days or a brief exposure to decreasing day lengths may have conditioned an increased responsiveness to ram introduction in early (present study) or late July (Lopez-Sebastian et al., 1985) compared to that observed in May. The reason for the differences in the response to ram introduction in early July in the two studies might be due to differences in breed. In both studies lambs were born in late October and early November and were older than the age at which ram-induced ovulations were observed in spring-born lambs (Al-Mauly, 1991). The degree of stimulus affects the ovulatory response of anestrous ewes to ram introduction (Nugent and Notter, 1990; Oldham and Fisher, 1992; Rosa et al., 2000). In the present study, a low ewe to ram ratio (7:1) was utilized, but the ewe to ram ratio was not stated in Lopez-Sebastian's 
study. It has been suggested that during the anestrous period, puberty may be repressed in ewe lambs due to the retardation of sexual development (Foster, 1981), or, the expression of already achieved sexual competence may be inhibited by the prevailing photoperiod (Land, 1978; Foster, 1981). If the ability to respond to abrupt ram introduction is an indicator of attainment of sexual competence (Al-Mauly et al., 1991), then it appears that the expression rather than the development of sexual competence is inhibited during seasonal anestrus in fall-born ewe lambs.

Progesterone pre-treatment and removal without ram introduction did not increase mean LH concentration or induce an LH surge. During the normal breeding season, progesterone removal is thought to set into a motion a cascade that includes increased $\mathrm{GnRH} / \mathrm{LH}$ secretion, which stimulates a follicular phase increase in estradiol that triggers the LH surge and ovulation (Barrell et al., 1992; Goodman, 1994). In contrast, in anestrous ewes, no increases in GnRH or LH secretion were observed following withdrawal of exogenous progesterone. Therefore progesterone pretreatment, without ram introduction, of fall-born ewe lambs during anestrous does not stimulate $\mathrm{LH}$ secretion or remove the effect of inhibitory photoperiod.

The ram-induced LH surge was delayed by progesterone pretreatment. A similar observation was made in anestrous ewes by Pearce et al. (1985). This delay synchronized the initiation of estrous behavior and the LH surge. Estrogen administered $24 \mathrm{~h}$ after removal of progesterone prevented the delay of the raminduced LH surge and increased the mean LH concentration, but did not affect 
the time to initiation of behavioral estrus. The LH surge in estrogen-treated lambs occurred at $33 \mathrm{~h}$ after progesterone removal/ram introduction or $10 \mathrm{~h}$ after estrogen administration, comparable to the $14 \mathrm{~h}$ observed in ovariectomized ewes primed with progesterone for 7 days (Fabre-Nys and Martin, 1991). Therefore, estrogen administration may need to be delayed until 34 to $36 \mathrm{~h}$ after progesterone withdrawal to ensure similar timing of the start of the LH surge and initiation of estrous behavior in progesterone pre-treated lambs.

Only lambs pre-treated with progesterone expressed estrus, consistent with the requirement for a period of progesterone priming for the induction of estrus at ram introduction (Knights et al., 2000). While estrogen administration did not affect the time to onset of estrous behavior, administration increased the percentage of ewes displaying estrus. The lower estrous response in progesterone-primed lambs in the absence of estrogen may be due to the inability of the ram-induced increases in $\mathrm{LH}$ secretion to stimulate adequate secretion of estrogen in all lambs. This may explain the numerically lower percentages of lambs that ovulated or in which an LH surge was induced. The lower estrous response may also be related to a lower sensitivity to the increased concentrations of estrogen. Robinson (1955) observed a poor estrous response to equine chorionic gonadotropin in progesterone-primed yearlings during the anestrous period unless estrogen was administered. However, in adult ewes a similar requirement for estrogen was not observed.

Only lambs exposed to rams ovulated. Among ram-exposed groups the ovulatory response was lower in progesterone pre-treated lambs if estrogen was 
not also administered. The reason for this suppression in the ovulatory response is not clear. For example, follicles of progesterone pre-treated anestrous ewes show an increase in steroidogenesis (Khalid et al., 1997; Noël et al., 1999), hCG binding (Hunter and Southee, 1987) and, follicular development and ovulation rates in response to gonadotropins (Leyva et al., 1998). The interval from the onset of the LH surge to ovulation is $22-26 \mathrm{~h}$ in ewes (Cumming et al., 1973). Therefore, the delay in the start of the LH surge $(42 \mathrm{~h})$ in progesteronepretreated, ram-exposed ewe lambs might have resulted in ovulation being delayed beyond $60 \mathrm{~h}$ in some ewe lambs.

In conclusion, abrupt ram-introduction increased LH secretion, stimulated follicular development, and induced an LH surge and ovulation in fall born ewe lambs during seasonal anestrous. The poor response of fall-born ewe lambs to estrous induction protocols during seasonal anestrous is, therefore, not a result of failure of rams to induce the ram-effect response, but may be related to inadequate estrogen production or a reduced sensitivity to estrogen. 


\section{GENERAL DISCUSSION}

The first two experiments in this series evaluated the ability of pretreatment with progesterone delivered by new (experiment 1; $\mathrm{PCL}, 0.8 \mathrm{~g} \mathrm{P}_{4}$ ) or conventional (experiment 2; CIDR-G, $0.3 \mathrm{~g} \mathrm{P}_{4}$ ) intravaginal releasing devices to increase lambing rates in anestrous ewes beyond that in ewes introduced to rams only. A second objective of these studies was to evaluate the ability of a single injection of $\mathrm{FSH}$ to increase prolificacy in anestrous ewes. In experiment one, the new PCL insert did not release sufficient progesterone to elevate serum concentrations to within the range observed during the luteal phase of the estrous cycle (Haugher et al., 1977; Van Cleeff et al., 1988) or to that observed with CIDR devices in ovariectomized ewes (Carlson et al., 1989; Wheaton et al., 1993). Despite the low serum concentrations of progesterone, fertility at estrus was comparable to that observed when higher circulating concentrations of progesterone were achieved (Wheaton et al., 1993) or was expected to be achieved with the use of CIDR-G devices (experiment 2). In contrast, in cyclic ewes, the fertility at estrus synchronized with progestogens is positively correlated with the concentration of progestogen (Robinson et al., 1967; Allison and Robinson, 1968; Johnson et al., 1996). The observations in this study are consistent with those of other studies in which dosage of progestogen did not affect fertility of ewes bred during anestrus (Greyling et al., 1994; RodriguezIglesias et al., 1997). It is suggested that the threshold dosage of progestogen 
below which fertility is compromised is lower for induction of estrus in anestrous ewes than for synchronization of estrus during the breeding season.

In experiment 1 , it was established that a $5 \mathrm{~d}$ pre-treatment with the PCL insert was as effective as pre-treatment for $12 \mathrm{~d}$ for induction of fertile estrus in anestrous ewes. The effectiveness of short-term progesterone pre-treatment was confirmed in experiment 2 using CIDR devices. Increasing the duration of progesterone treatment from 6 to 12 days reduced the median effective dose of estrogen needed to induce estrus from 16 to $12 \mu \mathrm{g}$ estradiol benzoate in ovariectomized ewes (Robinson et al., 1956). Treatment of anestrous ewes with progestogens for 3 days or less resulted in a lower estrous response and conception rates (Dutt, 1953; Gordon, 1958; Ungerfeld and Rubianes, 1999). In contrast, increasing the duration of progestogen treatment from 8 to 14 (Powell et al., 1996), or 6 to 13 days (Ungerfeld and Rubianes, 1999) did not affect fertility. Therefore, a short-term pre-treatment with progesterone is effective for induction of fertile estrus in anestrous ewes.

In both experiments 1 and 2, progesterone pre-treatment resulted in 20 percent more ewes lambing than ram introduction alone. This is probably due to the ability of progesterone pre-treated ewes to express estrus at the first raminduced ovulation. Some anestrous ewes that ovulate in response to ram introduction loose their sensitivity to the ram stimulus prior to the end of the first normal luteal phase (Oldham and Fisher, 1992). These ewes will not have a ram-induced follicular phase with synchronous estrus and ovulation and as such will not be bred. Progesterone pre-treatment of anestrous ewes allowed estrus 
to occur with the first ram-induced ovulation and therefore increased the opportunity for mating and conception.

Follicle stimulating hormone tended to increase prolificacy to the first service period compared to that observed in ewes pre-treated with progesterone only, and increased (experiment 1) or tended to increase (experiment 2) prolificacy over that observed in control ewes and all ewes conceiving to the second service period. The follicles of anestrous ewes show a reduced responsiveness to gonadotropins (Bister et al., 1999; Noel et al., 1999), but responsiveness may be improved by progesterone pre-treatment (Hunter and Southee, 1987; Khalid et al., 1997; Leyva et al., 1998). Further, the ovulation rate at the first ram-induced ovulation was higher than that observed in ewes spontaneously ovulating during the period of seasonal anestrous (Cognie et al., 1980; Pearce and Oldham, 1984). These observations may explain the failure of FSH to increase prolificacy significantly in progesterone-pre-treated ewes at the first service period.

The fertility of fall-born ewe lambs during seasonal anestrous was lower (11\%) than that observed in second lambing ewes (45\%) or for adults $(59 \%$; AlShorepy and Notter, 1996). In the third experiment, it was observed that this lower fertility was not due to failure of ram introduction to induce a "ram effect" response in fall-born ewe lambs. Ram introduction induced increased follicular development, increased LH pulse frequency, and induced an LH surge and ovulation in fall-born ewe lambs in early July. Previous reports on fall- (LopezSebastian et al., 1985b) and spring- (Al-Mauly et al., 1991) born lambs 
suggested that the ability to respond to ram introduction was associated with the attainment of puberty in control flock mates. In experiment 3 , the ram effect was observed in early July at least 2 months before expected commencement of puberty in fall born ewe lambs (Lopez-Sebastian et al., 1985b; Vesely and Swiersta, 1987; Forcada et al., 1991). If the ability to respond to ram introduction is an indicator of attainment of sexual competence (Al-Mauly et al., 1991), then the expression rather than the development of sexual competence is inhibited during seasonal anestrus in fall-born ewe lambs.

Progesterone pre-treatment before ram introduction resulted in the expression of estrus in only $45 \%$ of lambs. A small dosage of estrogen significantly increased the estrous response by more than 40 percentage points. A low estrous response was observed in progesterone primed-eCG treated yearling ewes unless estrogen also was applied; however, in adult ewes treatment with estrogen was not required. The lower estrous response in the absence of exogenous administration of estrogen may be due to the inability of the ram-induced increases in $\mathrm{LH}$ secretion to stimulate adequate secretion of estrogen, or due to a lower sensitivity to the increased concentrations of estrogen. 


\section{LITERATURE CITED}

Abdennebi, L., Monget, P., Pisselet, C., Remy, J. J., Salesse, R., and Monniaux, D. 1999. Comparative expression of luteinizing hormone and follicle stimulating hormone receptors in ovarian follicles from high and low prolific sheep breeds. Biol.Reprod. 60, 845-854.

Ahmad, N., Lewis, P. E., Walker, C. Z., Alt, F. L., and Inskeep, E. K. 1996. FSH in Propylene Glycol on Ovulation Rate and Prolificacy in Anestrous Ewes. J.Anim.Sci. 74[Suppl. 1], 212.

Ainsworth, L., Hackett, A. J., Heaney, D. P., Langford, G. A., and Peters, H. F. 1977. A Multidisciplinary Approach to the development of Controlled Breeding and Intensive Production Systems for Sheep. 101-108. Management of reproduction in Sheep and Goats Symposium. The University of Wisconsin, Madison.

Ainsworth, L., and Downey, B. R. 1986. A Controlled Internal Drug-Release Dispenser Containing Progesterone for Control of the Estrous Cycle of Ewes. Theriogenology 26[6], 847-857.

Ainsworth, L., and Shrestha, J. N. B. 1987. The reproductive performance of ewe lambs in a controlled environment. Anim.Prod. 44, 233-240.

Ainsworth, L., Heaney, D. P., and Shrestha, J. N. B. 1991. Age at puberty, fertility and litter size of ewe lambs reared under different photoregimens.

Theriogenology 36, 401-409.

Al-Mauly, N. Z. N., Bryant, M. J., and Cunningham, F. J. 1991. Effect of introduction of rams on the pulsatile release of luteinizing hormone and the onset of reproductive activity in the ewe. Anim.Prod. 53, 209-214.

al-Shorepy, S. A and Notter, D. R. 1997. Response to selection for fertility in a fall-lambing sheep flock. J.Anim.Sci. 75, 2033-2040.

Alifakiotis, T., Michailidis, I., and Gavrilidis, G. 1982. Induced Breeding in Anestrous Milking ewes of Dairy Breeds: Comparisons of Norgestomet, Medroxyprogesterone and Fluorogestone in Two Regimes of PMSG. Theriogenology 17[6], 603-610.

Allison, A. J., and Robinson, T. J. 1970. The Effect of Dose Level of Intravaginal Progestagen on Sperm Transport, Fertilization and Lambing in The Cyclic Merino Ewe. J.Reprod.Fertil. 22, 515-531. 
Atkinson, S., and Williamson, P. 1985. Ram-induced growth of ovarian follicles and gonadotrophin inhibition in anoestrous ewes. J.Reprod.Fertil. 73, 185189.

Baird, D. T. and Scaramuzzi, R. J. 1976. Changes in the secretion of ovarian steroid and pituitary luteinizing hormone in the peri-ovulatory period in the ewe: the effect of progesterone. J.Endocrinol. 70, 237-245.

Barnes, D. R. 1987. CIDR dispensers-ewe and hogget plasma progesterone levels during the insertion period. 4, 228. Proc. $4^{\text {th }}$ Asian/Aust. Assoc. Anim. Prod., Soc.

Barrell, G. K., Moenter, S. M., Caraty, A., and Karsch, F. J. 1992. Seasonal changes of gonadotropin-releasing hormone secretion in the ewe. Biol.Reprod. 46, 1130-1135.

Bartlewski, P. M., Beard, A. P., and Rawlings, N. C. 1998. Ovarian follicular dynamics during anoestrus in ewes. J.Reprod.Fertil. 113, 275-285.

Bartlewski, P. M., Beard, A. P., and Rawlings, N. C. 1999a. Ovarian Function in Ewes During the Transition From Breeding Season to Anestrous. Anim.Reprod.Sci. 57, 51-66.

Bartlewski, P. M., Beard, A. P., and Rawlings, N. C. 1999b. Ovarian Function in Ewes at the Onset of the Breeding Season. Anim.Reprod.Sci. 57, 67-88.

Bartlewski, P. M., Vanderpol, J., Beard, A. P., Cook, S. J., and Rawlings, N. C. 2000. Ovarian antral follicular dynamics and their associations with peripheral concentrations of gonadotropins and ovarian steroids in anoestrous Finnish Landrace ewes. Anim.Reprod.Sci. 58, 273-291.

Bell, A. W., Wilkening, R. B., and Meschia, G. 1987. Some aspects of placental function in chronically heat-stressed ewes. J.Dev.Physiol. 9, 17-29.

Bell, A. W., McBride, B. W., Slepetis, R., Early, R. J., and Currie, W. B. 1989. Chronic Heat Stress and Prenatal Development in Sheep: I. Conceptus Growth and Maternal Plasma Hormones and Metabolites. J.Anim.Sci. 67, 3289-3299.

Bell, T. D., Casida, L. E., Bohstedt, G., and Darlow, A. E. 1941. J.Agric.Res. 62, 573.

Berardinelli, J. G. 1979. Factors involved in the attainment of puberty in female domestic ruminants. Ph.D. Dissertation, -137 pp. West Virginia University. 
Bister, J.-L. and Paquay, R. 1983. Fluctuations in the plasma level of the folliclestimulating hormone during oestrus cycle, anestrus, gestation and lactation in the ewe. Evidence for an endogenous rhythm of $\mathrm{FSH}$ release. Theriogenology 19, 565-582.

Bister, J.-L., Noël, B., Perrad, B., Mandinki, S. N. M., Mbayahaga, J., and Paquay, R. 1999. Control of Ovarian Follicles Activity in the Ewe. Domestic Animal Endocrinology 17, 315-328.

Bittman, E. L., Karsch, F. J., Hopkins, J. W. 1983. Role of the pineal gland in ovine photoperiodism: regulation of seasonal breeding and negative feedback effects of estradiol upon luteinizing hormone secretion. Endocrinology 113:329-336.

Boland, M. P., Kelleher, D., and Gordon, I. 1978/79. Comparison of control of oestrus and ovulation in sheep by an ear implant (SC-21009) or by intravaginal sponge (Cronolone or MAP). Anim.Reprod.Sci. 1, 275-281.

Boland, M. P., Crosby, T. F., and Gordon, I. 1981. Effect of Mating Management and PMSG Dose on Lambing Outcome in Ewes bred in Late Anoestrous. J.Agric.Sci. 97, 445-446.

Boland, M. P. and Crosby, T. F. 1993. Fecundin: An immunological approach to enhance fertility. Theriogenology 33, 143-158.

Bolet, G. 1986. Timing and extent of embryonic mortality in pigs, sheep and goats:genetic variability. Current Topics Vet.Med. 34, 12-43.

Boulton, M. I., Haley, C. S., Springbett, A. J., and Webb, R. 1995. The effect of the Booroola (FecB) gene on peripheral FSH concentrations and ovulation rates during oestrus, seasonal anoestrus and on FSH concentrations following ovariectomy in Scottish Blackface ewes. J.Reprod.Fertil. 103, 199-207.

Bryant, M. J., and T. Tomkins. 1975. The Flock Mating of ProgestagenSynchronised Ewes. 1. The Influence of Ram to Ewe Ratio Upon Mating Behaviour and Lambing Performance. Anim.Prod. 20, 381-390.

Burfening, P. J., and Van Horn, J. L. 1970. Induction of fertile oestrus in prepubertal ewes during the anoestrous season. J.Reprod.Fertil. 23, 147150.

Burrell, C., Wiltbank, J. N., LeFever, D. G., and Rodeffer, G. 1972. Ear implant (SC-210009) for estrous control in heifers. J.Anim.Sci. 34[5], 915-916.

Cahill, L. P. 1981. Folliculogenesis in the sheep as influenced by breed, season and oestrous cycle. J.Reprod.Fertil. 30[Suppl.], 135-142. 
Cahill, L. P. 1984. Folliculogenesis and ovulation rate in sheep. Lindsay, D. R. and Pearce, D. T. Reproduction in Sheep. 92-98. Canberra, Australian Academy of Science.

Caraty, A., and Skinner, D. C. 1999. Progesterone priming is essential for the full expression of the positive feedback effect of estradiol in inducing the preovulatory gonadotropin releasing hormone surge in the ewe. Endocrinology 140, 165-170.

Carlson, K. M., Pohl, H. A., Marcek, J. M., Muser, R. K., and Wheaton, J. E. 1989. Evaluation of Progesterone Controlled Internal Drug Release Dispensers for Synchronization of Estrus in Sheep. Animal Reproduction Science 18, 205-218.

Carpenter, R. H. and Spitzer, J. C. 1981. Response of Anestrous Ewes to Norgestomet and PMSG. Theriogenology 15[4], 389-393.

Chamley, W. A., Buckmaster, J. M., Cain, M. D., Cerini, J., Cerini, M. E., and Cumming, I. A. 1972. The effect of prostaglandin $F_{2 \alpha}$ on progesterone, oestradiol and luteinizing hormone in sheep with ovarian transplants. J.Endocrinol. 55, 253-263.

Christenson, R. K. 1976. Effect of Short-term Progestogen Treatment on Induction of Estrus and Lambing in Anestrous Ewes. Journal of Animal Science 43, 795-801.

Clarke, I. J., and Cummins, J. T. 1982. The temporal relationship between gonadotropin releasing hormone $(\mathrm{GnRH})$ and luteinizing hormone $(\mathrm{LH})$ secretion in ovariectomized ewes. Endocrinology 111, 1737-1739.

Cognie, Y., Gayerie, F., Oldham, C. M., and Poindron, P. 1980. Increased ovulation rate at the ram-induced ovulation and its commercial application. Proc.Aust.Soc.Anim.Prod. 13, 80-81.

Cognie, Y., Gray, S. J., Lindsay, D. R., Oldham, C. L., and Pearce, D. T. 1982. A new approach to controlled breeding in sheep using the "ram effect". 14, 519-522. Proc. Aust. Soc. Anim. Prod.

Cognie.Y. 1990. Current technologies for synchronisation and artificial insemination of sheep. C.M.Oldham, G.B.Martin, and I.W.Purvis. Reproductive Physiology of Merino Sheep: Concept and Consequences. 207-216. School of Agriculture (Animal Science), The University of western Australia, Nedlands, Perth.

Cohen-Tannoudji, J., Locatelli, A., and Signoret, J. P. 1986. Non-pheremonal stimulation by the male of $\mathrm{LH}$ release in the anestrous ewe.

Physiol.Behav. 36, 921-924. 
Cohen-Tannoudji, J., Lavenet, C., Locatelli, A., Tillet, Y., and Signoret, J. P. 1989. Non-involvement of the accessory olfactory system in the $\mathrm{LH}$ response of anoestrous ewes to male odour. J.Reprod.Fertil. 86, 135-144.

Cole, H. H. and Miller, R. F. 1933. Amer.J.Physiol. 104, 165-171.

Cole, H. H. and Miller, R. F. 1935. Changes in the reproductive organs of the ewe with some data on their control. Am.J.Anat. 57, 39-97.

Coop, I. E. 1966. Effect of flushing on reproductive performance of ewes. J.Agric.Sci. 67, 305-323.

Cooper, D. A., Carver, P., Villeneuve, P., Silvia, W. J., and Inskeep, E. K. 1991. Effects of progestogen treatment on concentrations of prostaglandins and oxytocin in plasma from the posterior vena cava of post-partum beef cows. J.Reprod.Fertil. 91, 411-421.

Crighton, D. B., Foster, J. P., Haresign, W., and Scott, S. A. 1975. Plasma LH and progesterone levels after single or multiple injections of synthetic $\mathrm{LH}$ $\mathrm{RH}$ in anetrous ewes and comparison with levels during the oestrous cycle. J.Reprod.Fertil. 44, 121-124.

Crosby, T. F., Boland, M. P., and Gordon, I. 1991. Effect of Progestagen Treatments on the Incidence of Oestrous and Pregnancy Rates in Ewes. Anim.Reprod.Sci. 24, 109-118.

Cumming, I. A., Buckmaster, J. M., Blockey, M. A. deB., Goding, J. R., Winfield, C. G., and Baxter, R. W. 1973. Constancy of interval between luteinizing hormone release and ovulation in the ewe. Biol.Reprod. 9, 24-29.

Cunningham, N. F., Saba, N., Boarer, C. D. H., and Hattersely, J. J. P. 1980. Plasma Hormone Levels and Reproductive Behaviour in Anestrous Ewes after Treatment with Progesterone and PMSG. J.Reprod.Fertil. 60, 177185.

Dermody, W. C., Foote, W. C., and Hulet, C. V. 1970. Effects of season and progesterone synchronization on ovulation rate in mature western range ewes. J.Anim.Sci. 30, 214-218.

Dufour, J. J., Ginther, O. J., and Casida, L. E. 1972. Intraovarian Relationship Between Corpora Lutea and Ovarian Follicles in Ewes. Am.J.Vet.Res. 33, 1445-1451.

Dunn, R. B., Ahmed, W., and Morrant, A. J. 1960. Annual reproductive rhythm in Merino sheep related to the choice of mating time at Trangie, Central Western New South Wales. Aust.J.Agric.Res. 11, 805-825. 
Dutt, R. H. 1953. Induction of Estrus and Ovulation in Anestrual Ewes by use of Progesterone and Pregnant Mare Serum. Journal of Animal Science 12, 515-523.

Dutt, R. H., and Casida, L. E. 1948. Alteration of the Estrual Cycle in Sheep by Use of Progesterone and its Effects upon Subsequent Ovulation and Fertility. Endocrinology 43, 208-217.

Dýrmundsson, O. R. and Lees, J. L. 1972. Attainment of Puberty and reproductive performance in Clun Forest ewe lambs. J.Agric.Sci. 78, 3945.

Dýrmundsson, O. R. 1973. Puberty and early reproductive performance in sheep. I. Ewe Lambs. Anim.Abstr. 41, 273-289.

Early, R. J., McBride, B. W., Vatnick, I., and Bell, A. W. 1991. Chronic Heat Stress and Prenatal Development in Sheep: II. Placental cellularity and Metabolism. J.Anim.Sci. 69, 3610-3616.

Ebling, F. J. P., and Foster, D. L. 1988. Phtoperiod requirements for puberty differ from those for the onset of the adult breeding season in female sheep. J.Reprod.Fertil. 84, 283-293.

Edgar, D. G., and Bilkey, D. A. 1963. The influence of rams on the onset of the breeding season in ewes. Proc.New Zealand Soc.Anim.Prod. 23, 79-85.

Estienne, M. J., Schillo, K. K., Green, M. A., and Boling, J. A. 1989. Free fatty acids suppress growth hormone, but not luteinizing hormone, secretion in sheep. Endocrinology 125, 85-91.

Evans, J. S., Dutt, R. H., and Simpson, E. C. 1962. Breeding Performance in Ewes after Synchronizing Estrus by Feeding 6-methyl-17acetoxyprogesterone. Journal of Animal Science 21, 804-808.

Fabre-Nys, C., and Martin, G. B. 1991. Roles of progesterone and oestradiol in determining the temporal sequence and quantitative expression of sexual receptivity and the preovulatory LH surge in the ewe. J.Endocrinol. 130, 367-379.

Findlay, J. K., and Cumming, I. A. 1976. FSH in the ewe: Effects of season, live weight and plane of nutrition on plasma FSH and ovulation rate. Biol.Reprod. 15, 335-342.

Findlay, J. K., Doughton, B. W., Tsonis, C. G., Brown, R. W., Hungerford, J. W., Greenwood, P. E., and Forage, R. G. 1993. Inhibin as a fecundity vaccine. Theriogenology 33, 325-344. 
Fitzgerald, J. and Butler, W. R. 1982. Seasonal effects and hormonal patterns related to puberty in ewe lambs. Biol.Reprod. 27, 853-863.

Fitzgerald, J. 1992. Ram variation-An overlooked effect. 25-32. lowa State University, lowa State University extension. Out of Season Breeding Symposium.

Fitzgerald, J. A., and Stellflug, J. N. 1991. Effects of Melatonin on Seasonal Changes in reproduction of Rams. J.Anim.Sci. 69, 264-275.

Fletcher, I. C., Geytenbeek, P. E., and Allden, W. G. 1970. Interaction between the effects of nutrition and season of mating on reproductive performance in crossbred ewes. Aust.J.Exp.Agric.Anim.Husb. 10, 393-396.

Fletcher, I. C. 1971. Effects of nutrition, liveweight and season on the incidence of tein ovulation in South Australian Strong-Wool Merino ewes. Aust.J.Agric.Res. 22, 321-330.

Flores, J. A., Véliz, F. G., Pérez-Villanueva, J. A., Martínez de la Escalera, G., Chemineau, P., Poindron, P, Malpaux, B., and Delgadillo, J. A. 2000. Male reproductive condition is the limiting factor of efficiency in the male effect during seasonal anestrus in female goats. Biol.Reprod. 62, 1409-1414.

Fogarty, N. M., Hall, D. G., Dawe, S. T., Atkinson, W., and Allan, C. 1992. Management of high fecund ewe types and their lambs for 8-monthly lambing 1. Effect of lamb weaning age on ewe reproductive activity in spring. Aust.J.Exp.Agric. 34.

Foote, W. C. 1968. Control of Reproduction with or without Hormones. 104-129. Stillwater, Oklahoma, Oklahoma State Univ. . Proc. Symp. Physiology of reproduction in Sheep.

Forcada, F., Abecia, J. A., and Zarazaga, L. 1991. A note on the attainment of puberty of september-born early maturing ewe lambs in relation to level of nutrition. Anim.Prod. 53, 407-409.

Foster, D. L. 1981. Mechanisms for the delay in first ovulation in lambs born in the wrong season (fall). Biol.Reprod. 25, 85-92.

Foster, D. L., and Ryan, K. D. 1979. Mechanisms governing the onset of ovarian cyclicity at puberty in the lamb. Ann. Biol. Anim. Bioch. Biophys. 19:1369.

Foster, D. L., and Ryan, K. D. 1981. Endocrine mechanisms governing transition into adulthood in female sheep. J.Reprod.Fertil. 30[Suppl.], 75-90.

Foster, D. L., Ebling, F. J. P., and Claypool, L. E. 1988. Timing of puberty by photoperiod. Reprod.Nutr.Dev. 28, 349-364. 
Fry, R. C., Cahill, L. P., Cummins, J. T., Bindon, B. M., Piper, L. R., and Clarke, I. J. 1987. The Half-life of Follicle-Stimulating Hormone in Ovary Intact and Ovariectomized Booroola and Control Merino Ewes. J.Reprod.Fertil. 81, 611-615.

Fulkerson, W. J., Adams, N. R., and Gherardi, P. B. 1981. Ability of castrate male sheep treated with oestrogen or testosterone to induce and detect oestrus in ewes. Appl.Anim. Ethol. 7, 57-66.

Geytenbeek, P. E. and Oldham, C. M. 1984. The induction of ovulation in the postpartum ewe. Proc.Aust.Soc.Anim.Prod. 15, 353-356.

Gherardi, P. B. and Lindsay, D. R. 1980. The effect of season on the ovulatory response of Merino ewes to serum from pregnant mares. J.Reprod.Fertil. $60,425-429$.

Gill, J. L., and Hafs, H. D. 1971. Analyses of Repeated Measures of Animals. J.Anim.Sci. 33, 331-336.

Gitzen, J. F., and Ramierez, V. D. 1986. PC-Pulsar: Pulsar for the IBM-PC Operating Instructions. Urbana, Illinois, Neural and Behavioral Biology Program and Department of Physiology and Biophysics, University of Illinois.

Goding, J. R., Catt, K. J., Brown, J. M., Kaltenbach, C. C., Cumming, I. A., and Mole, B. J. 1969. Radioimmunoassay for ovine luteinizing hormone. Secretion of luteinizing hormone during estrus and following estrogen administration. Endocrinology 85, 133-142.

Goodman, R. L., Bittman, E. L., Foster, D. L., and Karsch, F. J. 1982. Alterations in the control of luteinizing hormone pulse frequency underlie the seasonal variation in estradiol negative feedback in the ewe. Biol.Reprod. 27, 580589.

Goodman, R. L., and Meyer, S. L. 1984. Effects of pentobarbital anesthesia on tonic luteinizing hormone secretion in the ewe: evidence for active inhibition of luteinizinh hormone in anestrus. Biol.Reprod. 30, 374-381.

Goodman, R. L. 1994. Neuroendocrine control of the ovine estrous cycle. Knobil, E. and Neill, J. D. The Physiology of Reproduction. 2nd[47], 659-709. New York, Raven Press.

Gordon, I. 1958. The use of progesterone and serum gonadotrophin (P.M.S.) in the control of fertility in the sheep II. Studies in the extra-seasonal production of lambs. J.Agric.Sci. 50, 152-197. 
Gordon, I. 1963b. The induction of pregnancy in the anoestrous ewe by hormonal therapy. II. Progesterone-pregnant mare's serum applications in anoestrus. J.Agric.Sci. 60, 43-66.

Gordon, I. 1963c. The induction of pregnancy in the anoestrous ewe by hormonal therapy. III. the use of repeated progesterone-pregnant mare's serum therapy. J.Agric.Sci. 60, 67-70.

Gordon, I. 1963d. The induction of pregnancy in the anoestrous ewe by hormonal therapy. IV. Simplification of hormone procedures. J.Agric.Sci. 60, 71-75.

Gordon, I. 1963e. The induction of pregnancy in the anoestrous ewe by hormonal therapy. V. Progesterone-pregnant mare's serum therapy on Clun forest maiden sheep and general conclusions. J.Agric.Sci. 60, 77-85.

Gordon, I., and Keane, M. G. 1967. Hormonal induction of early breeding in sheep. Ir.Vet.J. 21, 122.

Gordon, I. 1971. Induction of Early Breeding in Sheep by Standard and Modified Progestagen-PMS Treatments. J.Agric.Sci. 76, 337-341.

Gordon, I. 1975. Hormonal Control of Reproduction in the Sheep. Proc.Br.Soc.Anim.Prod. 4, 79-93.

Gordon, I. 1977. Application of synchronization of estrus and ovulation in sheep. Terrill, E. 15-30. Madison Wisconsin, University of Wisconsin. Management of reproduction in sheep and goats symposium.

Greyling, J. P. C., and Brink, W. C. J. 1987. Synchronization of Oestrus in Sheep: The use of Controlled Internal Drug release (CIDR) Dispensers. S.Afr.J.Anim.Sci. 17[3], 128-132.

Greyling, J. P. C., Kotzé, W. F., Taylor, G. J., and Hagendijk, W. J. 1994. Synchronization of oestrus in sheep: Use of different doses of progestagen outside the normal breeding season. S.Afr.J.Anim.Sci. 24, 33-37.

Hackett, A. J. 1982. Effect of Dose of Pregnant Mares', Serum Gonadotrophin on the Reproductive Performance of Ewes Synchronized for Estrus and Housed in Total Confinement. Can.J.of Anim.Sci. 62, 291-294.

Hafez, E. S. E. 1952. Reproduction of the ewe. J.Agric.Sci. 42, 189-265.

Hall, D. G., Forgarty, N. M., and Gilmour, A. R. 1986. Seasonality of Ovulation and Estrus, and the Ram Effect in Poll Dorset Ewes. Theriogenology 25[3], 455-461. 
Hammond, J. Jr., Hammond, J., and Parkes, A. S. 1942. Hormonal augmentation of fertility in sheep I. Induction of ovulation, superovulation and heat in sheep. J.Agric.Sci. 32, 308-323.

Hamra, A. H., Massri, Y. G., Marcek, J. M., and Wheaton, J. E. 1986. Plasma Progesterone Levels in Ewes Treated with Progesterone-Controlled Internal Drug-Release Dispensers, Implants and sponges. Animal Reproduction Science 11, 187-194.

Hamra, A. H., McNally, J. W., Marcek, J. M., Carlson, K. M., and Wheaton, J. E. 1989. Comparison of Progesterone Sponges, Cronolone Sponges and Controlled Internal Drug Release Dispensers on Fertility in Anestrous Ewes. Animal Reproduction Science 18, 219-226.

Hanrahan, J. P. 1980. Ovulation rate as the selection criterion for litter size in sheep. Proc.Aust.Soc.Anim.Prod. 13, 405-408.

Haresign, W., Foster, J. P., Haynes, N. B., Crighton, D. B., and Lamming, G. E. 1975. Progesterone levels following treatment of seasonally anoestrous ewes with synthetic LH-releasing hormone. J.Reprod.Fertil. 43, 269-279.

Harvern, R. L., Whisnant, C. S., and Goodman, R. L. 1994. Dopaminergic structures in the ovine hypothalamus mediating estradiol negative feedback in anestrous ewes. Endocrinology 134, 1905-1914.

Haugher, R. L., Karsch, F. J., and Foster, D. L. 1977. A New Concept for Control of the Estrous Cycle of the Ewe Based on the Temporal Relationships Between Luteinizing Hormone, Estradiol and Progesterone in Peripheral Serum and Evidence that Progesterone Inhibits Tonic LH Secretion. Endocrinology 101[3], 807-817.

Havern, R. L., Whisnant, C. S., and Goodman, R. L. 1994. Dopaminergic structures in the ovine hypothalamus mediating estradiol negative feedback in anestrous ewes. Endocrinology 134, 1905-1914.

Hawk, H. W., and Conley, H. H. 1971. Loss of spermatozoa from the reproductive tract of the ewe and intensification of sperm breakage by progestagen. J.Reprod.Fertil. 27, 339-347.

Hogue, D. E., Hansel, Wm, and Bratton, R. W. 1962. Fertility of ewes bred naturally and artificially after estrous cycle synchronization with an oral progestational agent. J.Anim.Sci. 21, 625-627.

Hoskinson, R. M., Scaramuzzi, R. J., Downing, J. A., Hinks, N. T., and Turnbull, K. E. 1982. Observations of oestrus and ovulation in ewes actively immunized against progesterone. Proc.Aust.Soc.Reprod.Biol. 14, 92. 
Hu, Y., Nephew, K. P., Pope, W. F., and Day, M. L. 1991. Uterine influences on the formation of subnormal corpora lutea in seasonally anestrous ewes. J.Anim.Sci. 69, 2532-2537.

Huffman, L. J., Inskeep, E. K., and Goodman, R.L. 1987. Changes in episodic luteinizing hormone secretion leading to puberty in the lamb. Biol. Reprod. 37: 755-761.

Hulet, C. V., Voightlander, H. P., Pope, A. L., and Casida, L. E. 1956. The Nature of Early-Season Infertility in Sheep. J.Anim.Sci. 15, 607-616.

Hulet, C. V., Ercanbrack, S. K., Price, D. A., Blackwell, R. L., and Wilson, L. O. 1962. Mating Behaviour of the Ram in the One-Sire Pen. J.Anim.Sci. 21, 857-869.

Hulet, C. V., Shelton, M., Gallagher, J. R., and Price, D. A. 1974. Effects of origin and environment on reproductive phenomena in Rambouillet ewes. I. Breeding season and ovulation. J.Anim.Sci. 38, 1210-1217.

Hulet, C. V. 1977. Management of reproduction in sheep. Terrill, C. E. 119-133. Madison, Wisconsin, Sheep Industry Development Program. Management of Reproduction in Sheep and Goats Symposium.

Hunter, M. G., Southee, J. A., McLeod, B. J., and Haresign, W. 1986. Progesterone Pretreatment has a direct Effect on GnRH-Induced Preovulatory Follicles to Determine their ability to Develop into Normal Corpora Lutea in Anoestrous Ewes. J.Reprod.Fertil. 76, 349-363.

Hunter, M. G., and Southee, J. A. 1987. Treatment with Progesterone Affects Follicular Steroidogenesis in Anoestrous Ewes. Anim.Reprod.Sci. 273279.

Hunter, M. G., Southee, J. A., and Lamming, G. E. 1988. Function of Abnormal Corpora Lutea in vitro after $\mathrm{GnRH}$-induced Ovulation in the Anestrous Ewe. J.Reprod.Fertil. 84[1], 139-148.

Hunter, M. G., Ayad, V. J., Gilbert, C. L., Southee, J. A., and Wathes, D. C. 1989. Role of prostaglandin $\mathrm{F}_{2 \alpha}$ and oxytocin in the regression of $\mathrm{GnRH}$-induced abnormal corpora lutea in anestrous ewes. J.Reprod.Fertil. 85, 551-561.

Husein, M. Q., Bailey, M. T., Ababneh, M. M., Romano, J. E., Crabo, B. G., and Wheaton, J. E. 1998. Effect of eCG on the pregnancy rate of ewes transervically inseminated with frozen-thawed semen outside the breeding season. Theriogenology 49, 997-1005. 
Inskeep, E. K., Lewis, P. E., Stilley, N., Mulledy, R., and Dinsmore, H. 1983. Synchronizarion of Estrus As a Management Tool in the Ewe Flock. WV, USA, WV Agricultural and Forestry Experiment Station, College of Agriculture and Forestry. 1983.

Jabbar, G., Umberger, S. H., and Lewis, G. S. 1994. Melengestrol Acetate and Norgestomet for the induction of synchronized estrus in seasonally anovular ewes. Journal of Animal Science 72, 3049-3054.

Jennings, J. J., and McWeeney, J. 1976. Effect of Frequent Ejaculation on Semen Characteristics in Rams. Vet.Rec. 98[12], 230-233.

Johnson, S. K., Dailey, R. A., and Inskeep, E. K. 1996. Effect of Peripheral Concentrations of Progesterone on Follicular Grpwth and Fertility in Ewes. Domestic Animal Endocrinology 13[1], 69-79.

Kammlade, Jr. W. G., Welch, J. A., Nablandov, A. V., and Norton, H. W. 1952. Pituitary activity of sheep in relation to the breeding season. J.Anim.Sci. 11, 646-655.

Karsch, F. J., Foster, D. L., Legan, S. J., Ryan, K. D., and Peter, G. K. 1979. Control of the preovulatory endocrine events in the ewe: interrelationship of estradiol, progesterone, and luteinizing hormone. Endocrinology 105, 421-426.

Karsch, F. J., Goodman, R. L., and Legan, S. J. 1980a. Feedback basis of seasonal breeding: Test of an hypothesis. J.Reprod.Fertil. 58, 521-535.

Karsch, F. J., Legan, S. J., Ryan, K. D., and Foster, D. L. 1980b. Importance of estradiol and progesterone in regulating $\mathrm{LH}$ secretion and estrous behavior during the sheep estrous cycle. Biol.Reprod. 23, 404-413.

Karsch, F. J., Bittman, E. L., Foster, D. L., Goodman, R. L., Legan, S. J., and Robinson, J. E. 1984. Neuroendocrine basis of seasonal reproduction. Recent Prog.Hor.Res. 40, 185-225.

Keefe, G. P., and Wichtel, J. J. 2000. Evaluation of melengestrol acetate and equine chorionic gonadotropin for out-of-season breeding in sheep on Prince Edward Island. Can.Vet.J. 41[3], 211-214.

Keisler, D.H. 1983. Sexual maturation in ewe lambs. Ph.D. Dissertation, -137 pp. West Virginia University.

Keisler, D. H. 1992. Use of Melengestrol Acetate (MGA) Based Treatments to Induce and Synchronize Ewes Out of Season. 98-108. Ames, lowa, lowa State University of Science and Technology, University Extension. Out-ofSeason Breeding Symposium. 
Keisler, D.H., Inskeep, E.K., and Dailey, R.D. 1983. First luteal tissue in ewe lambs: Influence on subsequent ovarian activity and response to hysterectomy. J. Anim. Sci. 57: 150-156.

Kennaway, D. J., Dunstan, E. A., and Staples, L. D. 1987. Photoperiodic control of the onset of breeding activity and fecundity in ewes. J.Reprod.Fertil. 34[(Suppl.)], 187-199.

Kessel, B., Liu, Y. X., Jia, X. C., and Hseuh, A. J. 1985. Autocrine role of estrogens in the augmentation of luteinizing hormone receptor formation in cultured rat granulosa cells. Biol.Reprod. 32, 1038-1050.

Khalid, M., Basiouni, G. F., and Haresign, W. 1997. Effect of Progesterone Pretreatment on Steroid Secretion Rates and Follicular Fluid Insulin-like Growth Factor-1 Concentrations in Seasonally anoestrous Ewes Treated With Gonadotrophin Releasing Hormone. Anim.Reprod.Sci. 46[1,2], 6978.

Kimberling, C. V., and Hastings, N. E. 1991. "Ram breeding soundness evaluation (BSE)". 258-274. Hastings, NE. Proc. Soc. Theriogenology.

Knight, T. W., Oldham, C. M., and Lindsay, D. R. 1975. Studies in ovine infertility in agricultural regions in Western Australia: The influence of a supplement of lupins (Lupinus angustifolius cv Uniwhite) at joining on the reproductive performance of ewes. Aust.J.Agric.Res. 26, 567-575.

Knight, T. W., and Lynch, P. R. 1980. The source of ram pheremones that stimulate ovulation in the ewe. Anim.Reprod.Sci. 3, 133-139.

Knight, T. W., Peterson, A. J., and Payne, E. 1978. The ovarian and hormonal response of the ewe to stimulation by the ram early in the breeding season. Theriogenology 10, 343-348.

Knights, M., Hoehn, T., Lewis, P. E., and Inskeep, E. K. 2000. Effectiveness of intravaginal progesterone inserts and $\mathrm{FSH}$ to induce synchronized estrus and increase lambing rate in anestrous ewes. J.Anim.Sci. 78[(Suppl 2) \# 216], 79.

Lamond, D. R. 1964. Anim.Breed.Abstr. 32, 269-285.

Land, R. B., Pelletier, J., Thimonier, J., and Mauléon, P. 1973. A quantitative study of genetic differences in the incidence of oestrus, ovulation and plasma luteinizing hormone concentration in sheep. J.Endocrinol. 58, 305315.

Land, R. B. 1978. Reproduction in young sheep: Some genetic and environmental sources of variation. J.Reprod.Fertil. 52, 427-436. 
Langford, G. A., Marcus, G. J., and Batra, T. R. 1983. Seasonal effects of PMSG and number of inseminations on fertility of progestogen-treated sheep. J.Anim.Sci. 57[2], 307-312.

Lassoued, N., Khaldi, G., Chemineau, P., Cognie, Y., and Thimonier, J. 1997. Role of the uterus in early regression of corpora lutea induced by the ram effect in seasonally anoestrous Barbarine ewes. Reprod.Nutr.Dev. 37, $559-571$.

Laster, D. B. 1973. Ovulation, fertility and prenatal mortality in heifers treated with PMSG or porcine FSH. J.Reprod.Fertil. 33, 275-282.

Legan, S. J., Karsch, F. J., and Foster, D. L. 1977. The endocrine control of seasonal reproductive function in the ewe: A marked change in response to the negative feedback action of estadiol on luteinizing hormone secretion. Endocrinology 101, 818-824.

Legan, S. J., and Karsch, F. J. 1980. Photoperiodic control of seasonal breeding in ewes: Modulation of the negative feedback action of estradiol. Biol.Reprod. 23, 1061-1068.

Legan, S. J., and Karsch, F. J. 1983. Importance of retinal photoreceptors to the photoperiodic control of seasonal breeding in the ewe. Biol Reprod. 1983 29:316-25.

Legan, S. J., and Winans, S. S. 1981. The photoneuroendocrine control of seasonal breeding in the ewe. Gen.Comp.Endocrinol. 45, 317-328.

Legan, S. J., Goodman, R. L., Ryan, K. D., Foster, D. L., and Karsch, F. J. 1985. Can the transition into anoestrus in the ewe be accounted for solely by insufficient tonic LH secretion? J.Endocrinol. 106, 55-60.

Lehman, M. N., Durham, D. M., Jansen, H. T., Adrian, B., and Goodman, R. L. 1996. Dopaminergic A14/A15 neurons are activated during estradiol negative feedback in anestrous, but not breeding season, ewes. Endocrinology 137, 4443-4450.

Lehman, M. N., Goodman, R. L., Karsch, F. J., Jackson, G. L., Berriman, S. J., and Jansen, H. T. 1997. The GnRH system of seasonal breeders: Anatomy and Plasticity. Brain Res.Bull. 44, 445-457.

Levine, J. E., Pau, K-Y., Ramirez, V. D., and Jackson, G. L. 1982. Simultaneous measurement of luteinizing hormone-releasing hormone and luteinizing hormone release in unanesthetized, ovariectomized sheep. Endocrinology $111,1449-1455$.

Lewis, P. E., and Inskeep, E. K. 1973. Effect of Rams on Progestin-Treated Ewes. J.Anim.Sci. 37, 1195-1200. 
Lewis, P. E., Bolt, D. J., and Inskeep, E. K. 1974. Pattern of Luteinizing Hormone Release in Progestin-Treated Ewes. J.Anim.Sci. 38[6], 1204-1209.

Lewis, P. E., Bolt, D. J., and Inskeep, E. K. 1974. Luteinizing Hormone Release and Ovulation in Anestrous Ewes. J.Anim.Sci. 38[6], 1197-1203.

Leyva, V., Buckrell, B. C., and Walton, J. S. 1998. Follicular Activity and Ovulation Regulated by Exogenous Progestagen and PMSG in Anestrous Ewes. Theriogenology 50, 377-393.

Lincoln, G. A., Peet, M. J., and Cunningham, R. A. 1977. Seasonal and circadian changes in the episodic release of follicle-stimulating hormone, lueinizing hormone and testosterone in rams exposed to artificial photoperiods. J.Endocrinol. 72, 337-349.

Lincoln, G. A., Almedia, O. F. X., Klandorf, H., and Cunningham, R. A. 1982. Hourly fluctuation in blood levels of melatonin, prolactin, luteinizing hormone, follicle-stimulating hormone, testosterone, tri-iodothyronine, thyroxine and cortisol in rams under artificial photoperiods, and the effect of cranial sympathectomy. J.Endocrinol. 92, 237-250.

Lindsay, D. R., Moore, N. W., Robinson, T. J., Salamon, S., and Shelton, J. N. 1967. The evaluation of an oral progestagen (Provera; MAP) for the synchronization of oestrus in the entire cyclic Merino ewe. Robinson, T. J. The control of the ovarian cycle in the sheep. ist[I], 3-13. Sydney, Sydney University Press.

Lindsay, D. R. 1976. The usefulness to the animal producer of research findings in nutrition on reproduction. Proc.Aust.Soc.Anim.Prod. 9, 217-224.

Lindsay, D. R., and Signoret, J. P. 1980. Influence of behaviour on reproduction. Proc.9th Int.Congr.Anim.Reprod.A.I. 1, 83-92. Madrid.

Lopez-Sebastian, A., Alonso de Miguel, M., and Gomez-Brunet, A. 1985a. Caracteristicas del comienzo de la pubertad en corderas manchegas mediante la estimulacion por machos en estacion desfavorable. An.INIA 22, 167-181.

Lopez-Sebastian, A., Gomez-Brunet, A., Pinilla, A., and Cabellos, B. 1985b. Influencia de la epoca de nacimiento y el efecto de los machos sobre la aparicion de la pubertad en corderas manchegas. ITEA 58, 45-50.

Lopez-Sebastian, A. and Inskeep, E. K. 1991. Response of ewes of Mediterranean sheep breeds to subcutaneous implants of melatonin. Livest.Prod.Sci. 27, 177-184. 
Lopez-Sebastian, A., Gomez-Brunet, A., Lishman, A. W., Johnson, S. K., and Inskeep, E. K. 1993. Modification by Propylene Glycol of Ovulation Rate in Ewes in Response to a Single Injection of FSH. J.Reprod.Fertil. 99, 437442.

Lunstra, D. D., and Christenson, R. K. 1981. Synchronization of Ewes During Anestrus: Influence of Time of Year and Interval to Onset of Estrus on Conception Rate. J.Anim.Sci. 53[2], 448-457.

Lunstra, D. D., and Christenson, R. K. 1981. Fertilization and embryonic survival in ewes synchronized with exogenous hormones during the anestrous and estrous seasons. J.Anim.Sci. 53, 458-466.

Mahieum, M., Jego, Y., Driancourt, M. A., and Chemineau, P. 1989. Reproductive performances of Creole and Black Belly Ewes in the West Indies. A new major gene controlling ovulation rate? Anim.Reprod.Sci. 19, 235-243.

Mallampati, R. S., Pope, A. L., and Casida, L. E. 1971. Breeding Pattern in Targhee Ewes and Ewe Lambs Throughout the Year. J.Anim.Sci. 33[6], 1278-1281.

Mallampati, R. S., Pope, A. L., and Casida, L. E. 1971. Effect of suckling on postpartum anestrus in ewes lambing in different seasons of the year. J.Anim.Sci. 32, 673-677.

Marshall, F. H. A. 1903. The oestrus cycle and formation of the corpus luteum in sheep. Phil.Trans.R.Soc.B 196, 47-96.

Marshall, F. H. A. 1937. On the change over in the oestrous cycle in animals after transference across the equators, with further observations on the incidence of the breeding seasons and the factors controlling sexual periodicity. Proc.Royal Soc.London 122, 413-428.

Martin, G. B., Cognie, Y., Gayerie, F., Oldham, C. M., Poindron, P, Scaramuzzi, R. J., and Thiery, J. C. 1980. The Hormonal response to Teasing.

Proc.Aust.Soc.Anim.Prod. 13, 77-79.

Martin, G. B., Oldham, C. M., and Lindsay, D. R. 1980. Increased plasma LH levels in seasonally anovular Merino ewes following the introduction of rams. Anim.Reprod.Sci. 3, 125-132.

Martin, G. B., Scaramuzzi, R. J., and Lindsay, D. R. 1981. Induction of ovulation in seasonally anovular ewes by the introduction of rams: effects of progesterone and active immunization against androstenidione. Aust.J.Biol.Sci. 34, 569-575. 
Martin, G. B. and Scaramuzzi, R. J. 1983. The induction of oestrus and ovulation in seasonally anovular ewes by exposure to rams. J.Steroid.Biochem. 19, 869-875.

Martin, G. B., Oldham, C. M., Cognie, Y., and Pearce, D. T. 1986. The Physiological responses of Anovulatory Ewes to the Introduction of RamsA Review. Livest.Prod.Sci. 15, 219-247.

Martin, G. B., Ford, J. R., and Purvis, I. W. 1990. Environmental and genetic factors affecting reproductive activity in the Merino Ram. Oldham, C. M., Martin, G. B., and Purvis, I. W. Reproductive Physiology of Merino Sheep: Concepts and Consequences. 109-130. Perth, The University of Western Australia.

Maxwell, W. M. C., and Barnes, D. R. 1986. Induction of Oestrus in Ewes using a Controlled Internal Drug Release Device and PMSG. J.Agric.Sci. 106, 201-203.

McKenzie, F. F., and Terrill, C. E. 1937. Estrus, ovulation, and related phenomena in the ewe. 264. Mo. Agr. Exp. Sta. Bull.

McLeod, B. J., Haresign, W., and Lamming, G. E. 1982. Response of seasonally anoestrous ewes to small-dose multiple injections of $\mathrm{GnRH}$ with and without progesterone pretreatment. J.Reprod.Fertil. 65, 223-230.

McLeod, B. J., Haresign, W., and Lamming, G. E. 1982. The induction of ovulation and luteal function in the seasonally anoestrous ewes treated with small dose multiple injections of GnRH. J.Reprod.Fertil. 65, 215-221.

McLeod, B. J. and Haresign, W. 1984. Evidence that Progesterone may Influence Subsequent Luteal Function in the Ewe by Modulating Preovulatory Follicle Development. J.Reprod.Fertil. 71, 381-386.

McNatty, K. P., Ball, K., Gibb, M., Dorson, C., and Thurley, D. C. 1982. Induction of cyclic ovarian activity in seasonally anoestrus ewes with exogenous GnRH. J.Reprod.Fertil. 64, 93-96.

McNatty, K. P., Smith, P., Hudson, N. L., Henderson, K. M., Lun, S., Heath, D. A., Gibb, M., Ball, K., McDiarmid, J. M., and Thurley, D. C. 1984a. Changes in gonadotrophin Secretion and Ovarian Antral Follicular Activity in Seasonally Breeding Sheep Throughout the Year. J.Reprod.Fertil. 70, 309-321.

McNatty, K. P., Hudson, N., Gibb, M., Ball, K., Fanning, J., Kieboum, L., and Thurley, D. C. 1984b. Effects of long-term treatment with LH on induction of cyclic ovarian activity in seasonally anoestrus ewes. J.Endocrinol. 100, 67-73. 
McNeilly, A. S., O'Connell, M, and Baird, D. T. 1982. Induction of ovulation and normal luteal function by pulsed injections of luteinizing hormone in anoestrous ewes. Endocrinology 110, 1292-1299.

Meyer, S. L., and Goodman, R. L. 1985. Neurotransmitters involved in mediating the steroid-dependent and steroid-independent suppression of tonic luteinizing hormone secretion in the anestrous ewe: effects of receptor antagonist. Endocrinology 116, 2054-2061.

Mieusset, R., Casares, P. Q., Partida, L. G. S., Sowerbutts, S. F., Zupp, J. L., and Setchell, B. P. 1992. Effects of Heating the Testes and Epididymides of Rams by Scrotal Insulation on Fertility and Embryonic Mortality in Ewes Inseminated with Frozen Semen. J.Reprod.Fertil. 94, 337-343.

Moore, N. W., and Robinson, T. J. 1957. The behavioural and vaginal response of the spayed ewe to oestrogen injected at various times relative to the injection of progesterone. J.Endocrinol. 15, 360-365.

Moore, N. W., and Holst, P. J. 1967. The evaluation of progesterone- and SC9880- impregnated intravaginal sponges used with PMS for the induction of breeding in the anestrous crossbred ewe. Robinson, T. J. The control of the ovarian cycle in the sheep. 1st[IX], 133-143. Sydney, Sydney University Press.

Morgan, J., Lack, R. E., and Robinson, T. J. 1967. The rate of absorption of SC9880 from impregnated sponges inserted intravaginally in cyclic crossbred ewes. Robinson, T. J. The control of the ovarian cycle in the sheep. 1st[XIV], 195-207. Sydney, Sydney University Press.

Morley, F. H. W., White, D. H., Kenney, P. A., and Davis, I. F. 1978. Predicting ovulation rate from live weight in ewes. Agricultural Systems 3, 27-45.

Notter, D. R. 1992. Genetic improvement of out-of-season breeding through Selection. 55-81. lowa state University, lowa State University Extension. Out of Season Breeding Symposium.

Nowak, R. and Rodway, R. G. 1985. Effect of intravaginal implants of melatonin on the onset of ovarian activity in adult and prepubertal ewes. J.Reprod.Fertil. 74, 287-293.

Noël, B., Perrad, B., Mandinki, S. N. M., Bister, J.-L., and Paquay, R. 1999. Effects of season and phase of the estrous cycle on steroidogenesis and $\mathrm{LH}-\mathrm{FSH}$ sensitivity of large ovine follicles perfused in vitro. Theriogenology 51, 559-568.

Nugent, R. A. III and Notter, D. R. 1990. Effect of Cohabitation with White-Faced Ewes on Estrus Activity of Hampshire and Suffolk Ewes Exposed to rams in June. J.Anim.Sci. 68, 1513. 
O'Brien, C. A., Bloss, R. E., and Nicks, E. F. 1968. Effect of melengesterol acetate on the growth and reproductive physiology of fattening heifers. J.Anim.Sci. 27, 664-667.

O'Mary, C. C., Pope, A. L., and Casida, L. E. 1950. The use of Progesterone in the Synchronization of Estrual Periods in a group of ewes and the Effect on their Subsequent Lambing records. Journal of Animal Science 9, 499503.

Oldham, C. M., Martin, G. B., and Knight, T. W. 1978/79. Stimulation of seasonally anovular Merino ewes by rams. I. Time from introduction of rams to the preovulatory surge and ovulation. Anim.Reprod.Sci. 1, 283290.

Oldham, C. M. and Martin, G. B. 1978/79. Stimulation of seasonally Anovular Merino ewes by Rams II. Premature regression of Ram-Induced Corpora Lutea. Animal Reproduction Science 1, 291-295.

Oldham, C. M. and Cognie, Y. 1980. Do ewes continue to cycle after teasing? Macintosh, J. B. Animal Production in Australia. 82-86. Sydney, Pergamon Press.

Oldham, C. M. 1980. Stimulation of ovulation in seasonally or lactationally anovular ewes by rams. Proc.Aust.Soc.Anim.Prod. 13, 73-76.

Oldham, C. M. 1980. A Study of Sexual and Ovarian Activity in Merino Sheep. University of Western Australia.

Oldham, C. M., Cognie, Y., Poindron, P, and Gayerie, F. 1980. The influence of progesterone or FGA priming on the ovarian function of seasonally anovular ewes induced to ovulate by their re-introduction to rams, teasing. Proc.9th Int.Congr.Anim.Reprod.A.I. 3[abstract], 50.

Oldham, C. M., Pearce, D. T., and Gray, S. J. 1985. Progesterone Priming and Age of ewe Affect the Life-span of Corpora Lutea Induced in the seasonally Anovulatory Merino ewe by the 'Ram-effect'. J.Reprod.Fertil. 75[1], 29-33.

Oldham, C. M., and Fisher, J. 1992. Utilizing the 'ram effect'. 33-54. lowa State University, lowa State University Extension. Out of Season Breeding Symposium.

Ortavant, R., Bocquier, F., Pelletier, J., Ravault, J. P., Thimonier, J., and VollandNail, P. 1988. Seasonality of reproduction in sheep and its control by photoperiod. Aust.J.Biol.Sci. 41, 69-85. 
Oussaid, B., Cognie, Y., and Mariana, J. C. 1993. Ovarian stimulation following repeated injections of $\mathrm{LH}$ or $\mathrm{LH}+\mathrm{FSH}$ in lle-de-France sheep in early and mid-seasonal anoestrus. Anim.Reprod.Sci. 31, 83-98.

Over, R. R., Cohen-Tannoudji, J., Dehnhard, M., Claus, R., and Signoret, J. P. 1990. Effect of pheromones from male goats on LH-secretion in anoestrous ewes. Physiol.Behav. 48, 665-668.

Pearce, D. T., and Oldham, C. M. 1984. The ram effect, its mechanism and application to the management of sheep. Lindsay, D. R. and Pearce, D. T. Reproduction in Sheep. 26-34. Canberra, Australian Academy of Science.

Pearce, D. T., and Robinson, T. J. 1985. Plasma Progesterone Concentrations, Ovarian Endocrinological responses and Sperm Transport in Ewes with Synchronized Estrus. J.Reprod.Fertil. 75, 49-62.

Pearce, D. T., Martin, G. B., and Oldham, C. M. 1985. Corpora lutea with a short life-span induced by rams in seasonally anovulatory ewes are prevented by progesterone delaying the preovulatory surge of LH. J.Reprod.Fertil. $75,79-84$.

Pearce, G. P., and Oldham, C. M. 1988. Importance of non-olfactory ram stimuli in mediating ram-induced ovulation in the ewe. J.Reprod.Fertil. 84, 333339.

Perkins, A. and Fitzgerald, J. 1994. The behavioral component of the ram effect: The influence of ram sexual behavior on the growth and induction of estrus in anovulatory ewes. J.Anim.Sci. 72, 51-55.

Philipon, P., Prieur, A. L., and Driancourt, M. A. 1989. Alterations in gonadotrophin secretion and ovarian sensitivity to gonadotrophins induced by active immunization against androstenidione. Anim.Reprod.Sci. 19, 5366.

Philips, D., Dunstan, E. A., and Walker, S. A. 1984. A definition of the breeding season of Poll Dorset ewes. Theriogenology 21, 561-568.

Powell, M. R., Kaps, M., Lamberson, W. R., and Keisler, D. H. 1996. Use of Melengesterol Acetate-Based treatments to Induce and Synchronize Estrus in Seasonally Anestrous Ewes. Journal of Animal Science 74, 2292-2302.

Powell, M. R., Kaps, M., Lamberson, W. R., and Keisler, D. H. 1996. Use of Melengestrol Acetate-Based Treatments to Induce and Synchronize Estrus in Seasonally Anestrous Ewes. J.Anim.Sci. 74, 2292-2302. 
Quinlivan, T. D., Martin, C. A., Taylor, W. B., and Cairney, I. M. 1966. Estimates of Pre- and Perinatal Mortality in the New Zealand Romney Marsh Ewe. J.Reprod.Fertil. 11, 379-390.

Quinlivan, T. D. and Robinson, T. J. 1967. The number of spermatozoa in the Fallopian Tubes of ewes at intervals after artificial insemination following withdrawal of SC-9880 impregnated intravaginal sponges. Robinson, T. J. The control of the ovarian cycle in the sheep. 1st[XIII], 177-194. Sydney, Sydney University Press.

Radford, H. M. 1959. Variation in the incidence of twin ovulation in Merino ewes on a constant plane of nutrition. Aust.J.Agric.Res. 10, 377-386.

Radford, H. M., Avenell, J. A., and Szell, A. 1984. Human chorionic gonadotropin induces multiple ovulation in sheep. Lindsay, D. R. and Pearce, D. T. Reproduction in Sheep. 338-341. Canberra, Australian Academy of Science.

Rexroad, C. E. Jr. and Casida, L. E. 1977. Effect of Injection of Progesterone into One Ovary of PMSG-Treated Anestrous Ewes on Follicle Growth and Ovarian Estradiol-17B. J.Anim.Sci. 44, 84-88.

Rhind, SM, Robinson, J. J., Chesworth, J. M., and Phillippo, M. 1980. Effects of season, lactation and plane of nutrtion on the reproductive performance and associated plasma LH and progesterone profiles in hormonally treated ewes. J.Reprod.Fertil. 58, 127-137.

Rhodes, L. and Nathanielsz, P. W. 1988. Comparison of a Controlled Internal Drug Release Device Containing Progesterone with Intravaginal Medroxyprogesterone Sponges for Estrus Synchronization in Ewes. Theriogenology 30[4], 831-836.

Robertson, H. A. 1977. Reproduction in the Ewe and the Goat. Cole, H. H. and Cupps, P. T. Reproduction in Domestic Animals. 475-498. New York, Academic Press.

Robinson, T. J. 1950. The control of fertility in sheep. I. Hormonal therapy in the induction of pregancy in the anestrous ewe. J.Agric.Sci. 40, 275.

Robinson, T. J. 1951. The control of fertility in sheep. II. The augmentation of fertility by gonadotrophin treatment of the ewe in the normal breeding season. J.Agric.Sci. 41, 6-63.

Robinson, T. J. 1954a. The production of coincident oestrus and ovulation in the anoestrous ewe with progesterone and pregnant mare serum. J.Endocrinol. 10, 117-124. 
Robinson, T. J. 1954b. Relationship of oestrogen and progesterone in oestrus behaviour of the ewe. Nature 173, 878.

Robinson, T. J. 1954c. The necessity for progesterone with estrogen for the induction of recurrent estrus in the ovariectomized ewe. Endocrinology 55, 403-408.

Robinson, T. J. 1955. Endocrine relationships in the induction of oestrus and ovulation in the anoestrous ewe. J.Agric.Sci. 37-43.

Robinson, T. J., Moore, N. W., and Binet, F. E. 1956. The effect of duration of progesterone pretreatment on the response of the spayed ewe to oestrogen. J.Endocrinol. 14, 1-7.

Robinson, T. J. 1965. Use of progestagen-impregnated sponges inserted intravaginally or subcutaneously for the control of the estrous cycle in the sheep. Nature 206, 39-41.

Robinson, T. J. 1967. Introduction. Robinson, T. J. The control of the ovarian cycle in the sheep. 1st, xiii-xviii. Sydney, Sydney University Press.

Robinson, T. J., Moore, N. W., Holst, P. J., and Smith, J. F. 1967a. The evaluation of several progestagens administered in intravaginal sponges for the synchronization of estrus in the entire cyclic Merino ewe. Robinson, T. J. The control of the ovarian cycle in the sheep. 1st[VI], 76-101. Sydney, Sydney University Press.

Robinson, T. J., and Moore, N. W. 1967. The evaluation of progesterone- and SC-9880- impregnated intravaginal sponges for the synchronization of oestrus for large scale artificial insemination of Merino ewes in spring. Robinson, T. J. The control of the ovarian cycle in the sheep. 1st[VIII], 116-132. Sydney, Sydney University Press.

Robinson, T. J., and Smith, J. F. 1967. The evaluation of SC-9880- impregnated intravaginal sponges used with or without PMS for the advancement of the breeding season of British Breed ewes. Robinson, T. J. The control of the ovarian cycle in the sheep. 1st[X], 144-157. Sydney, Sydney University Press.

Robinson, T. J., Salamon, S., Moore, N. W., and Smith, J. F. 1967b. The evaluation of SC-9880-impregnated intravaginal sponges for the synchronization of oestrus for large scale artificial insemination of Merino ewes in Summer and Autumn. Robinson, T. J. The control of the ovarian cycle in the sheep. 1st[XV], 208-236. Sydney, Sydney University Press. 
Robinson, T. J., Quinlivan, T. D., and Baxter, C. 1968. The Relationship between dose of Progestagen and Method of Preparation of Intravaginal Sponges on their Effectiveness for Control of Ovulation in the Ewe. J.Reprod.Fertil. 17, 471-483.

Rodriguez-Iglesias, R. M., Ciccioli, N. H., Irazoqui, H., and Rodriguez, B. T. 1991. Importance of behavioral stimuli in ram-induced ovulation in seasonally anovular Corriedale ewes. Applied Anim.Behav.Sci. 30, 323-332.

Rodriguez-Iglesias, R. M., Ciccioli, N. H., Irazoqui, H., and Giglioli, C. 1996. Ovulation rate in Ewes after Single Oral Glucogenic Dosage During a Ram-Induced Follicular Phase. Anim.Reprod.Sci. 44, 211-221.

Rodriguez-Iglesias, R. M., Ciccioli, N. H., and Irazoqui, H. 1997. Ram-induced reproduction in seasonally anovular Corriedale ewes: MAP doses for oestrus induction, ram percentages and post-mating progestagen supplementation. Animal Science 64, 119-125.

Rosa, H. J. D., Junniper, D. T., and Bryant, M. J. 2000. Effects of recent sexual experience and melatonin treatment of rams on plasma testosterone concentration, sexual behavior and ability to induce ovulation in seasonally anoestrous ewes. J.Reprod.Fertil. 120, 169-176.

Safranski, T. J., Lamberson, , W. R., and Keisler, D. H. 1992. Use of Melengestrol Acetate and Gonadotropins to Induce Fertile Estrus in Seasonally Anestrous Ewes. Journal of Animal Science 70, 2935-2941.

SAS Institute, Inc. 1988. SAS/STAT Users Guide. SAS Institute, Inc. 6.12. Cary, NC.

Scaramuzzi, R. J., Tillson, S. A., Thorneycroft, I. H., and Caldwell, B. V. 1971. Actions of exogenous progesterone and oestrogen on behavioral estrus and luteinizing hormone levels in the ovariectomized ewe. Endocrinology 88, 1184-1189.

Scaramuzzi, R. J., Lindsay, D. R., and Shelton, J. N. 1972. Effect of repeated oestrogen administrations on oestrus behaviour in ovariectomized ewes. J.Endocrinol. 52, 269-278.

Scaramuzzi, R. J. 1976. Physiological effects of immunizing sheep against oestradiol-17B. Edwards, R. G. and Johnson, M. H. Physiological Effects of Immunity Against Reproductive Hormones. 67-90. Cambridge, Cambridge University Press.

Scaramuzzi, R. J., Davidson, W. G., and Van Look, P. F. A. 1977. The effect of active immunization against androstenidione on oestrus and ovulation in sheep. Nature 269, 817-818. 
Scaramuzzi, R. J., and Baird, D. T. 1977. Pulsatile release of luteinizing hormone and the secretion of ovarian steroids in sheep during anestrus.

Endocrinology 101, 1801-1806.

Scaramuzzi, R. J., Martensz, N. D., and Van Look, P. F. A. 1980a. Ovarian morphology and the concentrations of steroids, and of gonadotropins during the breeding season in ewes actively immunized against oestradiol17B or estrone. J.Reprod.Fertil. 59, 303-310.

Scaramuzzi, R. J., Baird, D. T., Clarke, I. J., Martensz, N. D., and Van Look, P. F. A. 1980b. Ovarian morphology and the concentrations of steroids, during the oestrous cycle of sheep actively immunized against androstenidione. J.Reprod.Fertil. 58, 27-35.

Scaramuzzi, R. J., Baird, D. T., Martensz, N. D., Turnbull, K. E., and Van Look, P. F. A. 1981. Ovarian function in the ewe after active immunization against testosterone. J.Reprod.Fertil. 61, 1-9.

Scaramuzzi, R. J., and Radford, H. M. 1983. Factors regulating ovulation rate in the ewe. J.Reprod.Fertil. 69, 353-367.

Schinckel, P. G. 1954. The Effect of the Presence of the ram on Ovulation Activity of the Ewe. Aust.J.Agric.Res. 5, 465-469.

Schrick, F. N., Surface, R. A., Pritchard, J. Y., Dailey, R. A., Townsend, E. C., and Inskeep, E. K. 1993. Ovarian Structures During the Estrous Cycle and Early Pregnancy in Ewes. Biol.Reprod. 49, 1133-1140.

Schrick, F. N., and Inskeep, E. K. 1993. Determination of early pregnancy in ewes utilizing transrectal ultrasonography. Theriogenology 40, 295-306.

Sheffel, C. E., Pratt, B. R., Ferrel, W. L., and Inskeep, E. K. 1982. Induced Corpora Lutea in the Post Partum Beef Cow. II. Effects of Treatment with Progestogen and Gonadotropins. J.Anim.Sci. 54, 830-836.

Shelton, J. N., and Robinson, T. J. 1967. The evaluation of several progestagen treatments in the entire cyclic ewe. Robinson, T. J. The control of the ovarian cycle in the sheep. 1st[III], 39-47. Sydney, Sydney University Press.

Shelton, J. N., and Robinson, T. J. 1967. The evaluation of alternative methods of administration of progestagens in the spayed ewe. Robinson, T. J. The control of the ovarian cycle in the sheep. 1st[IV], 59-75. Sydney, Sydney University Press.

Signoret, J. P., Fulkerson, W. J., and Lindsay, D. R. 1982. Effectiveness of testosterone treated wethers and ewes as teasers. Appl.Anim.Ethol. 9, 3745. 
Signoret, J. P. 1990. The Influence of the Ram effect on the breeding Activity of ewes and its underlying Physiology. C.M.Oldham, G.B.Martin, and I.W.Purvis. Reproductive Physiology of Merino Sheep: Concept and Consequences. 59-70. Perth, School of Agriculture (Animal Science), The University of western Australia, Nedlands, Perth.

Smith, J. F., Konlechner, J. A., and Parr, J. 1991. The efficacy of used CIDR devices for synchronization of oestrus and postmating treatment. Proc.New Zealand Soc.Anim.Prod. 51, 111-115.

Smith, J. F., Jagusch, K. T., and Farquhar, P. A. 1981. Protein intake and multiple ovulation in ewes. Proc.Aust.Soc.Reprod.Biol. 13, 6.

Smith, M. F., Lishman, A. W., Lewis, G. S., Harms, P. G., and Ellersieck, E. K. 1983. Pituitary and ovarian responses to gonadotropin releasing hormone, calf removal and progestogen in anestrous beef cows. J.Anim.Sci. 57, 418-424.

Southee, J. A., Hunter, M. G., and Haresign, W. 1988a. Function of Abnormal Corpora Lutea in vivo after $\mathrm{GnRH}$-induced Ovulation in the Anoestrous Ewe. J.Reprod.Fertil. 84, 131-137.

Southee, J. A., Hunter, M. G., Law, A. S., and Haresign, W. 1988b. Effect of Hysterectomy on the Short Life-cycle Corpus Luteum produced after $\mathrm{GnRH}$-induced Ovulation in the Anoestrous Ewe. J.Reprod.Fertil. 84[1], 149-155.

Spitzer, J. C., and Carpenter, R. H. 1979. Synchronized breeding of cycling ewes to produce fetuses of known gestational age. Lab.Anim.Sci. 29, 755-758.

Spitzer, J. C., and Carpenter, R. H. 1981. Estrus and Pregnancy rates following Synchronization with Cronolone Intravaginal Sponge or Norgestomet Ear Implant in Cycling Ewes. Theriogenology 16[3], 287-294.

Stellflug, J. N. 1992. A review of use of melatonin in sheep. 82-97. Ames lowa, lowa State University of Science and Technology, University Extension.

Synnott, A. L., Fulkerson, W. J., and Lindsay, D. R. 1981. Sperm Output by Rams and Distribution Amongst Ewes under Conditions of Continual Mating. J.Reprod.Fertil. 61[2], 355-361.

Tervit, H. R., Havik, P. G., and Smith, J. F. 1977. Effect of Breed of Ram on the onset of the breeding season in Romney ewes. Proc.New Zealand Soc.Anim.Prod. 37, 142-148.

Thimonier, J., and Cognie, Y. 1977. Application of control of reproduction of sheep in France. Terrill, E. 109-118. Madison Wisconsin, University of Wisconsin. 
Thwaites, C. J. 1965. Photoperiodic control of breeding activity in the Southdown ewe with particular reference to the effects of an equatorial light regime. J.Agric.Sci. 65[57], 64.

Tilbrook, A. J., and Cameron, A. W. N. 1990. The contribution of the sexual behavior of rams to successful mating of ewes under field conditions. Oldham, C. M., Martin, G. B., and Purvis, I. W. Reproductive Physiology of Merino Sheep. 143-160. Perth, The University of Western Australia.

Tritschler, J. P. II, Duby, R. T., Parsons, E. M., Parsons, M. J., and Giordano, D. J. 1991. Comparison of Two Progestogens During Out-of-Season Breeding in a Commercial Ewe Flock. Theriogenology 35, 943-952

Underwood, E. J., Shier, F. L., and Davenport, N. J. 1944. The breeding season of Merino, crossbred and British breed ewes in the agricultural districts. J.Agric. 11, 135-143.

Ungerfeld, R., and Rubianes, E. 1999. Effectiveness of short-term progestogen primings for the induction of fertile oestrus with eCG in ewes during late seasonal anoestrus. Animal Science 68, 349-353.

Van Cleeff, J., Karsch, F. J., and Padmanabhan, V. 1998. Characterization of the Endocrine Events During the Periestrous Period in Sheep after Estrous Synchronization with Controlled Internal Drug Release (CIDR) Device. Domestic Animal Endocrinology 15[1], 23-34.

Vatnick, I., Ignotz, G., McBride, B. W., and Bell, A. W. 1991. Effect of Heat Stress on Ovine Placental Growth in Early Pregnancy. J.Dev.Physiol. 16, 163166.

Vesely, J. A., and Swierstra, E. E. 1987. Reproductive traits of ewe lambs representing eight genetic types born in winter, spring, summer and fall. J.Anim.Sci. 65, 1195-1200.

Vincent, J. N., McQuown, E. C., and Notter, D. C. 2000. Duration of the seasonal anestrus in sheep selected for fertility in the fall lambing season. J.Anim.Sci. 78, 1149-1154.

Walton, J. S., McNeilly, J. R., McNeilly, A. S., and Cunningham, F. J. 1977. Changes in Concentration of Follicle Stimulating Hormone, Lueinizing Hormone, Prolactin and Progesterone in the Plasma of ewes During the Transition From Anestrous to Breeding Activity. J.Endocrinol. 75, 127-136.

Walton, L. S., McNeilly, J. R., and Cunningham, F. J. 1977. Changes in concentrations of follicle stimulating hormone, luteinizing hormone, prolactin and progesterone in the plasma of ewes during the transition from anoestrus to beeding activity. J.Endocrinol. 75, 127-136. 
Watson, R. H., and Radford, H. M. 1960. The influence of rams on the onset of oestrus in Merino ewes in spring. Aust.J.Agric.Res. 11, 65-71.

Welch, R. A. S., Andrews, W. D., Barnes, D. R., Bremmer, K., and Harvey, T. G. 1984. CIDR Dispensers for Oestrus and Ovulation Control in Sheep.

Proc.10th Int.Congresson Animal reproduction and Artificial Insemination, University of Ilinois, Urbana-Champaign. 3, 356.

Wheaton, J. E, Carlson, K. M., Windels, H. F., and Johnston, L. J. 1992. Use of controlled internal drug release dispensers (CIDR) for controlled breeding of sheep. 123-133. Ames lowa, lowa State University Extension.

Wheaton, J. E, Carlson, K. M., Windels, H. F., and Johnson, L. J. 1993. CIDR: A new progesterone-releasing intravaginal device for induction of estrus and cycle control in sheep and goats. Animal Reproduction Science 33[1-4], 127-142.

Wheaton, J. E., Pohl, H. A., and Windels, H. F. 1990. Effects of Melatonin and Progesterone Administered to ewes in Spring and Summer. Journal of Animal Science 68, 923-930.

Wheaton, J. E., Windels, H. F., and Johnston, L. J. 1992. Accelerated Lambing Using Exogenous Progesterone and the Ram Effect. Journal of Animal Science 70, 2628-2635.

Wheeler, A. G., and Land, R. B. 1977. Seasonal variation in oestrus and ovarian activity of Finnish Landrace, Tasmanian Merino and Scottish Blackface ewes. Anim.Prod. 24, 363-376.

Whisnant, C. S., and Goodman, R. L. 1988. Effects of an opioid antagonist on pulsatile luteinizing hormone secretion in the ewe vary with changes in steroid negative feedback. Biol.Reprod. 39, 1032-1038.

Whisnant, C. S., and Inskeep, E. K. 1992. Biological aspects of out-of-season breeding in the ewe. 1-24. lowa State University, lowa State University Extension. Out of Season Breeding Symposium.

Whiteman, J. V., Zollinger, W. A., and Thrift, F. A. 1972. Postpartum mating performance of ewes involved in a twice-yearly lambing program. J.Anim.Sci. 35, 836-842.

Whitman, R. W., Wiltbank, J. N., LeFever, D. G., and Denhman, A. H. 1972. Ear implant (SC-2100) for estrous control in cows. J.Anim.Sci. 34[5], 915.

Wiggins, E. L., III Miller, W. W., and Barker, H. B. 1970. Age at puberty in fallborn ewe lambs. J.Anim.Sci. 30, 974-977. 
Wodzicka-Tomaszewska, M., Hutchinson, J. C. D., and Bennett, J. W. 1967. Control of the annual rhythm of breeding in ewes: effect of an equatorial daylength with reversed thermal seasons. J.Agric.Sci. 68, 61-67.

Woody, C. O., Beauchene, S. L., Feccia, R. C., Sepe, P. A., Higgins, F. M., Cowan, W. A., and Riesen, J. W. 1983. Regulation of the estrous cycle in ewes with progestin containing implants: influence of dose and day of cycle at treatment. Theriogenology 19, 677-684.

Wright, R. W. Jr., Bondioli, K., Grammer, J., Kuzan, F., and Menino, A. Jr. 1981. $\mathrm{FSH}$ or FSH plus LH superovulation in ewes following estrus synchronization with medroxyprogesterone acetate pessaries. J.Anim.Sci. 52, 115-118.

Yeates, N. T. M. 1949. The breeding season of the sheep with particular reference to its modification by artificial means using light. J.Agric.Sci. 39, $1-43$.

Yellon, S. M., and Foster, D. L. 1985. Alternate photoperiods time puberty in the female lamb. Endocrinology 116, 2090-2097.

Yuthasastrakosol, P., Palmer, W. M., and Howland, B. E. 1975. Luteinizing Hormone, Oestrogen and Progesterone Levels in Peripheral Serum of Anestrous and Cyclic Ewes as Determined by Radioimmunoassay. J.Reprod.Fertil. 43, 57-65.

Zimbelman, R. G. 1963. Inhibition of estrus in ewes with oral progestogens. J.Anim.Sci. 22[(Abstr)], 868. 


\section{VITA}

Name

Parents

Date of Birth

Place of Birth
Marlon Knights

Cecilia B. Knights Michael Clarence

November $20^{\text {th }} 1970$

San Fernando, Trinidad W.I.

Schools Attended

Tabaquite Roman Catholic

1976-1982

Williamsville Jnr. Secondary

1982-1985

Marabella Snr. Comprehensive

1985-1987

Eastern Caribbean Institute of

Agriculture and Forestry (ECIAF), Dip. 1987-1989

University of The West Indies, B. Sc. 1990-1993

University of The West Indies, M. Sc. 1994-1997

West Virginia University, Ph.D.

1997-2001 